
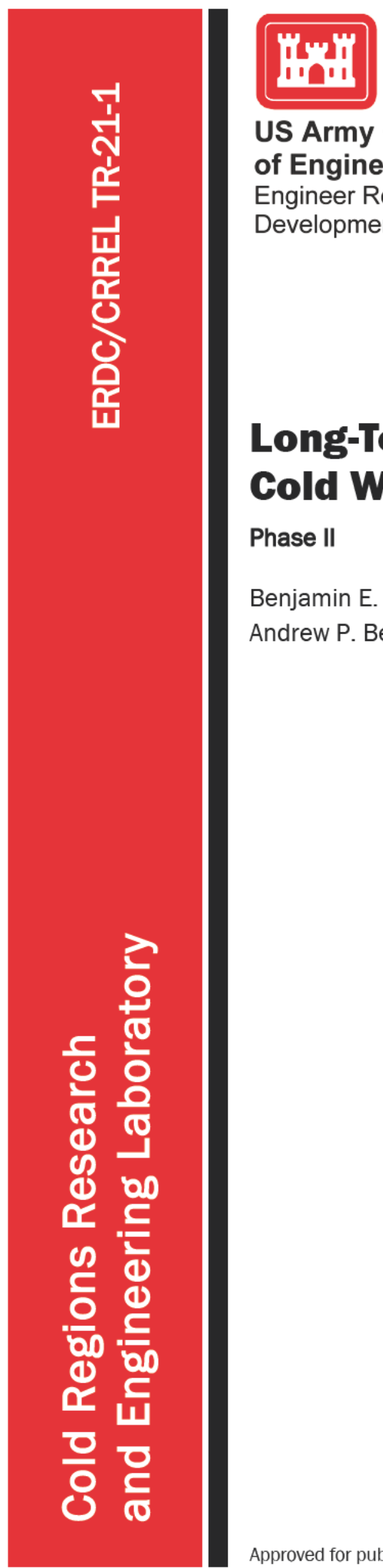

US Army Corps

of Engineers ${ }_{\circledast}$

Engineer Research and

Development Center

\title{
Long-Term Durability of
} Cold Weather Concrete

\section{Phase II}

Benjamin E. Watts, Danielle E. Kennedy, Ethan W. Thomas,

January 2021

Andrew P. Bernier, and Jared I. Oren 
The U.S. Army Engineer Research and Development Center (ERDC) solves the nation's toughest engineering and environmental challenges. ERDC develops innovative solutions in civil and military engineering, geospatial sciences, water resources, and environmental sciences for the Army, the Department of Defense, civilian agencies, and our nation's public good. Find out more at www.erdc.usace.army.mil.

To search for other technical reports published by ERDC, visit the ERDC online library at https://erdclibrary.on.worldcat.org/discovery. 


\section{Long-Term Durability of Cold Weather Concrete}

\section{Phase II}

Benjamin E. Watts, Danielle E. Kennedy, Ethan W. Thomas, Andrew P. Bernier, Jared I. Oren

U.S. Army Engineer Research and Development Center (ERDC) Cold Regions Research and Engineering Laboratory (CRREL)

72 Lyme Road

Hanover, NH 03755-1290

Final Technical Report (TR)

Approved for public release; distribution is unlimited.

Prepared for Headquarters, U.S. Army Corps of Engineers

Washington, DC 20314-1000

Under PE 62784/T53, “Innovative Construction Materials for the Arctic Program.” 


\section{Abstract}

Recent laboratory results confirm that it is possible to protect concrete from freezing solely using chemical admixtures and indicate that the amount of admixture required may be significantly less than previously recommended. Researchers have also verified that admixture-based freeze protection can produce concrete that is durable to winter exposure for a minimum of 20 years, through petrographic examination of core specimens obtained from past field demonstrations.

Freeze protection for concrete using chemical admixtures alone has been an area of active research for 3 decades; however, the most recent methodology recommends very high addition rates of accelerating and corrosion inhibiting admixtures, which result in significant challenges, including slump loss, rapid setting, and potentially excessive temperature rise. As part of a laboratory study, researchers systematically varied the dosage of freeze protection admixtures used in concrete cured in a $23{ }^{\circ} \mathrm{F}$ environment. Preliminary findings indicate that a 50\% reduction in admixture dose maintained adequate freeze protection and resulted in compressive strengths exceeding those of room-temperature controls at 7 and 28 days. The combination of improved handling, reduced cost, and verified durability associated with the use of admixtures for freeze protection makes a compelling case for broader adoption of this technique in winter operations.

DISCLAIMER: The contents of this report are not to be used for advertising, publication, or promotional purposes. Citation of trade names does not constitute an official endorsement or approval of the use of such commercial products. All product names and trademarks cited are the property of their respective owners. The findings of this report are not to be construed as an official Department of the Army position unless so designated by other authorized documents.

DESTROY THIS REPORT WHEN NO LONGER NEEDED. DO NOT RETURN IT TO THE ORIGINATOR. 


\section{Contents}

Abstract ................................................................................................................................................. ii

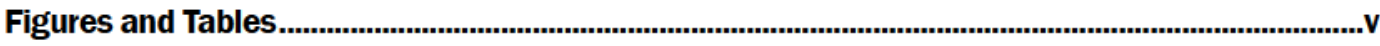

Preface ................................................................................................................................................................. viii

1 Introduction .....................................................................................................................1

1.1 Background

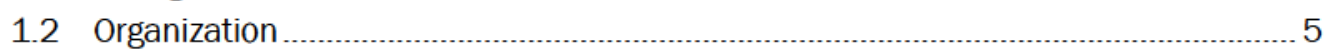

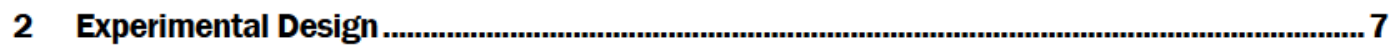

2.1 Goals

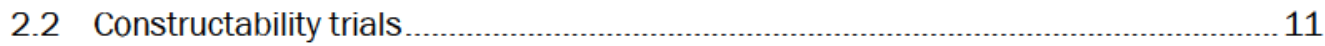

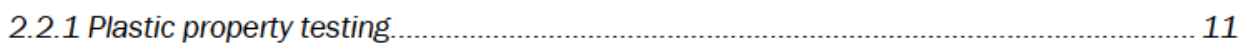

2.2.2 Mechanical property testing ……................................................................... 12

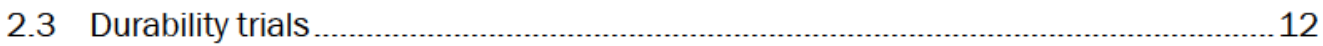

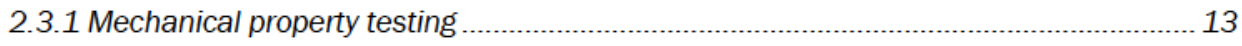

2.3.2 Compressive strength and modulus of elasticity …….......................................... 14

2.4 Durability property testing 16

2.4.1 Freeze-thaw resistance ......................................................................................... 16

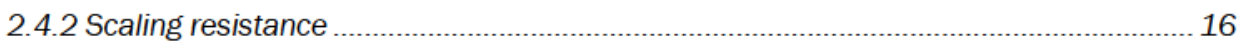

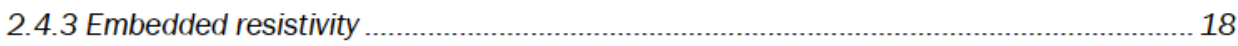

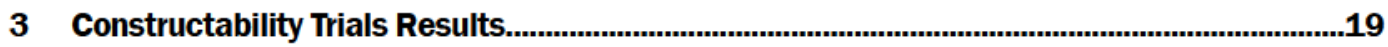

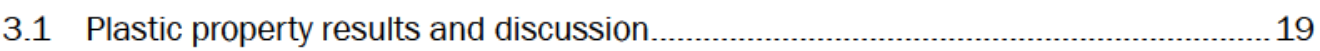

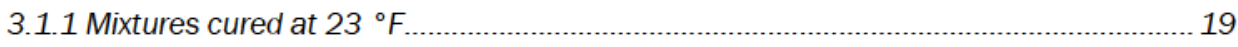

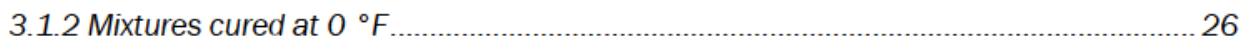

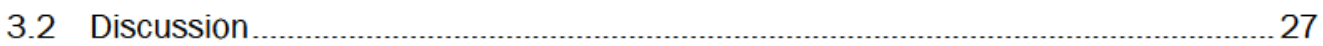

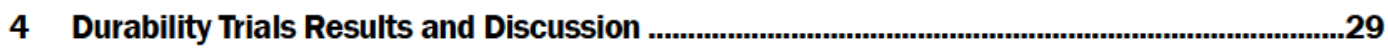

4.1 Overview ............................ 29

4.2 Plastic property results

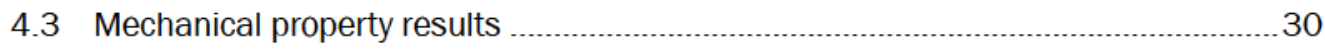

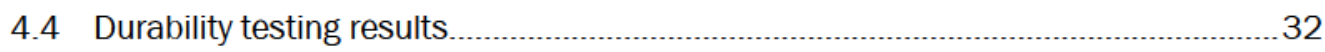

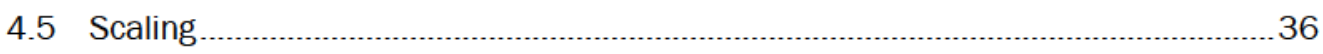

4.6 Discussion

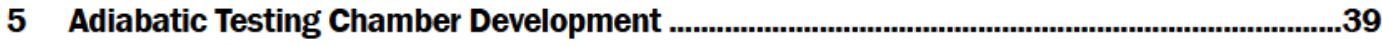

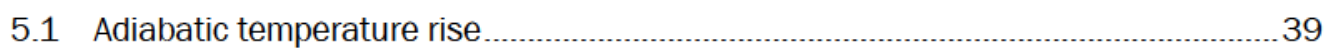

5.2 Adiabatic chamber design _........................................................................... 39

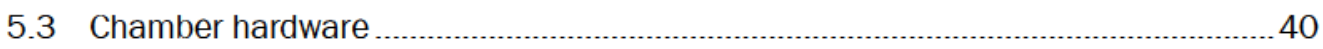

5.4 Temperature sensing 41

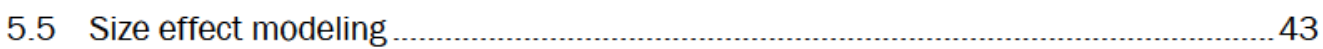

5.6 Dosage tool development

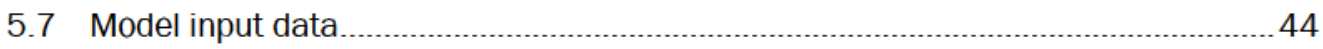




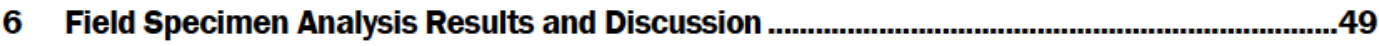

6.1 Introduction

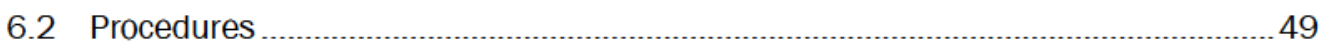

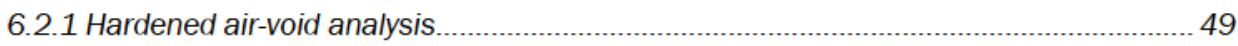

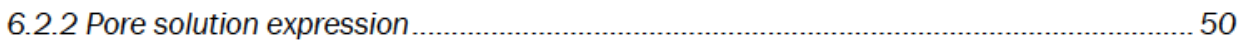

6.3 Results 50

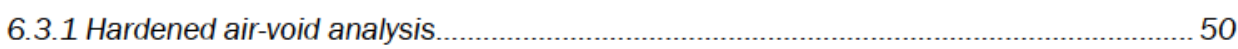

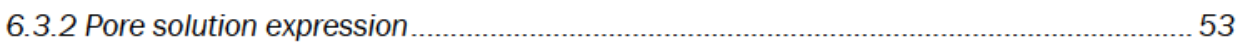

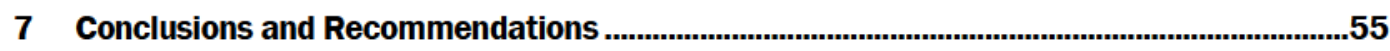

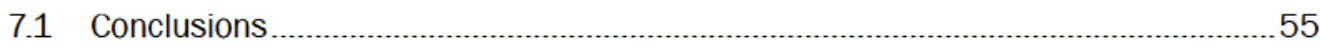

7.2 Recommendations

7.3 Future work

7.4 Additive regulated concrete for thermally extreme conditions _............................ 57

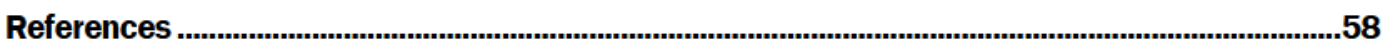

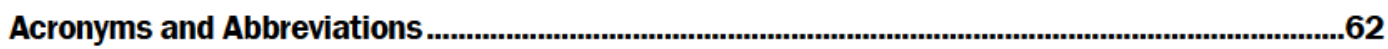

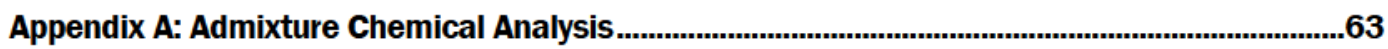

Appendix B: Durability Trials Temperature and Resistivity Curves .................................................64

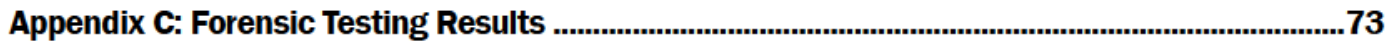

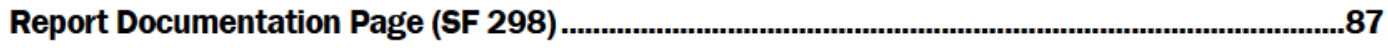




\section{Figures and Tables}

Figures

1 Bridge curb repairs performed in the winter of 2002, on the west and east sides of the Trues Brook Bridge in Lebanon, NH. The west side (left) of the bridge was repaired using CWAS concrete, while the east side (right) was repaired using conventional concrete in a heated enclosure.

2 Representative photos showing the conditions of the CWAS (left) and conventional (right) bridge curb repairs detailed in Fig. 1, circa September 2018. The repair performed using CWAS exhibits superior surface quality as well as less extensive cracking after 16 years of exposure to winter freeze-thaw cycling and road-deicing salts

3 Flow chart for test plan .

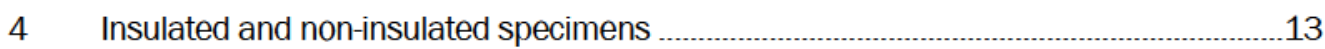

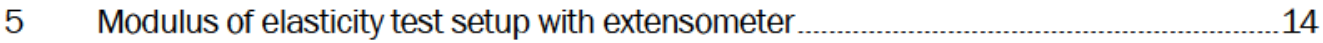

6 Resonant frequency testing conducted to calculate relative dynamic

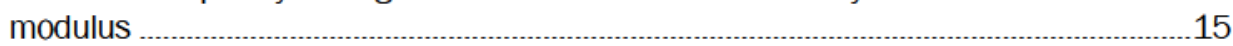

7 Freeze-thaw chamber with beam specimens _..._-_...-15

8 Scaling testing

9 Summary of 7-day compressive strength data for bare and insulated cylinders cured at $23^{\circ} \mathrm{F}$. Cylinders were tested immediately after removal from the cold room

10 Temperature profiles for the control mixture using manufacturer B, showing the difference in curing temperature for insulated and noninsulated cylinders.

11 Temperature profile for the AN30C3 mixture.

12 Results of investigation into differences in compressive strength for mixtures cured at below freezing for 7 days, vs. mixtures allowed to thaw for 24 hours before testing.

13 Summary of compressive strengths for mixtures cured at $0{ }^{\circ} \mathrm{F}$ in both bare and insulated conditions

14 Summary of compressive strength results for mixtures at 7, 28, and 90 days of age

15 Summary of elastic modulus results................

16 Summary of results for freeze-thaw testing per ASTM C666 (2015), showing relative dynamic modulus vs. number of cycles

17 Mass change data collected from specimens throughout freeze-thaw testing

18 Length change results of mixtures tested for resistance to damage from rapid freezing and thawing.

19 Results of mixtures tested for resistance to scaling damage from freezing and thawing while exposed to deicing chemicals

20 Functional diagram of adiabatic testing chamber.

21 Dosage tool development workflow 
22 Adiabatic temperature rise (ATR) curves for three mixtures with a target

fresh temperature of $55^{\circ} \mathrm{F}$. Mixtures tested were AP30, AP60, and AP100

23 ATR curves for two mixtures with a target fresh temperature of $35^{\circ} \mathrm{F}$.

Mixtures tested were AP30, AP60

24 ATR curve for AP30 at $55^{\circ} \mathrm{F}$, with insulated and bare cylinder data for two replicates each (A and $B$ )

25 ATR curve for AP60 at $55^{\circ} \mathrm{F}$, with insulated and bare cylinder data two replicates each (A and $B$ ).

26

ATR curve for AP100 at $55^{\circ} \mathrm{F}$, with insulated and bare cylinder data two replicates each (A and $B$ ).

27 ATR curve for AP30 at $35^{\circ} \mathrm{F}$, with insulated and bare cylinder data two replicates each (A and $B$ ).

28

ATR curve for AP60 at $35^{\circ} \mathrm{F}$, with insulated and bare cylinder data two replicates each (A and $\mathrm{B}$ ).

29 Hardened air-void analysis scans, Sample 2. 51

30 Functional diagram of ARCTEC detailing the role of the tool in design of a winter concrete mixture

B-1 Temperature curve for insulated and bare specimens for AN30C3 with $7.1 \%$ air

B-2 Resistivity curve for insulated and bare specimens for AN30C3 with 7.1\% air. Large values at t-zero are a result of the open circuit reading of the data logger before specimen connection.

B-3 Temperature curve for insulated and bare specimens for AN30C3 with $10.3 \%$ air

B-4 Resistivity curve for insulated and bare specimens for AN30C3 with 10.3\% air. Large values at t-zero are a result of the open circuit reading of the data logger before specimen connection.

B-5 Temperature curve for insulated and bare specimens for AN30C3.AO with $2.2 \%$ air

B-6 Resistivity curve for insulated and bare specimens for AN30C3.A0 with $2.2 \%$ air. Large values at t-zero are a result of the open circuit reading of the data logger before specimen connection

B-7 Temperature curve for insulated and bare specimens for AN30C3.F45

with $9.2 \%$ air

B-8 Resistivity curve for insulated and bare specimens for AN30C3.F45 with $9.2 \%$ air. Large values at t-zero are a result of the open circuit reading of the data logger before specimen connection

B-9 Temperature curve for insulated and bare specimens for AN45C45.AO with 2.3\% air

B-10 Resistivity curve for insulated and bare specimens for AN45C45.A0 with $2.3 \%$ air. Large values at t-zero are a result of the open circuit reading of the data logger before specimen connection

B-11 Temperature curve for insulated and bare specimens for AN45C45 with $4.2 \%$ air

B-12 Resistivity curve for insulated and bare specimens for AN45C45 with $4.2 \%$ air. Large values at t-zero are a result of the open circuit reading of the data logger before specimen connection 
B-13 Temperature curve for insulated and bare specimens for AP60 with 4.9\%

air

B-14 Resistivity curve for insulated and bare specimens for AP60 with $4.9 \%$ air. Large values at t-zero are a result of the open circuit reading of the data logger before specimen connection

B-15 Temperature curve for insulated and bare specimens for AP100 with $6.1 \%$ air

B-16 Resistivity curve for insulated and bare specimens for AP100 with $6.1 \%$ air. Large values at t-zero are a result of the open circuit reading of the data logger before specimen connection . 71

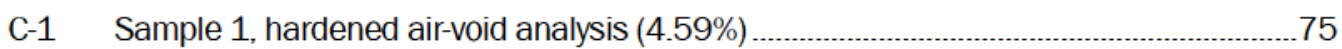

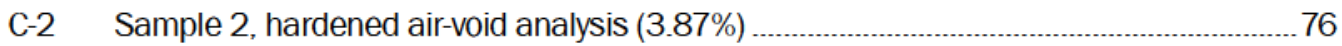

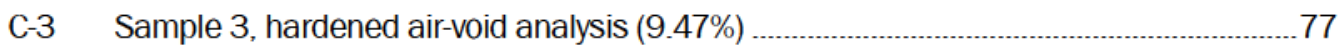

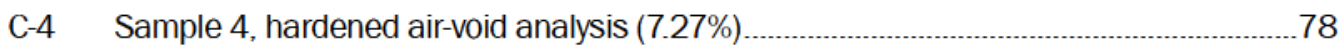

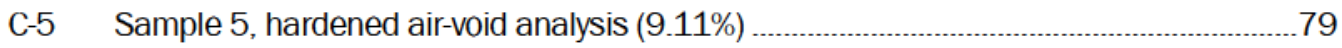

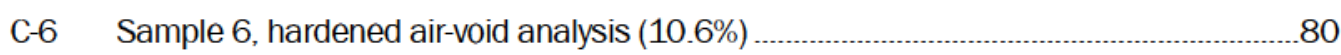

C-7 Sample 7, hardened air-void analysis $(10.84 \%) \ldots \ldots$

C-8 Sample 8, hardened air-void analysis $(6.61 \%)$

C-9 Sample 9, hardened air-void analysis $(8.64 \%)$

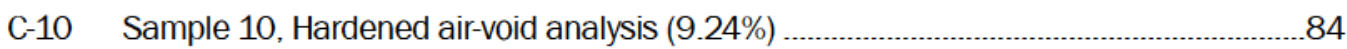

C-11 Sample 11, hardened air-void analysis (9.57\%) …..................................................85

C-12 Sample 12, hardened air-void analysis (23.05\%) ……................................................8

\section{Tables}

1 Admixture type codes

2 Non-default target parameter codes .

3 Mixture proportions used for all concrete made during constructability

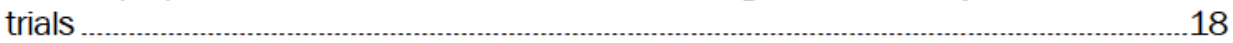

4 Summary of plastic properties for mixtures cured at $23^{\circ} \mathrm{F} \ldots \ldots$

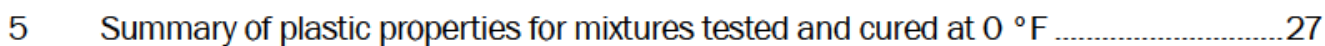

6 Summary of plastic properties measured from mixtures created for

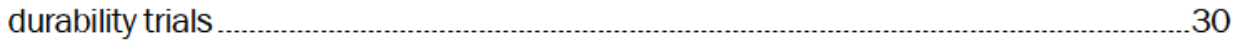

$7 \quad$ Scaling visual rating reproduced from ASTM C672 (2012b) _..._................................. 37

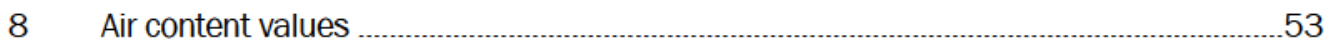

A-1 Admixture chemical analysis _.___.

C-1 Chemical ion concentrations in parts per million $(\mathrm{ppm})$ of concrete pore solution for specimens obtained from field structures. 


\section{Preface}

This study was conducted for the U.S. Army Corps of Engineers under Program Element 62784/T53, "Innovative Construction Materials for the Arctic Program.” The technical monitor was Mr. Josh Fairley (CEERD-GMM).

The work was performed by the Engineering Resources Branch of the Research and Engineering Division, U.S. Army Engineer Research and Development Center, Cold Regions Research and Engineering Laboratory (ERDC-CRREL). At the time of publication, Dr. Caitlin Callaghan was Acting Chief of the Engineering Resources Branch, and Dr. M. Andrew Niccolai was Acting Chief of the Research and Engineering Division. The Deputy Director of ERDC-CRREL was David B. Ringelberg, and the Director was Dr. Joseph L. Corriveau.

COL Teresa A. Schlosser was Commander of ERDC, and Dr. David W. Pittman was the Director. 


\section{Introduction}

The following report details research performed as part of an investigation into the long-term durability and early age behavior of concrete placed in freezing conditions. This concrete is protected from the damaging effects of early age freezing through the use of off-the-shelf additives, a technique that the Engineer Research and Development Center, Cold Regions Research and Engineering Laboratory (ERDC-CRREL) has used for several decades. The primary objectives of this study are to better determine the effects of these additives on the early age performance of concrete, and to assess the effects of this technology on long-term durability of concrete in cold climates. These objectives were set to enhance the transferability of additive-based freeze protection for concrete to both civil and military applications. This will be accomplished via improvements to the user friendliness and economy of the technology, and validation of the durability of the resulting product.

\subsection{Background}

Concrete placed in cold weather must be protected from the damaging effects of ice formation at early ages to ensure long-term durability and adequate strength. The American Concrete Institute (ACI) defines cold weather for concrete as "when air temperature has fallen to, or is expected to fall below, $40^{\circ} \mathrm{F}$ " (ACI 2016, p. 306). The primary guidance for protection is ACI 306R-16, Guide to Cold Weather Concreting; typical protection methods detailed by ACI in this guidance include "concrete mixture acceleration, insulation, heat systems, enclosures, or a combination."

The use of enclosures, heating systems, and insulated formwork can incur significant labor and material costs. These protection measures also must be stored onsite or furnished by a contractor. The challenges of these methods led to the development of Cold Weather Admixture Systems (CWAS) at CRREL. CWAS incorporated off-the-shelf admixtures that protect concrete from freezing through freeze-point depression and promotion of rapid strength development. The development of CWAS began at CRREL in the late 1980 s and continued until approximately 2012.

The primary advancement from this period was the ability to place and cure concrete using only off-the-shelf concrete admixtures, on frozen 
subgrade, with ambient temperatures down to $23^{\circ} \mathrm{F}$, while achieving a dramatic reduction in material and labor expense. Figure 1 shows an example of the difference between a CWAS placement and a conventional placement. Using the CWAS approach, the cost of the admixtures could be less than the cost required only for fuel to heat the enclosure used in a conventional approach.

Several successful field demonstrations of the technology took place during this period of research (1989-2012), including wintertime slab replacements at the Soo Locks in Sault Ste. Marie, MI and military hardstands constructed during winter months at Fort Wainwright, AK. An American Society for Testing and Materials (ASTM) specification, C1622 (2016a), was also developed with the support of CRREL research to specify performance requirements for admixtures to be used as part of CWAS, and language describing the general use of admixtures for cold weather concreting was added to the ACI 306R (2016) Guide to Cold Weather Concreting.

While the current ACI 306R guidance document mentions the use of admixtures for cold weather concreting, it provides no specific guidance for the quantity or type of admixture required for protection under specific exposure conditions. The 306R document is also a guidance document, meaning that it does not carry the mandatory requirements of a specification. For cold weather concreting, the specification document is ACI 306.1, Standard Specification for Cold Weather Concreting (ACI 1990), which has not been modified since 1990. The only mention of admixtures in the 306.1 document is for the purpose of reducing the protection period from 3 to 2 days when used.

While the successes of the CWAS research program were substantial, adoption and transfer of the technology to military and civil use was limited due to a number of factors. The most substantial of these was the general lack of performance-based guidance for additive dosage rates. The primary admixtures used in CWAS accelerate the chemical curing of concrete, and depress the freezing point of the mixture. CWAS was conservative, in that the amount of admixture used was typically the maximum recommended by the manufacturer. The quantity and number of admixtures used in CWAS presented a significant challenge to concrete placement logistics, specifically related to truck haul-time and premature hardening. 
Figure 1. Bridge curb repairs performed in the winter of 2002, on the west and east sides of the Trues Brook Bridge in Lebanon, NH. The west side (left) of the bridge was repaired using CWAS concrete, while the east side (right) was repaired using conventional concrete in a heated enclosure.
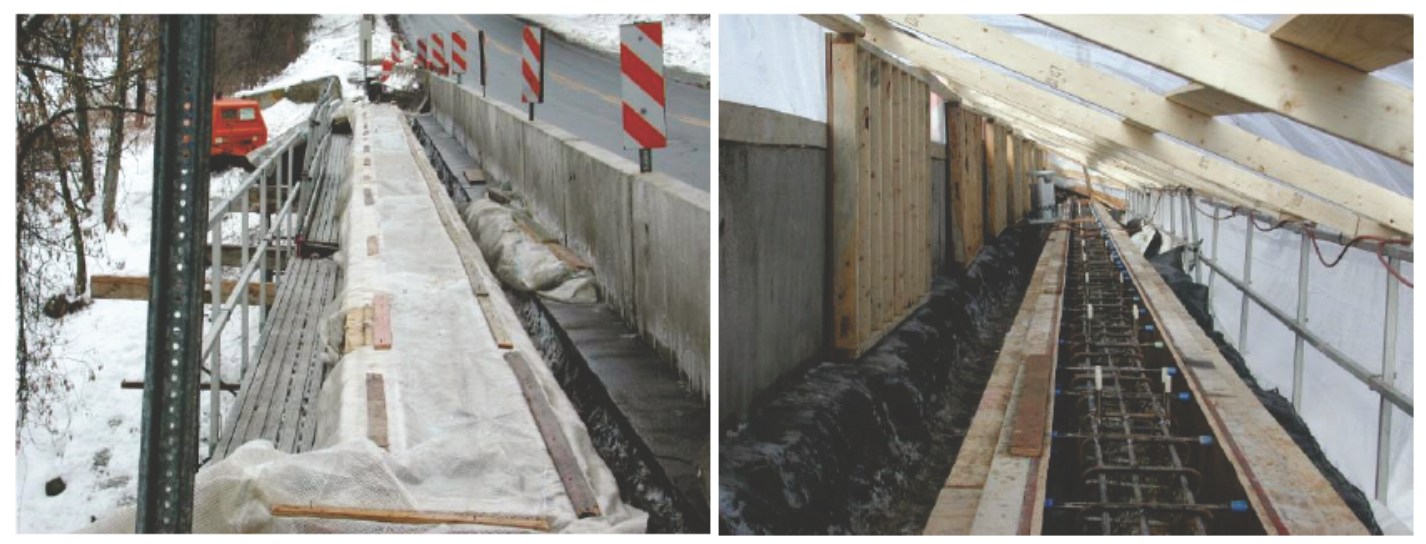

The guiding principle behind the development of CWAS was to protect concrete from freezing; the possibility of ice formation must be eliminated through the depression of the freezing point of the fresh mixture. To accomplish this, the amount of admixture required by CWAS is high: typically on the order of more than 10 gallons per cubic yard, and the admixtures that are typically used also act as accelerators. The result was that a mixture containing these admixtures in the recommended quantity might have an extremely short handling time before initial setting.

In the past, this was compensated for through the delay of CWAS addition until the arrival of the concrete truck at the job site; however, this creates issues related to the large quantity of additional water contained in more than 10 gallons of admixture. To maintain an acceptable water-to-cement ratio with this amount of site-added admixture, the initial water added at the ready-mix plant needed to be relatively low. This necessitated the use of high dosages of water-reducing admixtures at the plant, and made control of slump difficult throughout the mixing and placement process.

Several factors other than directly lowering the freezing point of the mixture contribute to the protection of fresh concrete from frost damage:

- Concrete is only vulnerable to damage from ice formation before it has developed a compressive strength of 500 psi (Kosmatka and Wilson 2015), which can occur fairly quickly when a mixture contains accelerating admixtures. 
- Hydration of Portland cement is exothermic, and substantial heat is released during the first 24 hours of hydration (Mindess `et al. 2003); this effect is also increased through the addition of accelerating admixtures.

- Hydration of cement also binds water chemically (Taylor 2004), increasing the concentration of CWAS in the mixture and further lowering the freezing point as a result (Korhonen et al. 1998).

- When the freezing point of a concrete containing CWAS is reached, the ice that does form is pure water, which increases the concentration of CWAS in the remaining solution, thereby again lowering its freezing point.

These factors combined, together with empirical evidence from several field placements in which ambient temperatures were much colder than $23{ }^{\circ} \mathrm{F}$, indicate that the dosage of CWAS required is likely much lower than previously recommended. The hypothesis that depression of the freezing point to a temperature below that of ambient conditions is mandatory for freeze protection was never tested for concrete in a laboratory setting. The only published instance of deviation from the maximum recommended dosages used for CWAS in concrete is an experiment at Fort Wainwright, Alaska, in which several different amounts of admixture were used in the placement of military hardstands (Barna et al. 2010). This work did find that less than the maximum dose could be used successfully in field placements, but did not determine any recommendations for CWAS dosage based on temperature, mixture, or geometry.

The most recent efforts related to developing tools for CWAS dosage (Barna and Korhonen 2012) acknowledged the need to build a library of curves that capture the self-heating potential of a range of admixture dosages. This approach was to be based on the characterization of the heat of hydration for various CWAS dosages, in combination with a simple onedimensional thermal model; however, neither the model nor the heat of hydration curves was available at the time of this report.

A final issue during the development of CWAS was the unknown effect of the technology on long-term durability in field conditions. Many previous field demonstrations of CWAS have been in service for as long as 2 decades. Visually, these sites appear to be durable; however, this study discusses a follow-on study of cores obtained from several sites to better quantify the long-term performance of CWAS concrete under harsh winter conditions. Figure 2 shows an example of the relative weathering, circa 
2018, of concrete placed with and without CWAS in the winter of 2002 at the Trues Brook Bridge in Lebanon, NH. A laboratory study for Phase III of this effort conducted by CRREL researchers is also ongoing to determine the quantity of admixture required for freeze protection. This study is examining the effect of a range of additive dosages and types on the compressive strength, setting time, and freeze-thaw durability of concrete cured at below freezing temperatures.

Figure 2. Representative photos showing the conditions of the CWAS (left) and conventional (right) bridge curb repairs detailed in Fig. 1, circa September 2018. The repair performed using CWAS exhibits superior surface quality as well as less extensive cracking after 16 years of exposure to winter freeze-thaw cycling and road-deicing salts.
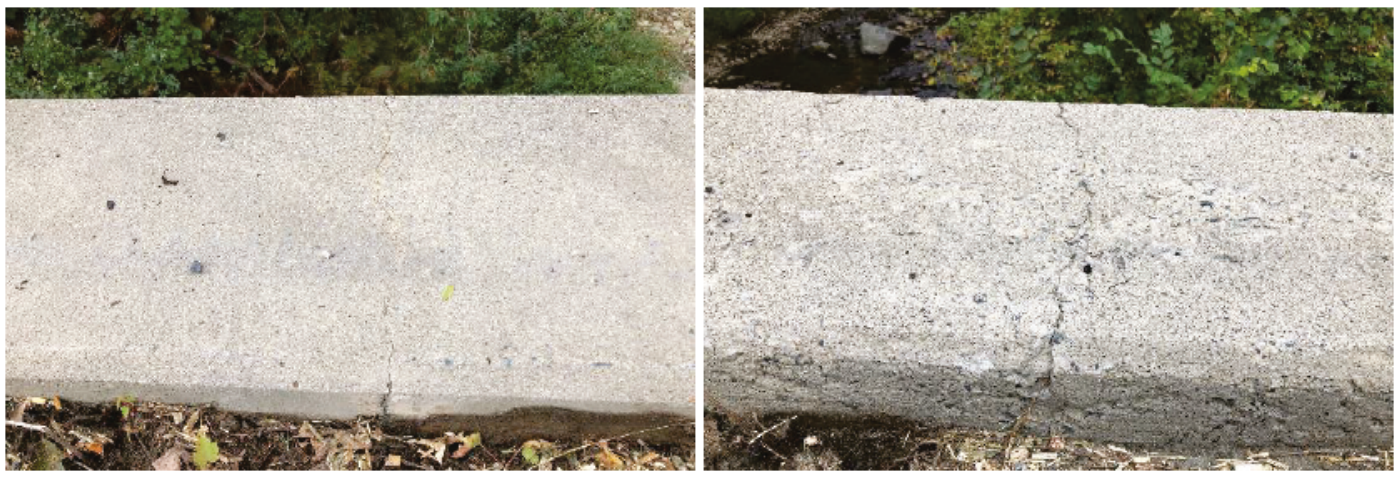

\subsection{Organization}

The content of this report is presented in the following structure:

- Chapter 2 discusses the experimental design of the testing program for the two major phases: constructability and durability trials. This chapter includes reviews of all testing procedures completed.

- Chapter 3 provides the results of the constructability trials for plastic properties and compressive strength testing for over 40 concrete mixtures at different curing temperatures.

- Chapter 4 discusses the mixtures selected from the screening process from the constructability trials. Chapter 4 also provides results of the durability trials for the plastic and mechanical properties at each specimen age.

- Chapter 5 discusses the development and results of an adiabatic testing chamber created to simulate mass effects and provides a brief background on temperature sensing.

- Chapter 6 provides details on the results of testing completed on field specimens collected during Phase 1 of this research. Tests completed 
included hardened air-void analysis and inspection of extracted pore water from cored specimens.

- Chapter 7 closes the document with a summary of the research and final discussion of results as well as recommendations based on findings. This chapter also introduces the Phase 3 efforts of this work titled "ARCTEC Additive Regulated Curing for Thermally Extreme Conditions.” 


\section{Experimental Design}

\subsection{Goals}

The primary findings of the Phase I report indicated that concrete placed in below freezing temperatures using CWAS technology is durable with regards to freezing and thawing cycles as well as exposure to deicing chemicals. These findings are based on the assessment of multiple field sites that range in age from 1 to over 2 decades. In many cases, CWAS concrete exhibits superior durability when compared to conventional cold weather concrete placed simultaneously and exposed to the same conditions. Past technical reports have documented the reduced cost and improved constructability of CWAS when compared to conventional sub-freezing concrete placement techniques.

Despite the cost and construction advantages of CWAS, as well as preliminary findings that indicate highly durable concrete made with these techniques, use of this technology in the last decade has been extremely minimal, particularly in the domain of civil works. Two critical needs that must be addressed to further the ultimate utility and application of CWAS are the need for published guidance or tools, and the need to increase the understanding of the mechanisms responsible for cold climate durability. To help fill these needs, this experimental program had two principal goals: to develop better guidance and tools to increase predictability when using CWAS technology, and to validate the long-term durability of in-service specimens collected during Phase I of this work. Figure 3 shows the flowchart and major milestones for the Phase II experimental program.

Figure 3. Flow chart for test plan.

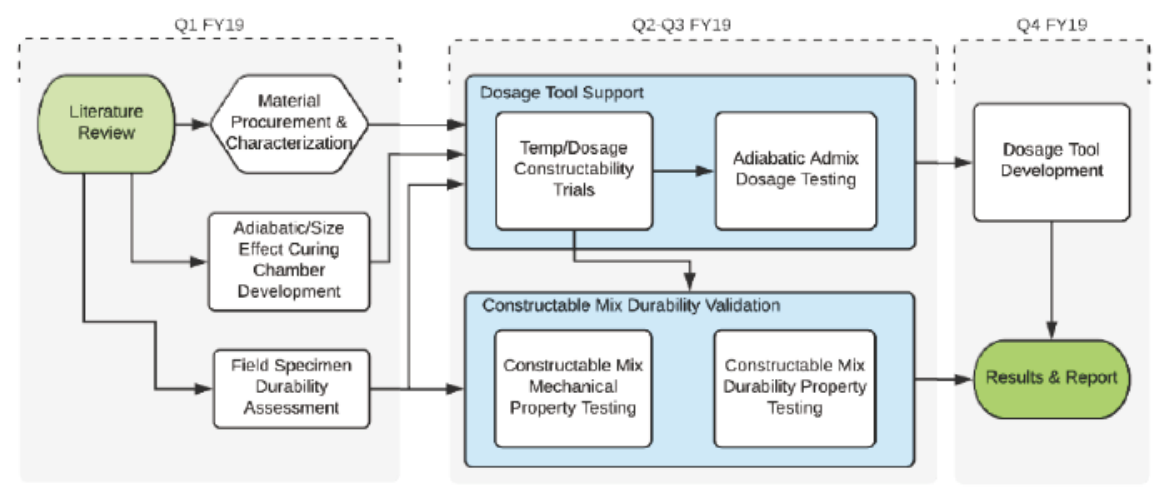


The first stages of this project phase included a brief literature review to build on what was reported in Phase I. Materials needed for concrete mixing including aggregates, cement, admixtures, and molds were procured and concrete materials were analyzed to determine relevant properties. Developing improved guidance involved creating a mix program to better determine the role of admixtures. The mix program was split into two parts: part one was known as "constructability trials" and included over 40 small trial mixtures that were used to screen mixtures for part two, known as "durability trials." The results from the constructability and durability trials, as well as adiabatic testing, will be compiled for a prototype dosage tool at the completion of Phase III of this work. Development of the adiabatic testing chamber proved to be an iterative process that required continuous changes and updates that will be discussed later in this document.

Field specimens collected during Phase I from four field sites including Sault Ste. Marie, Michigan, Fort Wainwright, Alaska, and Fairbanks, Alaska were sent to a fellow U.S. Army Engineer Research and Development Center (ERDC) laboratory, the Geotechnical and Structures Laboratory in Vicksburg, Mississippi, for hardened air-void analysis (ASTM 2016c; Peterson et al. 2001), as well as pore solution extraction and chemical analysis (Hooton and Thomas 2009).

A key objective of the laboratory testing program is to determine how CWAS concrete achieves durable performance in the field. This includes assessing the relative effects of the air-void system as well as the contribution of the additives themselves. Concrete with and without entrained air was created and tested to evaluate this, and to determine if freeze protection additives contribute to the freeze-thaw resistance of concrete independently of air entrainment. The freezing point of CWAS concrete is lower than that of conventional concrete, which may reduce the number of freeze-thaw cycles experienced in the field. The current standard for freeze-thaw testing, defined in ASTM C666 (2015), is not intended to correlate to field durability, but does provide a reliable method by which to compare the freeze-thaw durability of different concretes.

To conserve time and resources, the constructability trial mixtures were only evaluated based on plastic properties and 7-day strength. This screened out unviable mixes before choosing final designs for durability trials. Constructability trial mixtures were much smaller than durability 
trials; mixtures with varied curing temperatures, admixture types, and admixture dosages, were created with the goal of meeting specified plastic properties. The best performing mixtures were selected for the larger durability trials. The durability trials included compressive strength testing at three ages, modulus of elasticity testing at two ages, freeze-thaw resistance testing, and testing of resistance to deicers and scaling.

To easily keep track of the admixture types and dosages, a unique naming convention was developed. The notation was devised first with a set of default assumptions for mixture design and plastic property targets, based on typical winter concreting practices. These assumptions are described as follows:

1. Seven sack mix ( $658 \mathrm{lb} / \mathrm{yd} 3$ Portland cement)

2. Water-to-cement ratio of 0.42

3. Target slump of $6 \pm 2$ in.

4. Target air content of $6 \pm 2 \%$

5. Curing temperature of $23{ }^{\circ} \mathrm{F}$

6. Target fresh temperature of $60^{\circ} \mathrm{F}$.

These parameters are assumed unless indicated otherwise by the naming convention. The naming convention itself always begins with a single letter indicating admixture manufacturer; for this program, the two manufacturers were designated as "A" or "B." Immediately following the manufacturer code is a series of characters indicating freeze protection additive type and dosage. These are summarized in Table 1 , and admixture chemical composition is provided in Appendix A. Admixtures evaluated included those typically included in CWAS: non-chloride accelerators, calcium nitrite corrosion inhibitors, and cold weather specific admixtures. Cold weather specific admixtures are generally similar in formulation to non-chloride accelerators, with the primary difference being target use case. Also included were shrinkage reducers, which in the past have been evaluated as possible CWAS components (Korhonen and Brook 1996), and calcium nitrate fertilizer, which was evaluated as a possible expedient alternative to non-chloride accelerators (Korhonen 1999).

Dosage amounts for admixtures designated in Table 2 are also indicated in the name, using the units of dosage designated by the manufacturer. For most admixtures, this is fluid ounces per hundred pounds of cement (cwt); however, type $\mathrm{C}$ admixtures are dosed in gallons per cubic yard. 
Table 1. Admixture type codes.

\begin{tabular}{|l|c|}
\hline Admixture Type & Code \\
\hline Non-Chloride Accelerator & $\mathrm{N}$ \\
\hline Calcium Nitrite Corrosion Inhibitor/Accelerator & $\mathrm{C}$ \\
\hline Retarder & $\mathrm{R}$ \\
\hline Cold Weather Specific Admixture & $\mathrm{P}$ \\
\hline Shrinkage Reducing Admixture & $\mathrm{S}$ \\
\hline Other & $\mathrm{O}$ \\
\hline
\end{tabular}

Table 2. Non-default target parameter codes.

\begin{tabular}{|l|c|l|}
\hline Parameter & Code & Unit \\
\hline Cement Content & C & Sacks (94lb) \\
\hline Curing Temperature & T & Degrees Fahrenheit \\
\hline Target Fresh Temp & F & Degrees Fahrenheit \\
\hline Target Air & A & Air Percent \\
\hline
\end{tabular}

This is typical practice for admixture use in the concrete industry. Using this system, a mixture with a code of "AN45C45" would indicate manufacturer A, with a $45 \mathrm{oz} / \mathrm{cwt}$ dose of non-chloride accelerator and a 4.5 $\mathrm{gal} / \mathrm{yd}^{3}$ dose of calcium nitrite corrosion inhibitor, with the default waterto-cement ratio (w/c), cement content, slump and air targets, curing temperature, and fresh temperature indicated above. When mixtures deviated from these targets, a "." followed by a character and numeric value would indicate the differing parameter. These codes are summarized in Table 2.

For example, the same "AN45C45" mixture, altered to "AN45C45.To" would indicate that mixture was cured at $\mathrm{o}^{\circ} \mathrm{F}$. Admixture dosages were generally tested at three standardized levels, based on a percentage of the manufacturers' maximum recommended amounts. These levels were used in both constructability and durability trials.

1. $\mathrm{N}_{3} \mathrm{CC}_{3}$, representing a $50 \%$ dose of non-chloride accelerator and a $50 \%$ dose of calcium nitrite corrosion inhibitor

2. $\mathrm{N}_{45} \mathrm{C} 45$, representing a $75 \%$ dose of non-chloride accelerator and a $75 \%$ dose of calcium nitrite corrosion inhibitor

3. N6oC6, representing a 100\% dose of non-chloride accelerator and a $100 \%$ dose of calcium nitrite corrosion inhibitor. 
Unless otherwise stated, tests were performed according to ASTM standards. When discussing goals of the project with local concrete suppliers, recommendations were provided for fresh temperature and mixing time to simulate ready-mix concrete operations as much as possible in a laboratory setting. With this in mind, concrete was mixed for 20 minutes to simulate traveling to a project site and fresh concrete temperatures were targeted at approximately $60^{\circ} \mathrm{F}$. Ready-mix concrete suppliers typically achieve this temperature by heating mixing water when aggregates are stored outdoors in cold environments.

\subsection{Constructability trials}

The constructability trials portion of the testing program lasted for approximately 3 months and included over 40 mixtures. All mixes other than roomtemperature controls were mixed and cured in a cold room. To keep equipment from getting too cold, all testing materials were kept in a room-temperature environment and brought into the cold room just before the 20-minute mark and moistened according to the standards. Researchers had to be cautious regarding water use in the room to reduce ice formation on tools.

\subsubsection{Plastic property testing}

Plastic properties measured included slump (ASTM 2012a), unit weight (ASTM 2013a), temperature (ASTM 2013b), time of set (ASTM 2008b), and air content (volumetric) (ASTM 2016b). During constructability trials, the only hardened concrete test performed was a 7-day compressive strength test (ASTM 2014c). Mixtures were selected for the larger, durability trial mixes based on initial setting time and compressive strength results.

Fresh concrete temperature was measured at both the 10 (T1) and 20-minute (T2) mark to track the change over time. Immediately after the 20-minute mix period, slump was measured, and if the mix was workable, additional testing was conducted for unit weight and air content concurrently with specimen preparation. If the mix were too stiff and could not be adjusted with water reducer during the mixing period, it was immediately disposed of after measuring slump to prevent damage to equipment. Once all testing was completed and cylindrical specimens were made, the remaining concrete was removed from the cold room and sieved for time of set testing. The concrete was mixed in $23^{\circ} \mathrm{F}$, but sieved and tested outside of the cold room in an approximate $73{ }^{\circ} \mathrm{F}$ environment according to ASTM C403 (2008b); because 
colder concrete sets more slowly, this provided a conservative indicator of setting time in cold climates. Similarly, the base of the volumetric air meter was prepared with concrete in the cold room, but the remainder of the test was run in a $73^{\circ} \mathrm{F}$ environment according to ASTM C173 (2016b).

\subsubsection{Mechanical property testing}

During constructability trials, compressive strength samples were stored in the cold room until they were tested. Cylinders were removed from the cold room and demolded at 7 days and tested for unconfined compressive strength according at ASTM C39 (2014c) while still cold, using unbonded, neoprene caps.

Modifications were made to compressive strength testing for both the constructability and durability trials to capture the effects of specimen thermal environment on temperature rise and strength development. When curing in a cold environment, different specimen sizes will retain more or less heat. To capture this effect, specimens of different sizes can be made and cured concurrently; however, this creates a need for much larger batch sizes. To capture this effect without the need for multiple specimen sizes, individual specimen insulation sleeves were constructed from reflective insulation (Figure 4). These sleeves enable side-by-side and independent curing of 4-in. x 8-in. specimens in two different thermal conditions. In addition, thermocouples were inserted into one bare and one insulated cylinder to track internal temperature.

\subsection{Durability trials}

After compiling and comparing results of $40+$ constructability trial mixtures, best performing mixtures were selected to be remade for the durability trials. Durability trial mixtures were larger $(\approx 2.5 \mathrm{ft} 3)$ to create more specimens for testing. Additional hardened property tests were incorporated to better determine the durability of mixtures. 
Figure 4. Insulated and non-insulated specimens.

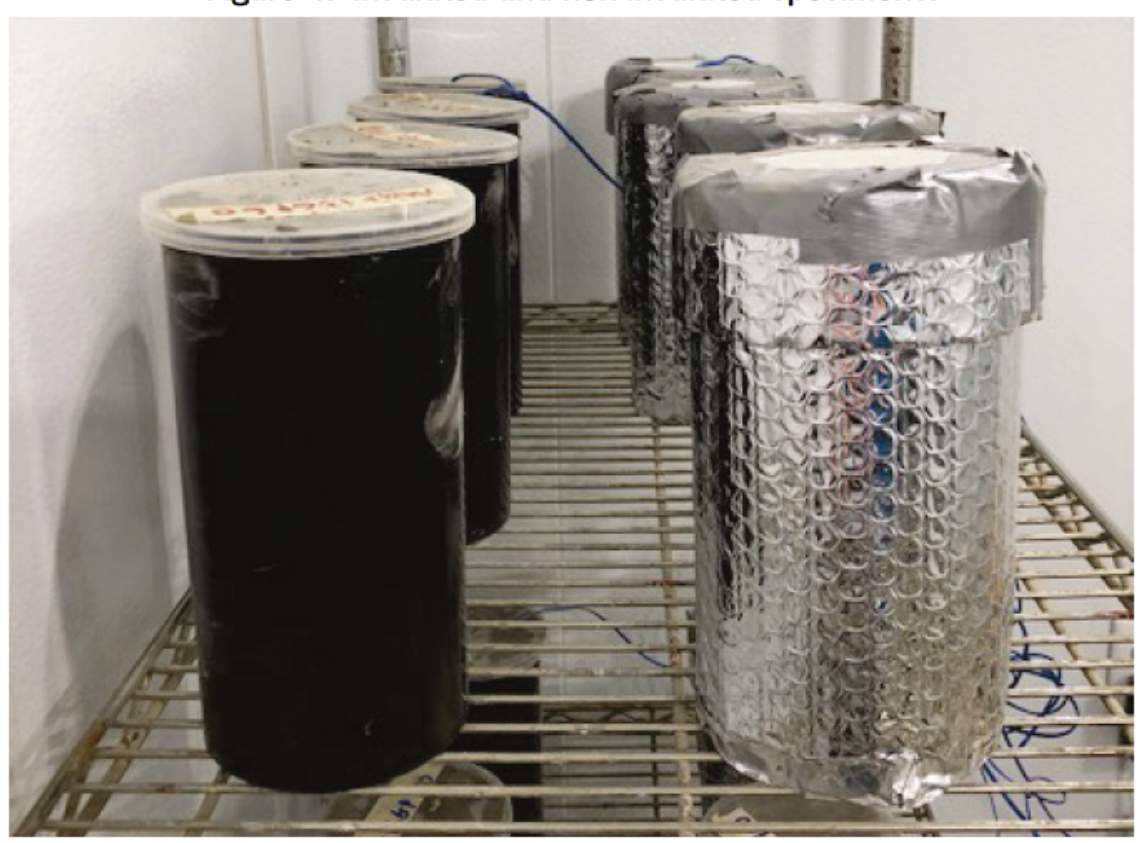

The same plastic property tests were run with the exception of air content, which was switched from the volumetric method to the pressure method (ASTM 2017). The performance of the two methods was verified to be the same through the testing of several mixtures with both methods near the end of constructability trials. The pressure meter used for testing is also capable of characterizing the air-void system via the sequential air method (SAM) (AASHTO 2018). This test has been adopted by a number of regional departments of transportation, including New York and Michigan. For the purposes of this research, the method was used for the sake of familiarity and to determine if any correlation exists between resistance to frost damage and concrete containing freeze protection additives.

\subsubsection{Mechanical property testing}

To produce more reliable results, cylindrical specimens created for durability tests were sulfur capped to ensure plane and perpendicular surfaces for compression and modulus testing instead of using unbonded, neoprene caps. Sulfur capping was also required due to the incorporation of modulus testing since lab resources did not allow for grinding cylinder ends. Specimens at 7 and 28 days of age were removed from the cold room 1 day before testing to allow them to warm to room temperature before sulfur capping. To optimize curing space in the cold room, all remaining specimens were removed from the cold room at 28 days and stored in a $73^{\circ} \mathrm{F}$ 
room. In most environments, it is not expected that freshly placed concrete will remain at constant below freezing temperatures with no warming for 4 weeks, so this was considered a conservative approach. Specimens remained in their molds until the day before testing, as moist curing would not be possible at early ages in freezing temperatures, and would not be practical to implement beyond 28 days of age.

\subsubsection{Compressive strength and modulus of elasticity}

Unconfined compressive strength was measured at 7,28 , and 90 days for both insulated and non-insulated specimens. Results from 28- and 9o-day specimens were used to inform the ultimate load for modulus of elasticity testing at 28 and 90 days. Modulus of elasticity specimens were tested on a universal testing frame according to ASTM C469 (2014b) using an Epsilon extensometer. The extensometer was attached to the concrete specimens to measure strain while loading the specimen to $40 \%$ of the ultimate load three times. The modulus of elasticity value was recorded for the final two tests and averaged to achieve the final value. Figure 5 shows the setup of the testing with the Materials Test System (MTS) frame and extensometer. Figure 6 shows resonant frequency testing conducted to calculate relative dynamic modulus. Figure 7 shows the freeze-thaw chamber with beam specimens.

Figure 5. Modulus of elasticity test setup with extensometer.

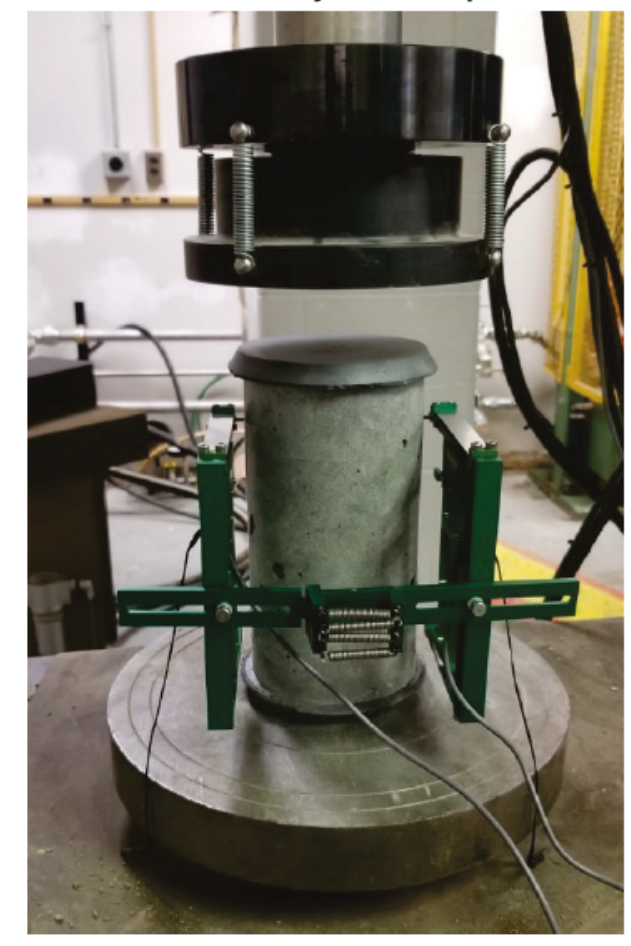


Figure 6. Resonant frequency testing conducted to calculate relative dynamic modulus.

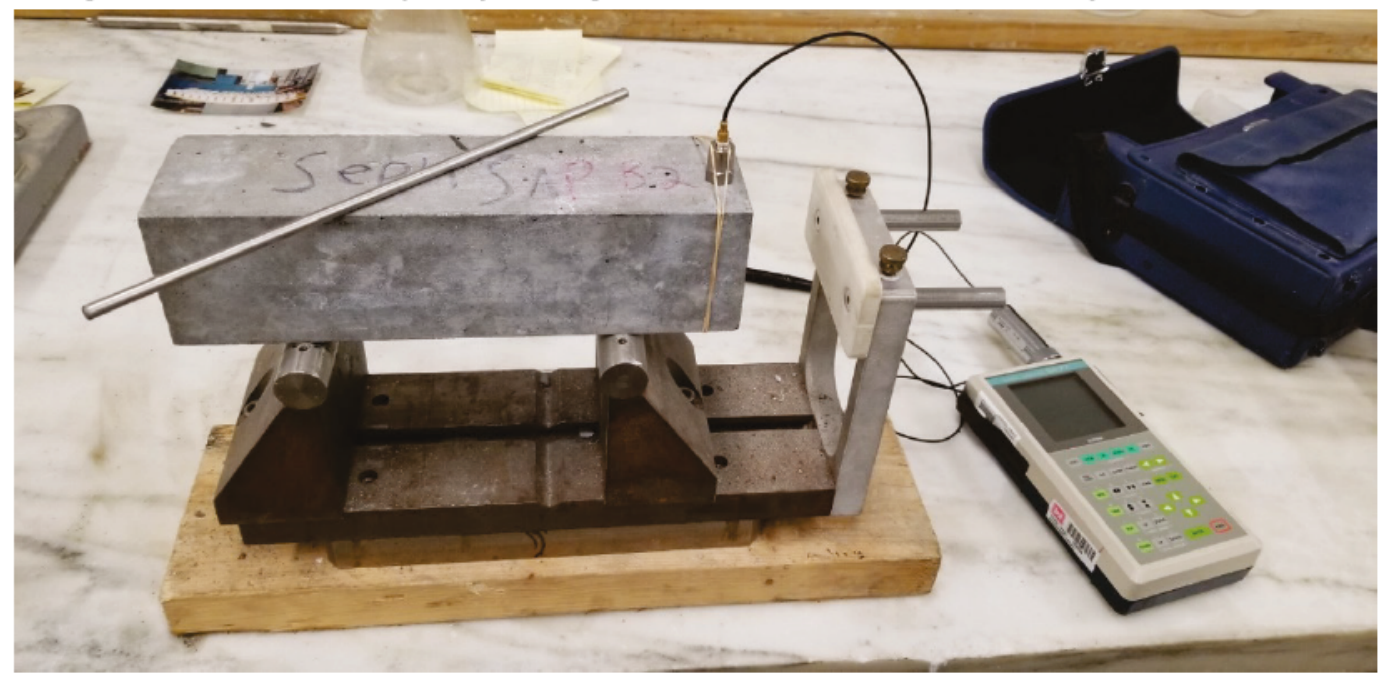

Figure 7. Freeze-thaw chamber with beam specimens.

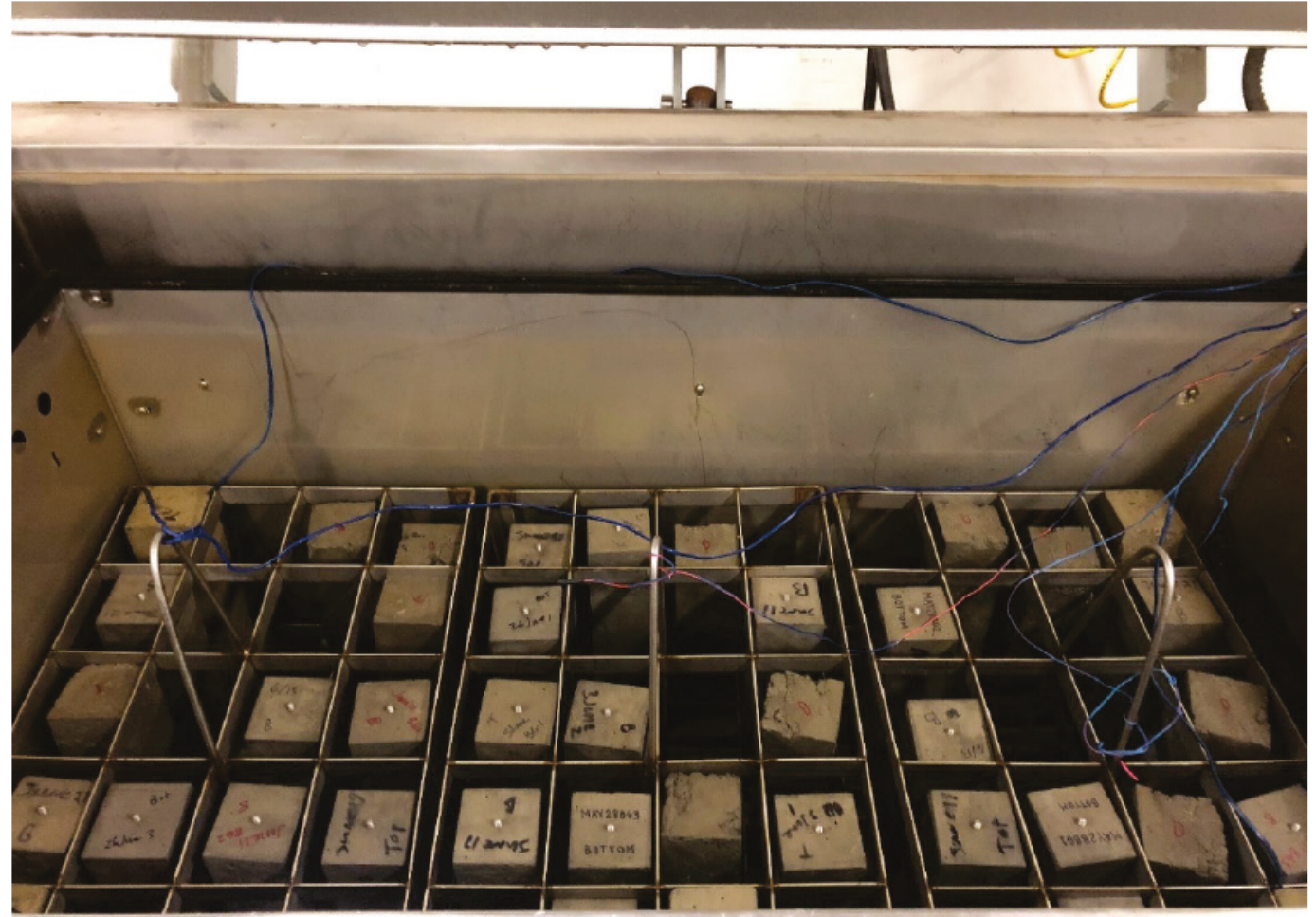




\subsection{Durability property testing}

\subsubsection{Freeze-thaw resistance}

Prism specimens of dimensions 3-in. x 3-in. x 11.125-in. were created for freeze-thaw testing according to ASTM C666 (2015), Procedure B. Modifications to the standard included omission of moist curing for specimens, as well as beginning the test at 7 days of age instead of 14. Earlier exposure to freeze-thaw cycling was implemented to more accurately reflect likely exposure conditions of concrete placed in winter climates. Specimens were cured in the $23^{\circ} \mathrm{F}$ cold room for the first 6 days, removed from molds, and on day 7 , measured and placed into the freeze-thaw chamber. Initial measurements for length change, mass, and resonant frequency were taken before placing them into the chamber. Initial measurements of these properties were important, as failure occurs when the relative dynamic modulus of the specimen reaches $60 \%$, as calculated from the initial and current fundamental transverse frequencies measured according to ASTM C215 (2014a). Length change measurements were recorded according to ASTM C157 (2008a), and provide an optional failure criteria of 0.10\% expansion defined in ASTM C666 (2015).

Specimens were measured in intervals according to the standard until they reached $60 \%$ of their initial frequency, or 300 cycles, whichever came first. Freeze-thaw testing cycled specimens with varying mixture designs through freezing in air for 2 hours, and thawing in water for 2 hours. This test procedure is used to validate the durability of specimens by determining resistance to rapid freeze-thaw cycles. Although these cycles do not reflect true environmental freezing and thawing cycles, the test provides an accurate way to compare the relative performance of different mixtures under exposure to many cycles of freezing and thawing. It is likely that this method is overly harsh when compared to freeze-thaw cycles in nature, as most freeze-thaw cycles occur with a periodic frequency of 24 hours (Nokken et al. 2004), and slow freezing is less likely to damage the interior void structure of concrete (Cai and Liu 1998; Fridh 2005; Powers 1955).

\subsubsection{Scaling resistance}

Field investigations from Phase I of this work showed that CWAS concrete in the field appeared to exhibit superior resistance to scaling caused by deicing chemicals when compared to conventional cold weather concrete; 
however, resistance to scaling has never been tested in the laboratory. For this experimental program, two specimens were created from each mix design to estimate the resistance to scaling of specimens after exposure to approximately 50 freeze-thaw cycles and a calcium chloride solution covering the surface for the duration of the test. Specimens were created and cycled between a freezing and room-temperature environment according to ASTM C672 (2012b). Specimens were kept on a cart and rolled in and out of the freezer each day (Figure 8). When removed from the freezer, lids were removed and the calcium chloride solution was replenished as needed to ensure that the surface was covered. Specimens were visually inspected every day and status was documented weekly.

Figure 8. Scaling testing.

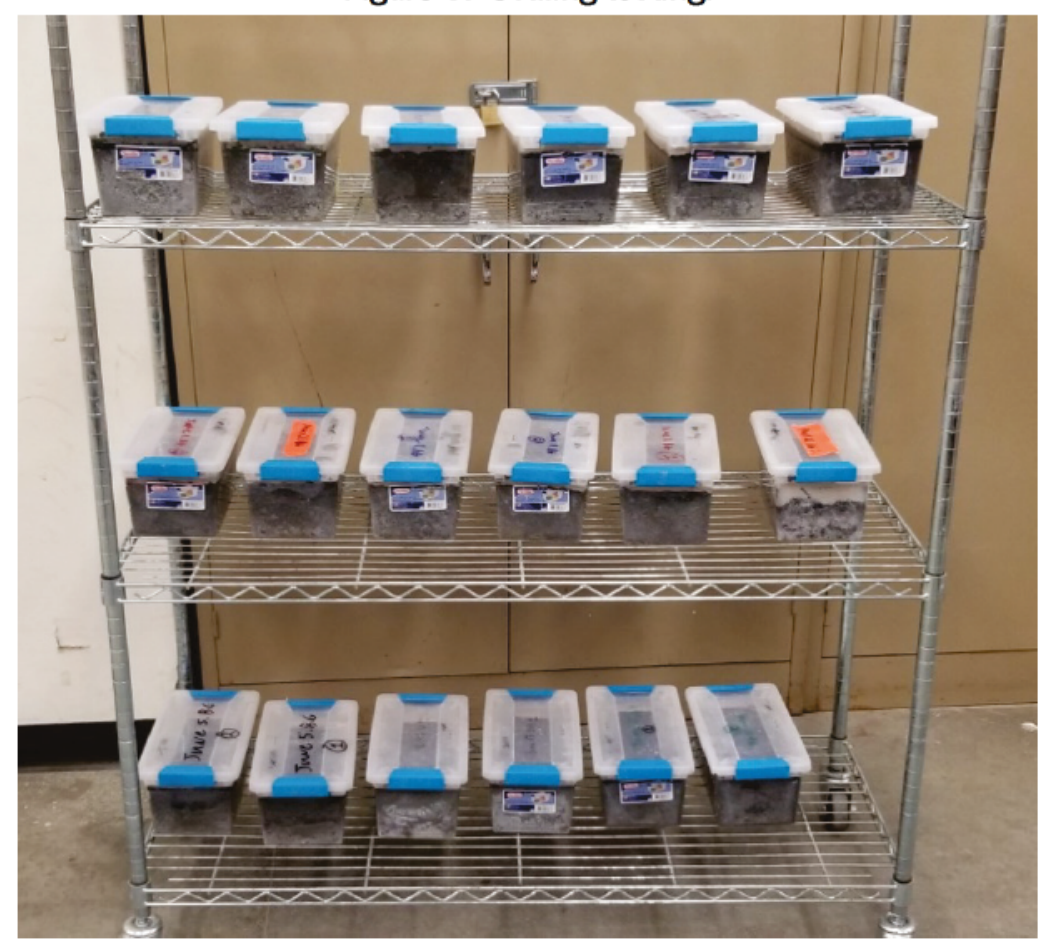

Table 3 lists the mixture design used for all constructability trials, based on a typical New Hampshire Department of Transportation (NHDOT) AA mixture design. all materials were locally sourced, and coarse and fine aggregate proportions were set based on the dry-rodded bulk density of the coarse aggregate, as well as the fineness modulus of the fine aggregate, according to the procedures described in ACI 211.1-91 (ACI 1996, p. 1). 
Table 3. Mixture proportions used for all concrete made during constructability trials.

\begin{tabular}{|l|c|c|c|}
\hline & Specific Gravity & Absorption \% & $\mathrm{Ib} / \mathrm{yd}^{3}$ \\
\hline Type I/II Portland Cement & 3.15 & - & 658 \\
\hline Water & 1.00 & - & 277 \\
\hline Coarse Aggregate & 2.82 & 0.33 & 1782 \\
\hline Fine Aggregate & 2.68 & 0.88 & 1250 \\
\hline
\end{tabular}

\subsubsection{Embedded resistivity}

Concrete resistivity, typically measured per AASHTO TP 358 (AASHTO 2017), is widely accepted as a metric for evaluating the concrete's resistance to ion ingress (Spragg et al. 2013). The curing regime of this study precluded use of standardized methods; however, an alternative method was explored. Embedded resistivity measurements were obtained continuously from curing concrete specimens. Electrodes were embedded in the bottom face of a 4-in. $x$ 8-in. cylinder, 2 in. apart and 3 in. into the depth of the concrete. Resistivity was measured using a Campbell scientific CR1oX datalogger, using alternating current (AC) excitation to avoid polarization of the concrete pore solution (Layssi et al. 2015; Spragg et al. 2013). Measurements were collected every 30 seconds, and reported in $\mathrm{k} \Omega$. Resistivity of concrete microstructure can be used as a relative indicator of the permeability of the cementitious matrix; however, certain chemical admixtures can have an effect on the results of the test, due to changes in the ionic concentration of the pore solution (Nokken et al. 2008). Due to the exploratory nature of this technique, data collected were used solely for informational purposes. 


\section{Constructability Trials Results}

The first phase of the experimental concrete testing program consisted of constructability trials. These mixtures were designed to screen useful mixtures from a broad range of additive dosages, admixture combinations, curing temperatures, and fresh concrete temperatures. Most of the mixtures created during this program were cured at $23{ }^{\circ} \mathrm{F}$; however, some mixtures were tested at a much harsher $\mathrm{o}^{\circ} \mathrm{F}$. The goal of the screening process was to select mixtures that had favorable plastic properties for the larger testing. Specifically, mixtures that possessed useful setting times and high 7-day compressive strengths were chosen.

\subsection{Plastic property results and discussion}

\subsubsection{Mixtures cured at $23^{\circ} \mathrm{F}$}

Table 4 summarizes all plastic mixtures cured at $23^{\circ} \mathrm{F}$ for which data could be collected. These include $\mathrm{N}_{3} \mathrm{OC} 3$ and $\mathrm{N}_{45} \mathrm{C}_{45}$ dosages for both manufacturers A and B, P100 and P6o dosages for manufacturer A, as well as some variations on these mixtures with no entrained air. Several mixtures were also tested with calcium nitrate fertilizer in the place of non-chloride accelerator, with the dosage of fertilizer set to equate to the nitrate content of different admixture combinations. Appendix A includes chemical properties of admixtures used in this study, as obtained during research for the first phase of this project (Kennedy et al. 2019).These mixtures carry an "O" admixture type in their name code. The calcium nitrate fertilizer, in solid form, had a distinct advantage in that it could be added toward the very end of the 20-minute mixing period without any apparent impact on slump.

Table 4. Summary of plastic properties for mixtures cured at $23^{\circ} \mathrm{F}$.

\begin{tabular}{|l|c|c|c|c|c|c|c|}
\hline \multicolumn{1}{|c|}{ Mix ID } & $\begin{array}{c}\text { Cure Temp } \\
\left({ }^{\circ} \mathrm{F}\right)\end{array}$ & $\begin{array}{c}\mathrm{T} 1 \\
\left({ }^{\circ} \mathrm{F}\right)\end{array}$ & $\begin{array}{c}\mathrm{T} 2 \\
\left({ }^{\circ} \mathrm{F}\right)\end{array}$ & $\begin{array}{c}\text { Slump } \\
(\mathrm{in})\end{array}$ & $\begin{array}{c}\text { Air } \\
(\%)\end{array}$ & $\begin{array}{c}\text { Initial Set } \\
(\mathrm{hr})\end{array}$ & $\begin{array}{c}\text { Final Set } \\
(\mathrm{hr})\end{array}$ \\
\hline Control & 73.0 & 78.4 & 78.9 & 2.8 & 4.5 & 4.7 & 8.4 \\
\hline A & 23.0 & 59.7 & - & 5.5 & 4.5 & 9.0 & 11.7 \\
\hline B & 23.0 & 59.3 & 53.4 & 7.5 & 9.5 & 6.6 & 12.1 \\
\hline AN30C3 & 23.0 & 65.6 & 59.9 & 4.3 & 4.3 & 3.66 & 5.66 \\
\hline AN30C3A0 & 23.0 & 69.5 & 63.4 & 4.0 & 2.5 & 16 & 7.2 \\
\hline BN30C3 & 23.0 & 62.4 & 58.3 & 9.8 & 14.0 & 3.4 & 10.5 \\
\hline AN45C45 & 23.0 & 60.1 & - & 3.8 & 3.0 & 3.3 & 8.7 \\
\hline AN45C45A0 & 23.0 & 716 & 65.5 & 2.0 & 3.0 & 3.4 & 8.9 \\
\hline BN45C45 & 23.0 & 61.0 & 58.7 & 8.8 & 4.5 & 3.8 & 7.3 \\
\hline
\end{tabular}




\begin{tabular}{|l|c|c|c|c|c|c|c|}
\hline \multicolumn{1}{|c|}{ Mix ID } & $\begin{array}{c}\text { Cure Temp } \\
\left({ }^{\circ} \mathrm{F}\right)\end{array}$ & $\begin{array}{c}\mathrm{T} 1 \\
\left({ }^{\circ} \mathrm{F}\right)\end{array}$ & $\begin{array}{c}\text { T2 } \\
\left({ }^{\circ} \mathrm{F}\right)\end{array}$ & $\begin{array}{c}\text { Slump } \\
(\mathrm{in})\end{array}$ & $\begin{array}{c}\text { Air } \\
(\%)\end{array}$ & $\begin{array}{c}\text { Initial Set } \\
(\mathrm{hr})\end{array}$ & $\begin{array}{c}\text { Final Set } \\
(\mathrm{hr})\end{array}$ \\
\hline BC60 & 23.0 & 63.9 & 59.1 & 7.5 & 6.5 & 2.5 & 5.6 \\
\hline BC60.F45 & 23.0 & 38.7 & 42.3 & 7.5 & 3.3 & 11 & 7.3 \\
\hline BN60C6.F45 & 23.0 & 40.6 & 45.3 & 7.5 & 3.8 & - & - \\
\hline AP100 & 23.0 & 60.8 & 55.2 & 3.8 & 5.0 & 2.8 & 4.3 \\
\hline AP60 & 23.0 & 612 & 55.3 & 4.8 & 5.0 & 3.6 & 5.1 \\
\hline BN449C303 & 23.0 & 64.9 & 59.6 & 7.3 & 8.3 & 2.1 & 5.9 \\
\hline BN269C182 & 23.0 & 63.4 & 55.7 & 12.0 & 0.3 & 4.0 & 14.7 \\
\hline
\end{tabular}

Mixtures at the $\mathbf{1 0 0 \%}$ dose with a normal target fresh temperature were mixed but are missing from Table 4 . These mixtures were attempted; however the setting time was so rapid that specimens could not be made following the 20-minute mixing time. These mixtures were attempted with a colder fresh temperature; however, the setting of the mix was still so rapid that setting time could not be measured.

Examination of the plastic property results for the constructability trials reveals a great deal of variability in both slump and air content. The addition of large quantities of admixture in fact made achieving target slump and air contents challenging, particularly with admixtures from manufacturer B. The cold weather specific admixtures from manufacturer A, designated "P" carried a nominal maximum dosage of $60 \mathrm{oz} / \mathrm{cwt}$ in the technical documentation, with a mention of applications using as much as 100 $\mathrm{oz} / \mathrm{cwt}$ in special circumstances. These dosages were chosen as the "P" admixture was used alone, in contrast to other mixtures that used a combination of two admixtures. Both dosages were tested, and plastic property behavior was among the most predictable of the combinations tried. The use of a single admixture as opposed to two in combination also reduced the complexity of batching to a certain extent. The $\mathrm{N}_{30} \mathrm{C}_{3}$ and $\mathrm{N}_{45} \mathrm{C} 45$ admixture combinations generally resulted in satisfactory initial setting times; however the air contents were generally low with manufacturer A, and unpredictable with manufacturer B.

Figure 9 summarizes the 7-day compressive strengths for insulated and bare cylinders cured at $23{ }^{\circ} \mathrm{F}$, and tested in a frozen state. These results show that several of the admixture dosages are capable of achieving compressive strengths comparable to those of a room-temperature control specimen at this age. Insulated compressive strengths are universally higher than those of bare cylinders; however, the difference is less 
dramatic as the dosage of admixture increases. The most substantial differences in insulated and bare compressive strengths occurred in mixtures with lower air contents, specifically $\mathrm{AN}_{3} \mathrm{OC}_{3}$. Ao and $\mathrm{AN}_{45} \mathrm{C}_{45}$, for which air entrainment was omitted. This may indicate that entrained air plays a role in preventing early age damage due to ice formation in mixtures containing freeze protection additives. This is further reinforced by the dramatic difference between $\mathrm{AN}_{45} \mathrm{C} 45$.Ao and $\mathrm{AN}_{45} \mathrm{C} 45$. While both mixtures contained approximately the same amount of air, the mixture for which air was deliberately entrained achieved dramatically higher bare strengths, and slightly higher insulated strengths.

Temperature profiles for mixtures with insulated and bare cylinders are shown in Figures 10 and 11; the insulation allows the specimen to maintain a temperature above that of the ambient surroundings for significantly longer than a bare cylinder, allowing for more strength development. Both insulated and non-insulated cylinders reached their freezing point before 24 hours of age, indicating that ice did form in the microstructure. Comparison of temperature profiles for a control mixture (Figure 10) and the $\mathrm{AN}_{3} \mathrm{OC} 3$ mixture (Figure 11) show similar behavior, though the freezing point of the control was higher.

While the strength of insulated cylinders was larger than that of bare cylinders, all admixtures improve compressive strength when compared to control mixtures cured at $23{ }^{\circ} \mathrm{F}$. This indicates that any amount of freeze protection additive reduces the damage caused by early age ice formation. This may be due to the acceleration of hydration, resulting in adequate compressive strength before the formation of ice begins, or possibly a reduction in the total amount of ice formed due to the presence of cold weather additives.

For a subset of the mixtures cured at $23{ }^{\circ} \mathrm{F}$, the difference between testing compressive strength in a frozen or thawed stated was investigated. For these mixtures, the number of compressive strength specimens was doubled, and half of the specimens were removed from the cold room 24 hours before testing, while the other half were tested in a frozen state. The goal of this exercise was to ensure that cylinders retained strength after thawing, and to demonstrate that they were not adversely affected by ice formation. Figure 12 shows the results of this investigation. 


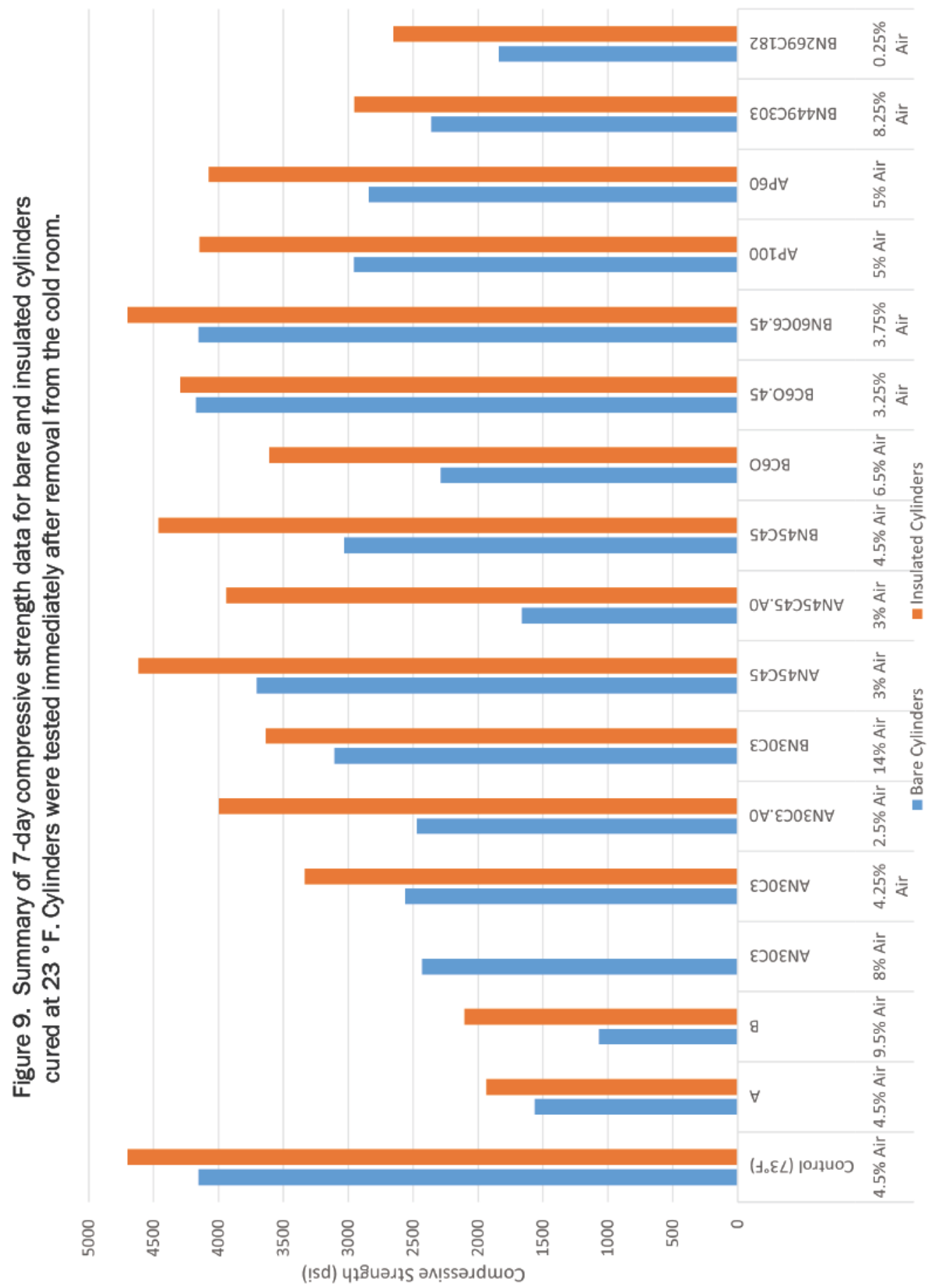




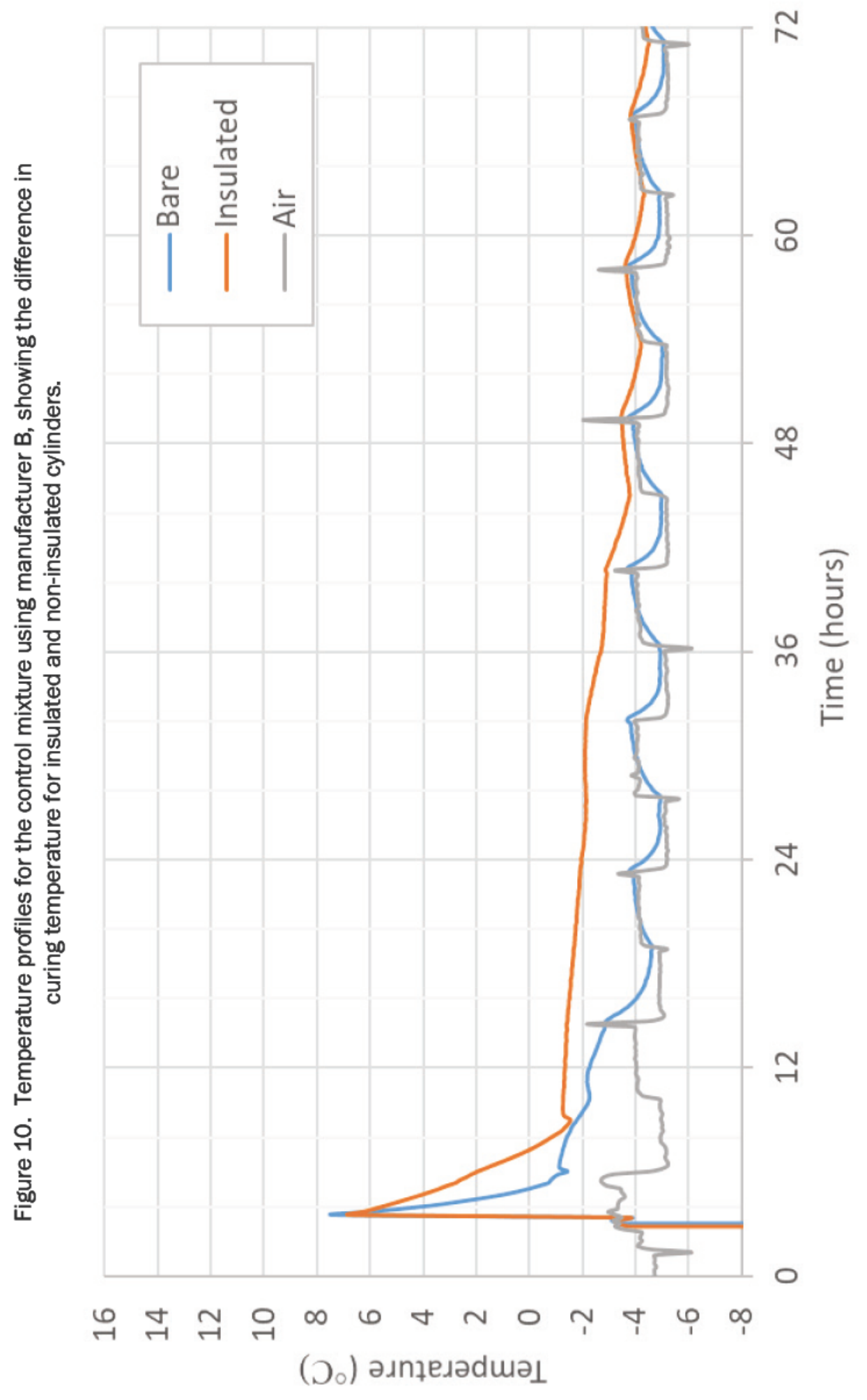




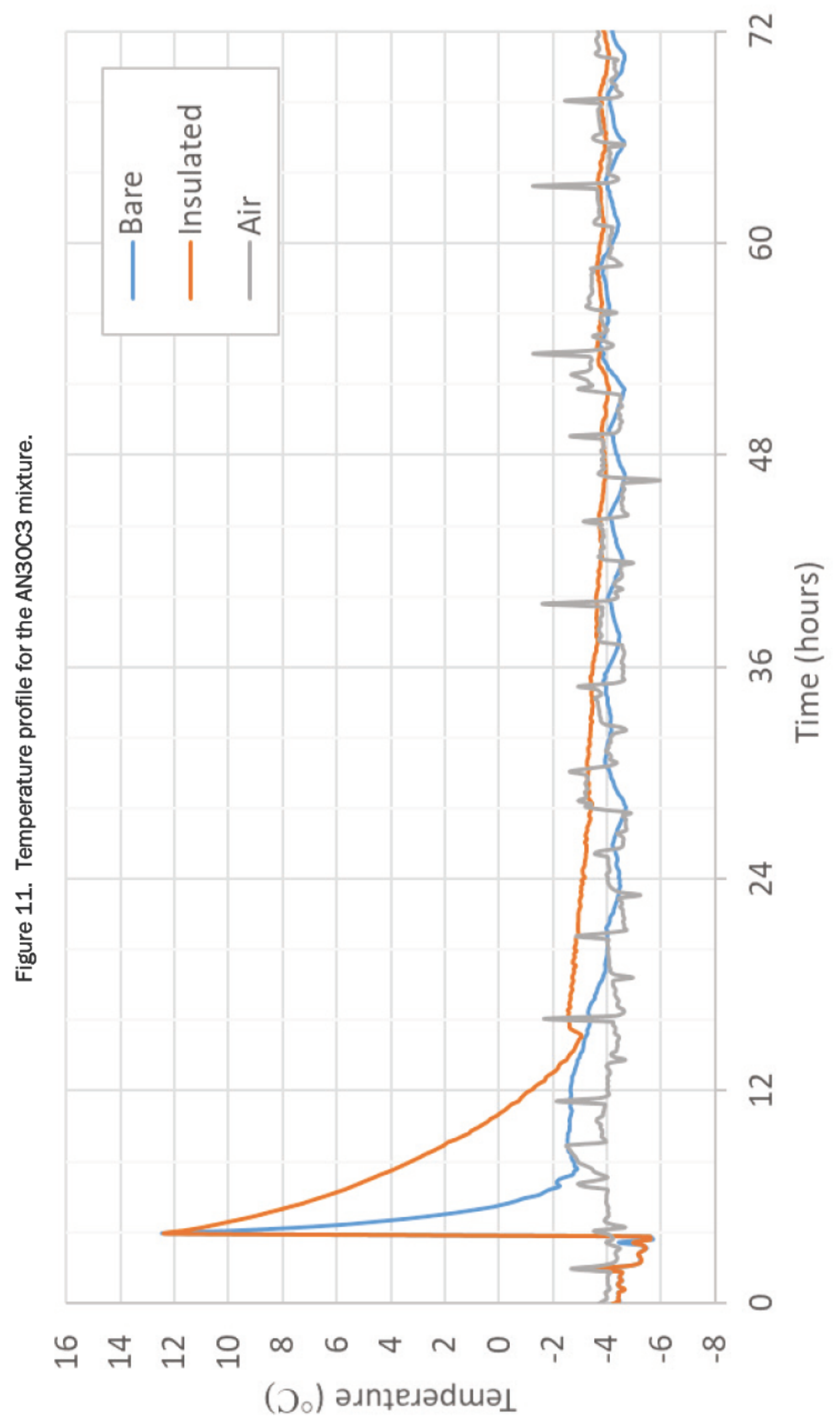




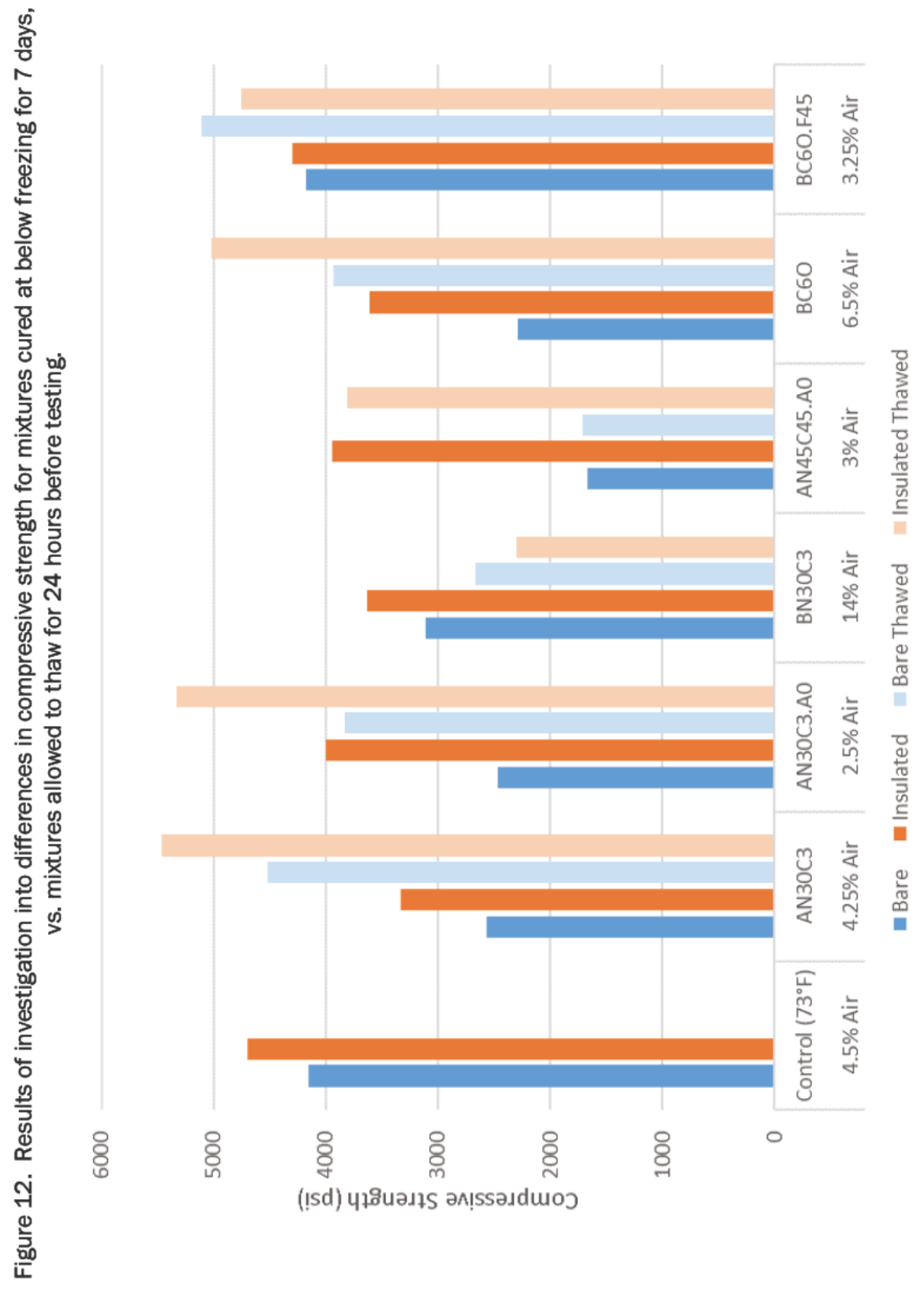


For all but two of the mixtures, the strength of cylinders tested after being allowed to thaw for 24 hours was significantly higher than that of cylinders tested in a frozen state. This indicates that, for these mixtures, the effects of ice formation at early ages did not significantly impact the ability of the hydrating microstructure to gain compressive strength. Two mixtures, $\mathrm{AN}_{30 \mathrm{OC}} 3$ with $4.25 \%$ air and BC6O.F45 with $3.25 \%$ air (a fertilizer mix), exceeded the compressive strength of the control concrete cured at room temperature, despite spending a majority of a week curing at temperatures of $23{ }^{\circ} \mathrm{F}$ (Figure 13).

Figure 13. Summary of compressive strengths for mixtures cured at $0{ }^{\circ} \mathrm{F}$ in both bare and insulated conditions.

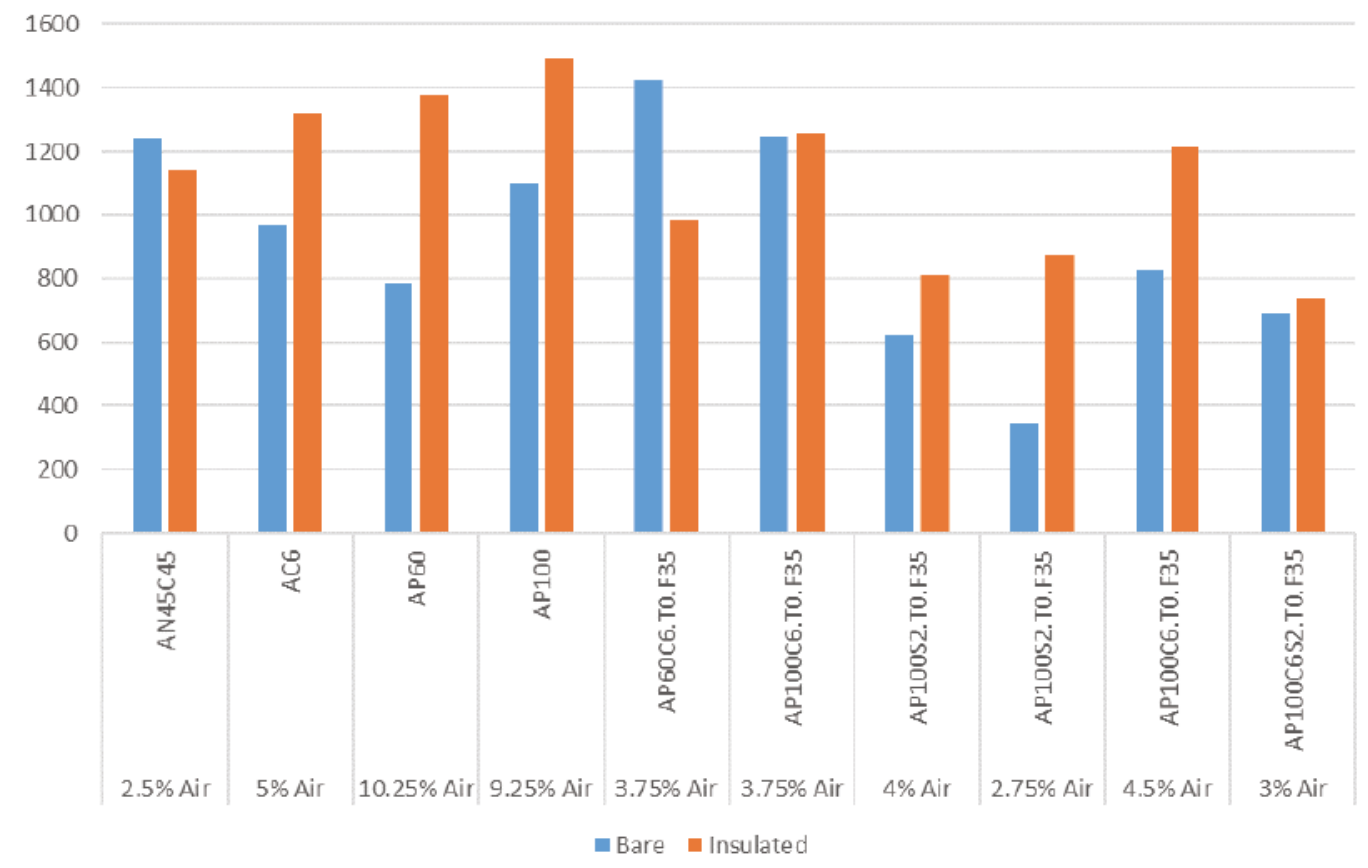

\subsubsection{Mixtures cured at $0^{\circ} \mathrm{F}$}

During constructability trials, several mixtures were tested at temperatures much colder than previously studied. These mixtures were mixed and cured in a $\mathrm{o}^{\circ} \mathrm{F}$ environment, following the same procedures used for all other mixtures tested during constructability trials. Table 5 lists the plastic property results for these mixtures. Mixtures with a target fresh temperature of $60^{\circ} \mathrm{F}$ experienced a much larger temperature drop during mixing in the colder environment, while slump and air behavior was generally similar to that of the mixtures tested at $23{ }^{\circ} \mathrm{F}$. A notable difference 
for these mixtures was the incorporation of a shrinkage reducing admixture from manufacturer A; this admixture is glycol based, and therefore possesses some antifreeze characteristics of its own.

Table 5. Summary of plastic properties for mixtures tested and cured at $0{ }^{\circ} \mathrm{F}$.

\begin{tabular}{|l|c|c|c|c|c|c|c|}
\hline \multicolumn{1}{|c|}{ Mix ID } & $\begin{array}{c}\text { Cure Temp } \\
\left({ }^{\circ} \mathrm{F}\right)\end{array}$ & $\begin{array}{c}\mathrm{T} 1 \\
\left({ }^{\circ} \mathrm{F}\right)\end{array}$ & $\begin{array}{c}\text { T2 } \\
\left({ }^{\circ} \mathrm{F}\right)\end{array}$ & $\begin{array}{c}\text { Slump } \\
(\mathrm{in})\end{array}$ & $\begin{array}{c}\text { Air } \\
(\%)\end{array}$ & $\begin{array}{c}\text { Initial Set } \\
(\mathrm{hr})\end{array}$ & $\begin{array}{c}\text { Final Set } \\
(\mathrm{hr})\end{array}$ \\
\hline AN45C45 & 0 & 60.1 & 54.1 & 3.5 & 2.5 & 3.27 & 10.83 \\
\hline AC6 & 0 & 58.9 & 51.1 & 5.5 & 5 & - & - \\
\hline AP60 & 0 & 57.6 & 48.5 & 7.25 & 10.25 & 4.43 & 6.53 \\
\hline AP100 & 0 & 52.8 & 45 & 6 & 9.25 & 4.6 & 8.66 \\
\hline AP60C6.T0.F35 & 0 & 34.7 & 35.4 & 7.5 & 3.75 & 1.15 & 5.85 \\
\hline AP100C6.T0.F35 & 0 & 33.5 & 33 & 8.75 & 3.75 & 0.9 & 5.44 \\
\hline AP100S2.T0.F35 & 0 & 33.3 & 34.9 & 4.75 & 4 & 2.36 & 6.13 \\
\hline AP100S2.T0.F35 & 0 & 36.4 & 35.2 & 7.5 & 2.75 & - & - \\
\hline AP100C6.T0.F35 & 0 & 35.4 & 35 & 8.25 & 4.5 & - & - \\
\hline AP100C6S2.T0.F35 & 0 & 35.4 & 36.2 & 7.5 & 3 & - & - \\
\hline
\end{tabular}

The 7-day compressive strengths of the mixtures cured at the colder temperature were much lower than those cured at $23{ }^{\circ} \mathrm{F}$ (see Figure 13). These mixtures were tested directly from the cold room in a frozen state, and no mixture exceeded 1500 psi when tested under these conditions. Notably, the best performing strength was a mixture containing "P" alone, the cold weather specific admixture from manufacturer $\mathrm{A}$. The insulation of the cylinders also played a similar role in most mixtures as with the $23{ }^{\circ} \mathrm{F}$ cured cylinders, resulting in an increase in strength.

\subsection{Discussion}

The results presented in this chapter provided an early indication that lower quantities of freeze protection additive than previously recommended could be used to produce concrete with good early age behavior. Specifically, an amount of admixture that allows for 3 hours of handling time before initial set can also provide sufficient freeze protection and strength development to achieve a compressive strength comparable to that of a control concrete at 7 days of age. This round of mixes also found that calcium nitrate fertilizer can tentatively act as a substitute for a calcium nitrate-based non-chloride accelerator, with the handling benefit of being a solid admixture that can be easily added near the end of mixing. This application is potentially valuable in adverse conditions when 
conventional concrete admixtures are unavailable, but would not be practical in a civil works application, due to the non-standard material addition. This round of testing also found that it would be exceedingly difficult to implement the highest dosages of freeze protection additive used in past work from CRREL in modern ready-mix practice, without the significant complicating step of delayed addition of admixture.

The information obtained during these trials was used to inform the next stage of mixing, wherein much larger mixes would be created to accommodate a larger number of testing ages and methods, including several tests for concrete durability. Eight admixture combinations were selected for the larger round of mixtures, based primarily on mechanical performance and time to initial setting. Mixtures for which air entrainment was deliberately omitted were also included, to investigate the role of air content in the long-term performance of mixtures containing freeze protection additive. It was also determined that additives from manufacturer A would be used exclusively for the larger mixes, due to the more predictable behavior of the slump and air content of mixtures containing these additives. The mixtures selected were as follows:
1. Control (A.T73)
2. $\mathrm{AN}_{3} \mathrm{OC} 3$
3. $\mathrm{AN}_{3} \mathrm{OC} 3 . \mathrm{Ao}$
4. $\mathrm{AN}_{3} \mathrm{OC} 3 . \mathrm{F} 45$
5. $\mathrm{AN}_{45} \mathrm{C} 45$
6. AN45C45.Ao
7. $\mathrm{AN}_{45} \mathrm{C} 45 \cdot \mathrm{F} 45$
8. $\mathrm{AP} 100$
9. AP6o. 


\section{Durability Trials Results and Discussion}

\subsection{Overview}

The mixtures selected for durability trials were identical in their proportions to the corresponding mixtures from constructability trials; however, the testing program necessitated a larger batch size due to a much larger number of specimens. The plastic properties measured were similar to those of constructability trials, with the omission of setting time. The method of measuring fresh air content was also changed from the volumetric method (ASTM 2016b), to the pressure method (ASTM 2017). The performance of the two methods was verified to be the same through the testing of several mixtures with both methods near the end of constructability trials. For the purposes of this research, the method was used for the sake of familiarity and to determine if any correlation between resistance to frost damage exists for concrete containing freeze protection additives. As with constructability trials, temperature was measured continuously during the first 7 days of curing; resistivity was also measured using probes embedded in cylinders. While the embedded resistivity measurements were obtained as a possible indicator of durability, the resulting data did not provide any clear trends, likely due the wide array of admixture dosages used in this study. Appendix A includes the results of embedded resistivity testing.

\subsection{Plastic property results}

Table 6 lists the results of the plastic property testing performed during durability trials. Several of the mixtures selected for this round of testing were made more than once due to excessively high air content; however, the control of air content and slump was more consistent overall, largely due to experience gained by the researchers over the $\approx 40$ mixtures made during constructability trials. One mixture, $\mathrm{AN}_{45} \mathrm{C} 45 . \mathrm{F} 45$, was also omitted due to a failure of the cold mixing and curing space near the end of the mixing phase of this round of testing. The overall temperatures during mixing were higher for these mixtures; this is due both to the larger mass of concrete in the mixer losing less heat in the cold room, as well as a failure of the material conditioning location to maintain a consistent temperature year-round. Finally, the SAM numbers measured from the different mixtures frequently met the most recently published guidance value of 0.22 or below (Ley et al. 2017). This value is the current recommended design value for resistance to freeze-thaw damage. 
Table 6. Summary of plastic properties measured from mixtures created for durability trials.

\begin{tabular}{|l|c|c|c|c|c|c|}
\hline \multicolumn{1}{|c|}{ Mix ID } & $\begin{array}{c}\text { Cure Temp } \\
\left({ }^{\circ} \mathrm{F}\right)\end{array}$ & $\begin{array}{c}\mathrm{T} 1 \\
\left({ }^{\circ} \mathrm{F}\right)\end{array}$ & $\begin{array}{c}\text { T2 } \\
\left({ }^{\circ} \mathrm{F}\right)\end{array}$ & $\begin{array}{c}\text { Slump } \\
(\mathrm{in} .)\end{array}$ & $\begin{array}{c}\text { Air } \\
(\%)\end{array}$ & SAM \\
\hline Control & 73 & 78.2 & 79.1 & 6.25 & 7.9 & 0.09 \\
\hline Control & 73 & 78.8 & 79.5 & 5 & 11.0 & 0.11 \\
\hline AN30C3.A0 & 23 & 68.4 & 64.7 & 7.5 & 2.2 & 0.24 \\
\hline AN30C3 & 23 & 73.9 & 70.6 & 7.5 & 7.1 & 0.1 \\
\hline AN30C3 & 23 & 67.2 & 65.7 & 7.5 & 10.3 & 0.17 \\
\hline AN30C3.F45 & 23 & 43.1 & 43.8 & 8.5 & 9.2 & 0.05 \\
\hline AN45C45.A0 & 23 & 68.6 & 67.6 & 7 & 2.3 & 0.17 \\
\hline AN45C45 & 23 & 74.4 & 72.6 & 6.5 & 4.2 & 0.41 \\
\hline AP60 & 23 & 72.3 & 68.2 & 4.9 & 4.9 & 0.19 \\
\hline AP100 & 23 & 71.7 & 69.2 & 7.25 & 6.1 & 0.32 \\
\hline
\end{tabular}

\subsection{Mechanical property results}

Figure 14 summarizes the results of compressive strength testing for the mixtures described in Table 6. Figure 14 illustrates the evolution of compressive strength for each mixture at 7,28 , and 90 days for both insulated and bare cylinders. The air content of each mixture is also presented near the mixture ID to facilitate rapid assessment of the influence of air content on compressive strength. The influence of air content on compressive strength is evident in the measurements obtained from the control mixtures cured at room temperature, where the $11 \%$ air mixture has significantly reduced performance compared to the control mixture containing 7.9\%. With very few exceptions, mixtures containing any amount or type of freeze protection additive, cured at $23{ }^{\circ} \mathrm{F}$, outperformed the control mixtures cured at room temperature. Mixtures universally continued to gain strength throughout the curing period, despite a lack of water for curing.

Insulation during the first 7-days of curing played a significant role in the strength development of some mixtures. As in constructability trials, the mixtures with the lowest air content generally exhibited the greatest difference between insulated and bare strength. This is most evident in the AN45C45.Ao mixture, in which the insulated strength exceeds the bare cured strength by more than 1500 psi at all ages. The same mixture with air entrainment, $\mathrm{AN} 45 \mathrm{C} 45$, exhibits greater bare cured strengths than AN45C45.Ao at all ages. This is contrary to the increase in air content: in general, for every $1 \%$ increase in air content, compressive strength decreases by $5 \%$ (Kosmatka and Wilson 2015) if no other factor is present. 


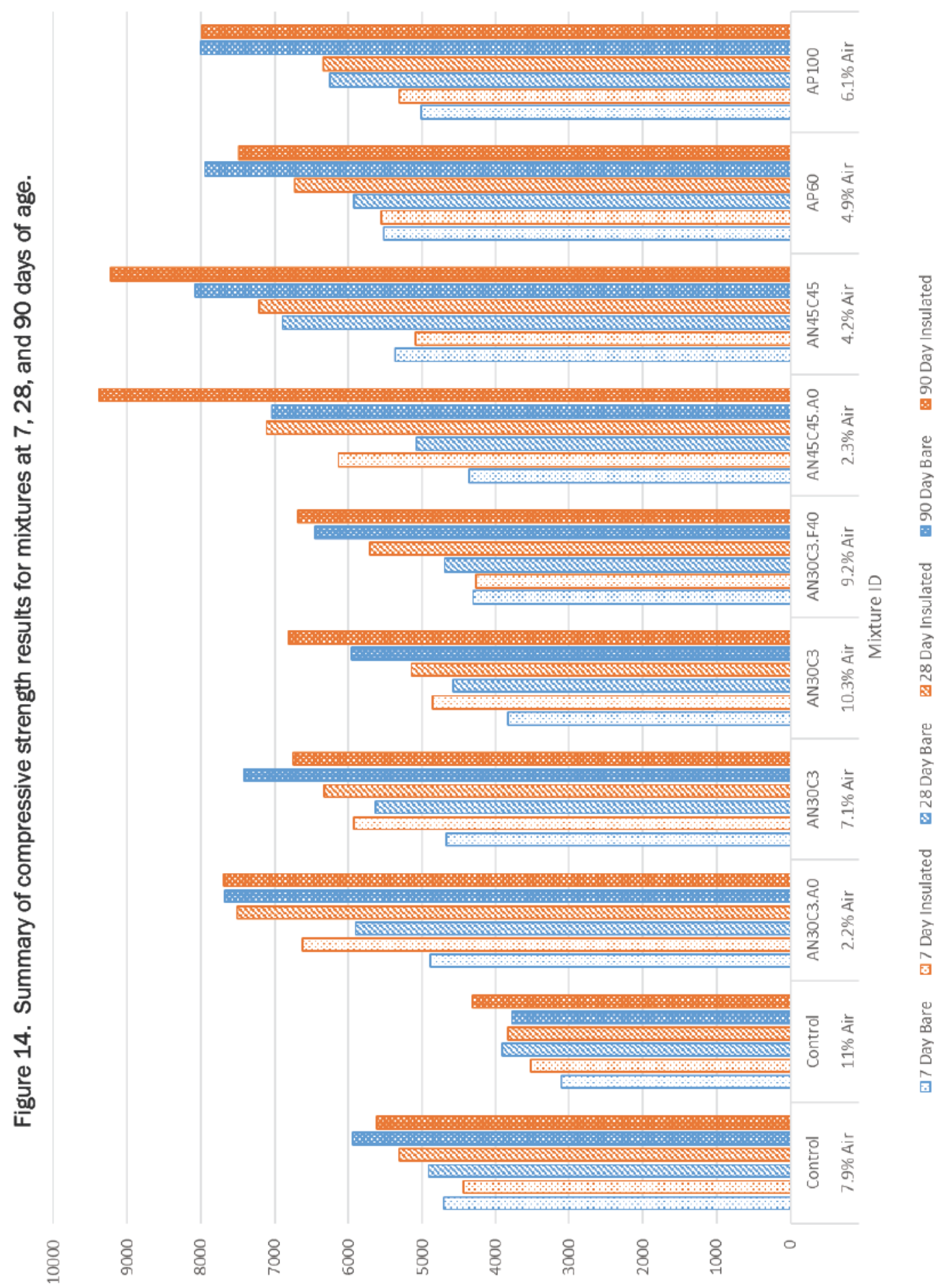

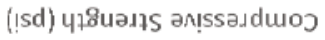


This provides more evidence to suggest that air entrainment in mixtures containing freeze protection additives plays a role in protection of the microstructure from damage due to formation of ice. The two mixtures made with a single cold weather admixture, AP6o and AP10o, exhibited the most uniform compressive strength performance with age, and exhibited the smallest differences between insulated and bare cured strengths. AP6o contains the smallest total quantity of admixture of any of the mixtures tested, but exceeds all other mixtures in strength at 7 days of age.

Figure 15 shows the results for elastic modulus, which generally exhibit less variation than results for compressive strength. The influence of air on elastic modulus is visible in the control specimens, but not to the same degree as the strength results. Mixtures containing freeze protection additives typically exceeded the modulus of the controls at 90 days of age, while 28-day moduli were approximately similar to control values.

\subsection{Durability testing results}

Figure 16 summarizes the result of testing for resistance to damage from rapid freeze-thaw cycling. The failure criteria for the test is a relative dynamic modulus of less than $60 \%$ at the end of 300 cycles. Of the mixtures tested, only two approached or exceeded this limit, mixtures $\mathrm{AN}_{3} \mathrm{OC}_{3}$.Ao and $\mathrm{AN}_{45} \mathrm{C} 45$.Ao. Both of these mixtures did not contain any air entrainment, with the purpose of assessing the potential for freeze protection additives to provide resistance to freeze-thaw damage in the absence of entrained air. While $\mathrm{AN}_{45} \mathrm{C} 45$.Ao did not ultimately fail, the progressive decrease in relative dynamic modulus from 175 to 300 cycles is an indicator that damage was occurring.

All air-entrained specimens tested for resistance to freeze-thaw exhibited similar behavior, generally showing an increasing relative modulus as the number of cycles increase. Some specimens exhibited an increase of $\approx 50 \%$, which is not typical of the test when performed as described in ASTM C666 (2015). The modified curing schedule used in this research, which did not involve moist curing before the beginning of the test, was likely the cause of this unexpected behavior. 


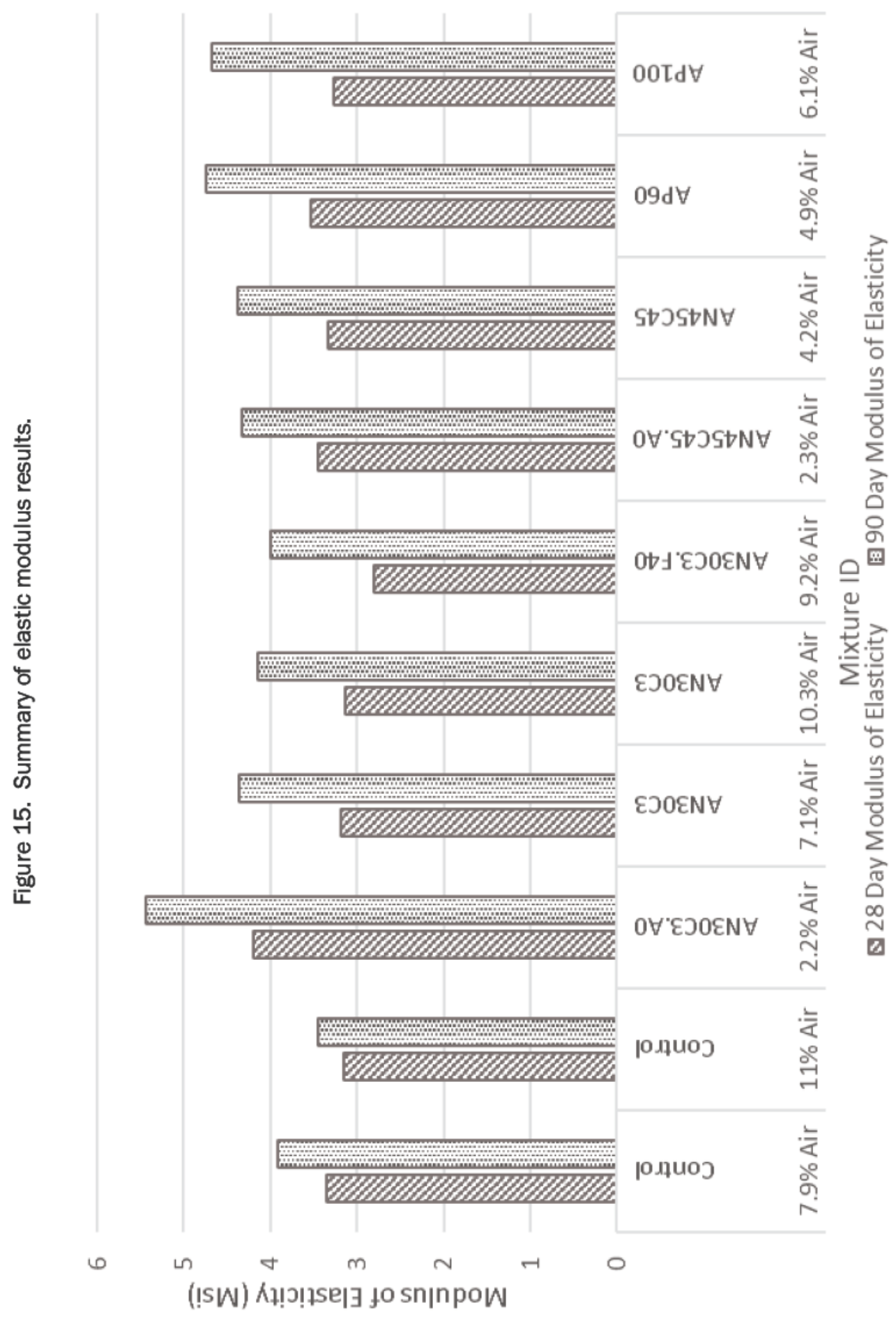




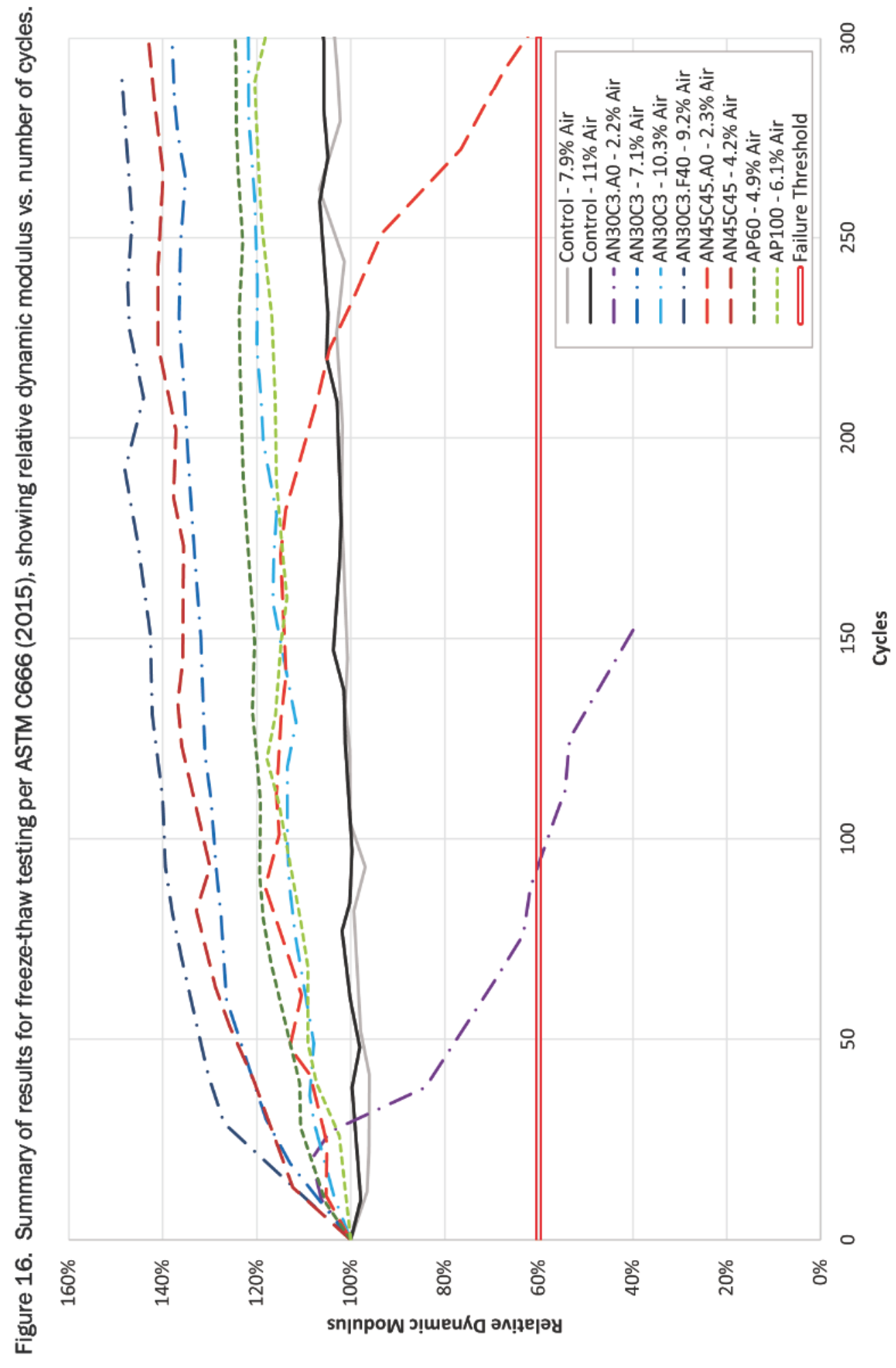


During the test, the specimens are thawed via submergence in water. During this time, the saturation of the specimens increased, and dynamic modulus increases with saturation in concrete (Kazmierczak et al. 2019). The increasing saturation of specimens with cycles can be confirmed through examination of the mass change data summarized in Figure 17. All specimens tested experienced an increase in mass throughout the duration of the test.

Figure 17. Mass change data collected from specimens throughout freeze-thaw testing.

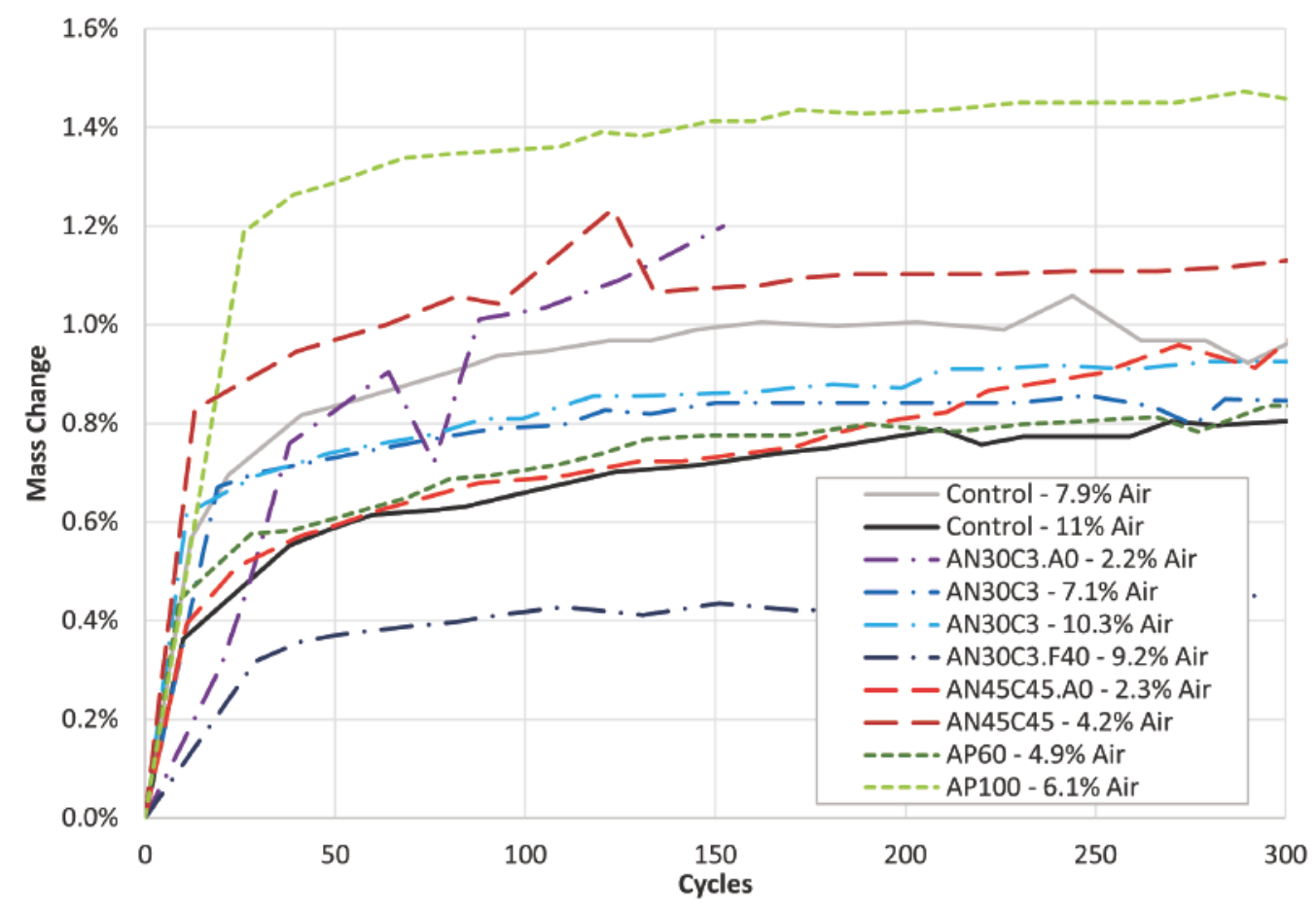

The length change data collected from freeze-thaw specimens during testing, summarized in Figure 18, provide additional information relating to the failure mechanism of the two mixtures that did not contain entrained air. $\mathrm{AN}_{3} \mathrm{OC} 3$.Ao expanded substantially during the testing period.

AN45C45.Ao also exhibited a significant amount of expansion, particularly relative to its lowest overall value. These results provide further indication that the mixtures without air entrainment were being damaged progressively by the test. All air-entrained mixtures exhibited very little change in length throughout the course of the test, generally remaining within $\pm 0.05 \%$ of their original length. 
Figure 18. Length change results of mixtures tested for resistance to damage from rapid freezing and thawing.

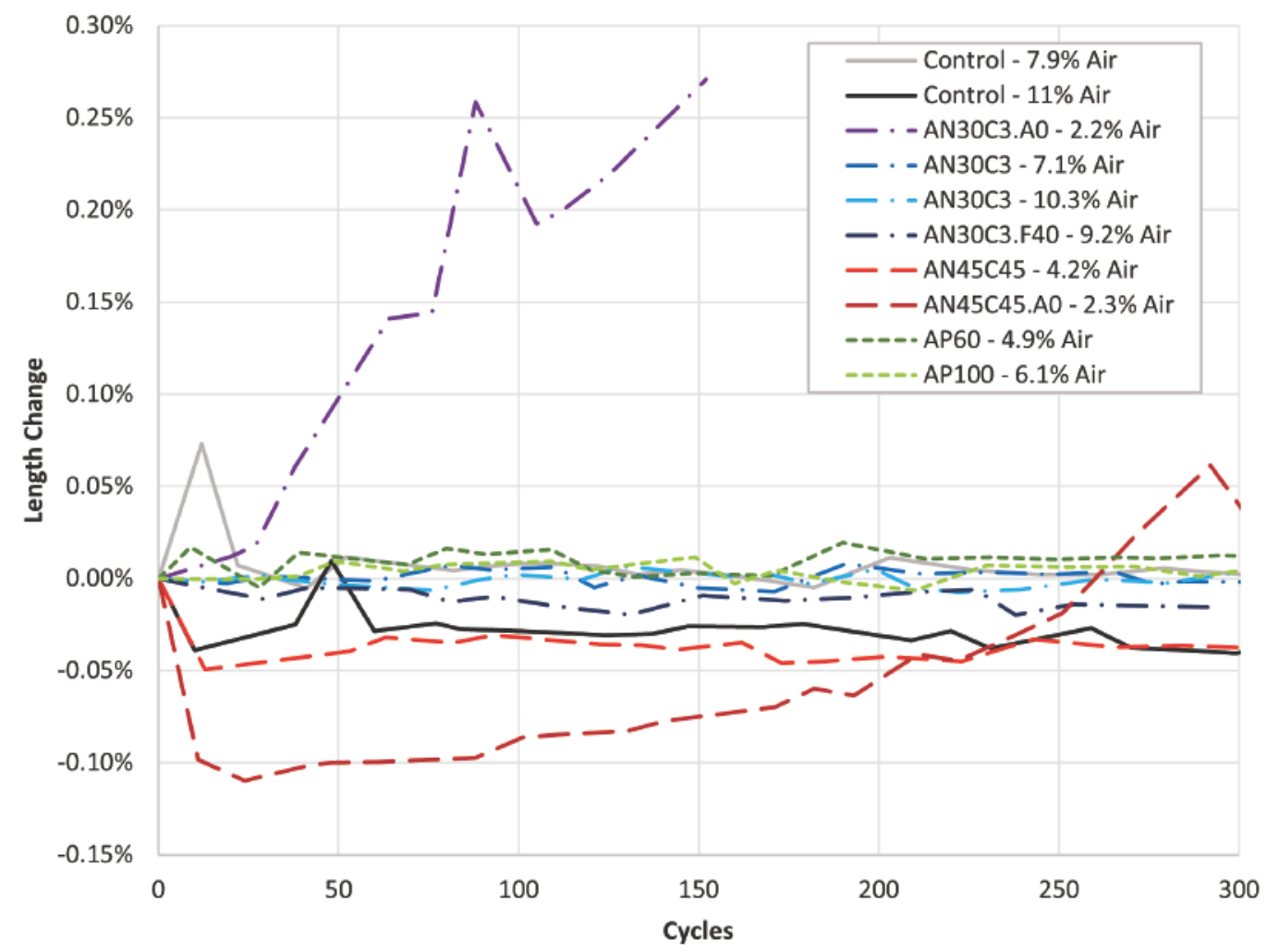

\subsection{Scaling}

Scaling data were collected from two specimens of each of the 10 durability trial mixtures over 50 cycles. These data included weekly pictures and ratings of scaling damage according to ASTM C672 (2012b). Visual ratings of the surface of each specimen were recorded by three people on the project since it is a subjective measurement. Guidance is provided in the specification but open to interpretation of the rater. The results, shown in Figure 19, are the average of six total ratings for each mixture: three different raters independently rated two replicates for each mix. Rating is based on a scale provided within the specification (Table 7). 
Table 7. Scaling visual rating reproduced from ASTM C672 (2012b).

\begin{tabular}{|c|l|}
\hline Rating & Condition of Surface \\
\hline 0 & No scaling \\
\hline 1 & Very slight scaling (3 mm [1/8 in.] depth, max, no coarse aggregate visible) \\
\hline 2 & Slight to moderate scaling \\
\hline 3 & Moderate scaling (some coarse aggregate visible) \\
\hline 4 & Moderate to severe scaling \\
\hline 5 & Severe scaling (coarse aggregate visible over entire surface) \\
\hline Source: ASTM c672/C672M-12 (2012b) \\
\hline
\end{tabular}

This qualitative test allows mixtures to be compared by their ability to resist scaling when exposed to freezing and thawing cycles and deicing chemicals. All mixtures experienced some level of scaling over the 50+ cycles of freezing and thawing. The best performing mixture during the scaling testing was $\mathrm{AN}_{3} \mathrm{OC} 3$, which also had the highest air content at $10.3 \%$. The worst performing mix was AP100, which contained the cold weather specific admixture and had an air content of $6.1 \%$. All mixtures began to show coarse aggregate by cycle number 50 except $\mathrm{AN}_{3} \mathrm{OC} 3$, both with and without air entrainment.

Figure 19. Results of mixtures tested for resistance to scaling damage from freezing and thawing while exposed to deicing chemicals.

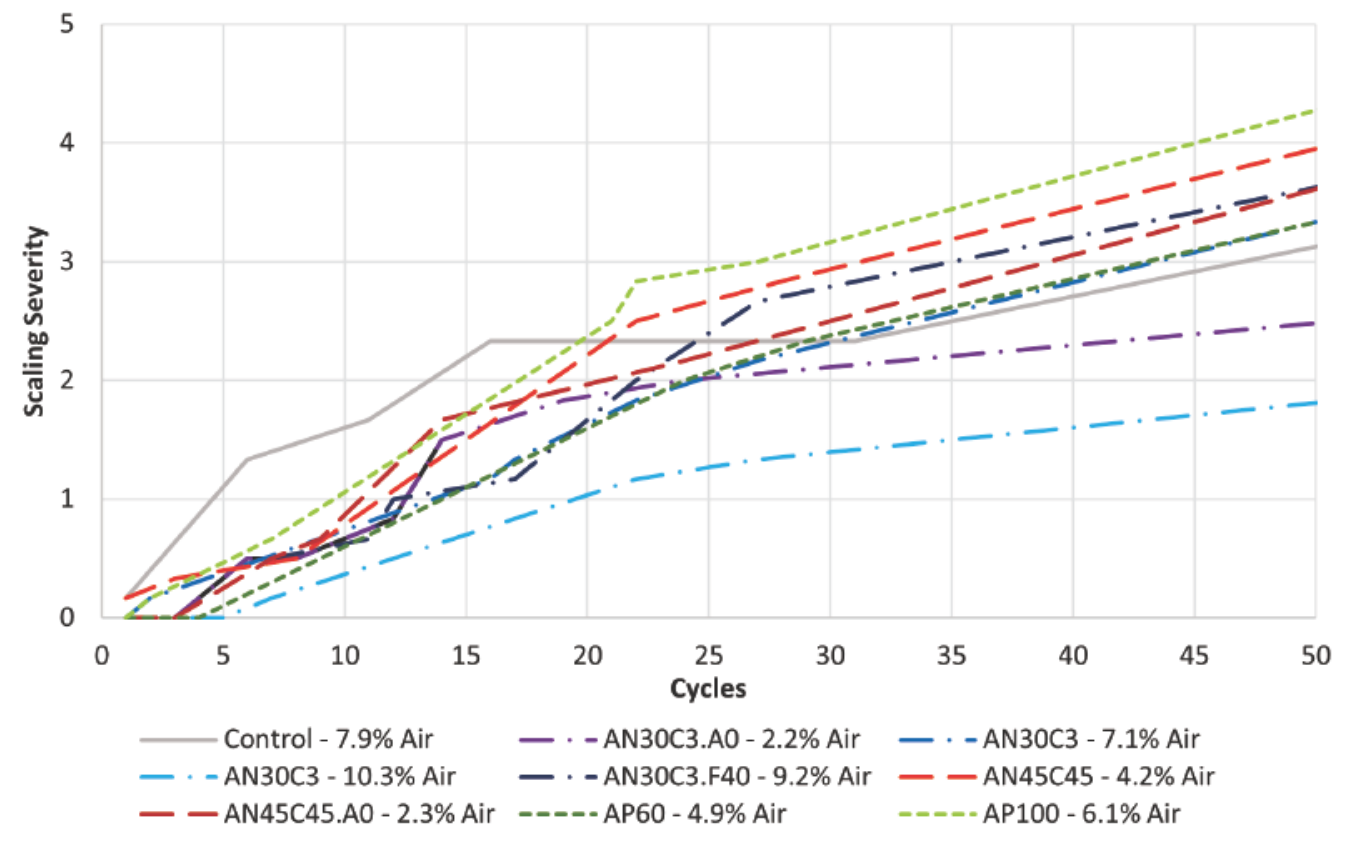




\subsection{Discussion}

The results of mechanical, plastic, and durability testing for mixtures containing freeze protection additive have produced several observations that are new to the state of research with regards to additive-based cold weather concreting. The most impactful result from this experiment is the performance of the AP admixture. This admixture, at a dosage of 60 $\mathrm{oz} / \mathrm{cwt}$, produces concrete with can be placed and cured at $23^{\circ} \mathrm{F}$, can be resistant to damage from rapid freezing and thawing, and can achieve compressive strengths in excess of 7000 psi at 90 days of age. This represents a significant reduction in the amount of admixture required to protect concrete from damage due to early age freezing when compared to past recommendations for CWAS. The $\mathrm{AN}_{3} \mathrm{OC}_{3}$ combination of additives achieves similar results, with slightly lower ultimate strengths.

The role of entrained air in the behavior of concrete containing freeze protection additives is significant at the dosages examined in this study. Air appears to have an impact on early age properties, particularly compressive strength, and may play an important role in protection of mixtures in which the freezing point of the mixture is higher than the minimum temperature experienced. The role of air in resistance to rapid freezing and thawing is clear: at the dosages examined in this study, entrained air is essential. The only mixtures that experienced damage from freezing and thawing were those in which no air-entraining admixture was used. During scaling testing, all mixtures experienced scaling with a severity of at least 1 after $50+$ cycles of freezing and thawing. The best performing mixture was that with the lowest dosage of freeze protection additives, $\mathrm{AN}_{3} \mathrm{OC}_{3}$. This mixture also had an air content higher than the targeted 6\% at $10.3 \%$. Although AP10o performed well during freeze-thaw, modulus, and strength testing, it proved to be the worst performing mix during scaling. This further proves that there is not one test method that exists to determine durability of concrete specimens in cold environments. Mixtures that produce high strengths and perform well during freeze-thaw testing could still be exposed to scaling on the surface due to de-icing salts. 


\section{Adiabatic Testing Chamber Development}

\subsection{Adiabatic temperature rise}

In regions where temperature rise in mass concrete is a concern, thermal finite difference modeling is commonly employed to predict temperature rise based on placement temperature, ambient temperature, and a calculated adiabatic temperature rise (ATR) based on the Portland cement content of the mix (ACI 2005). A simple, one-dimensional model can be created to model concrete temperature over time using this method, which could be applied to mixtures containing CWAS admixtures. To support this, an experimental apparatus was developed to cure concrete cylinders under precisely controlled dynamic thermal conditions. USACE maintains a standard testing procedure, CRD-C38-73, Method of Test for Temperature Rise in Concrete (HQUSACE 1973), to measure ATR; however, this specification was developed with mixtures containing large ( $>3$-in.) aggregates in mind, and requires the use of prohibitively large $(11 \mathrm{ft} 3)$ specimens. The guidance provided in $\mathrm{CRD}-\mathrm{C}_{3} 8-73$ was used to inform the development of a smaller, more modern testing chamber that measures ATR from 4-in. x 8-in. cylinders. The resulting chamber enables ATR measurement through both match curing, as well as curing of cylinders as though they were part of a much larger structure. Combined with variations in mixture design, this test provides data points to eventually quantify the effects of varying cement content and dimensions on the temperature rise associated with a range of CWAS dosages.

Development of a prototype adiabatic testing chamber was conducted throughout the duration of the project detailed in this report. The operation of this chamber is relatively simple in principle; however challenges exist related to minimization of error, consumable temperature sensors, and a control loop with independent sensing elements. The following chapter describes details of the current solutions to these issues and the development process.

\subsection{Adiabatic chamber design}

To produce an adiabatic condition in fresh concrete, specimens must be placed in an environment that prevents any loss of heat from the specimen to the environment. There are two broadly used approaches to this issue. 
The first, and simplest, is to use a very large specimen $(\approx 3-\mathrm{ft} \times 3-\mathrm{ft}$ x 3 -ft) and insulate the specimen heavily. This approach, while not truly adiabatic, results in minimal heat loss to the environment relative to that produced in the specimen. The second approach, which does not require large volumes of concrete or heavy insulation, involves maintaining the specimen in an environment that tracks the temperature of the concrete. By maintaining a temperature equal to that of the test specimen, heat is prevented from either entering or leaving the specimen, resulting in an adiabatic condition. Figure 20 shows a functional diagram of the test chamber.

Figure 20. Functional diagram of adiabatic testing chamber.

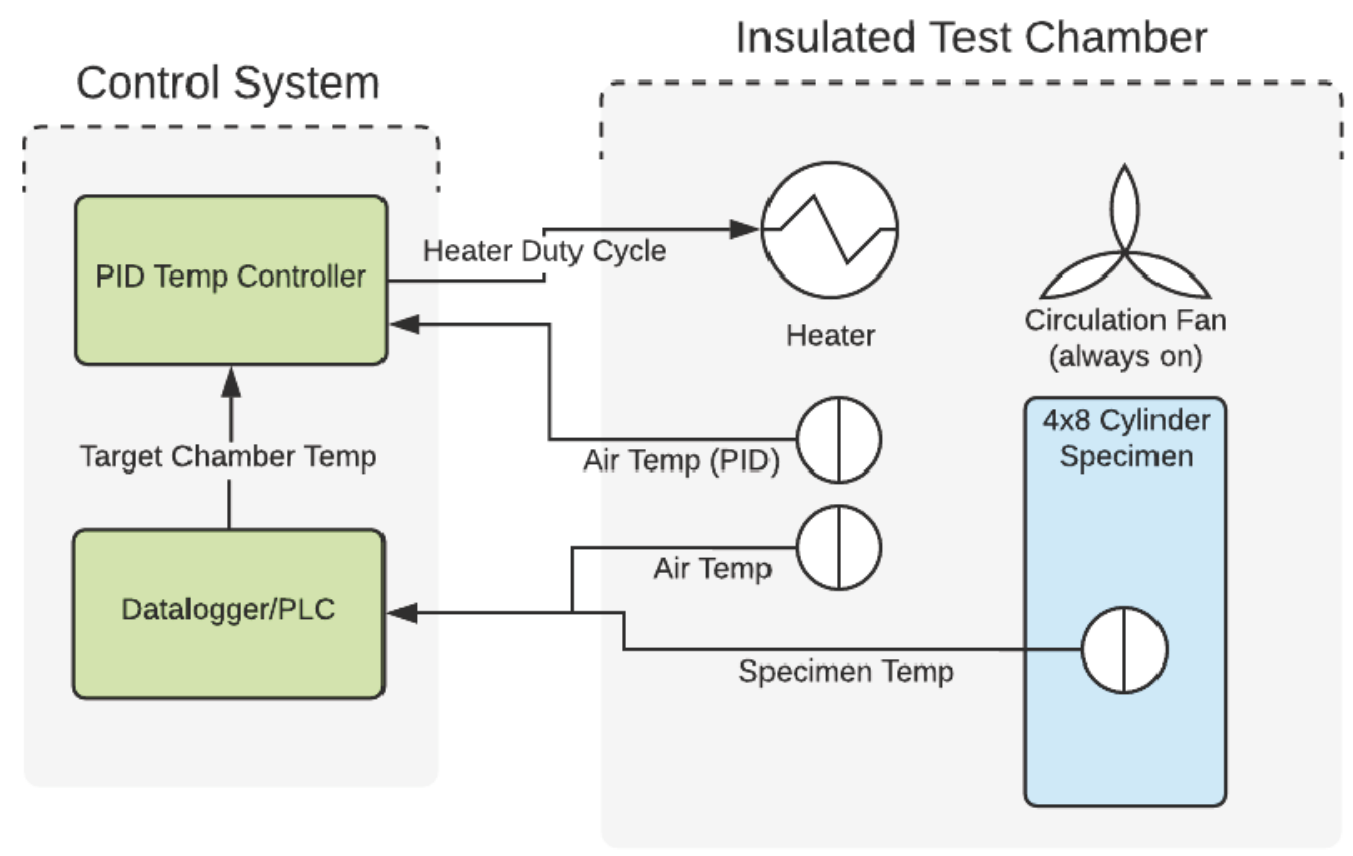

\subsection{Chamber hardware}

The specific hardware used for each component in the current prototype chamber are:

1. Proportional-Integral-Derivative (PID) Temperature Controller: Panasonic $\mathrm{KT}_{4} \mathrm{R}$ PID controller with Modbus input

2. Datalogger/PLC: Campbell Scientific CR1ooox datalogger

3. Heater: 8ow flexible adhesive oil pan heater with aluminum heatsink

4. Insulated Test Chamber: 9 gallon beverage cooler 
The primary control elements of the chamber consist of the datalogger and PID controller. These elements are responsible for the tasks of reading the specimen temperature, logging the specimen and chamber temperature, setting the chamber temperature, and setting the necessary heater duty cycle required to reach a specific chamber temperature. The PID controller includes an auto-tune functionality, which optimizes the heater duty cycle response to produce an accurate temperature in the chamber without under or overshooting the target temperature. The datalogger keeps a record of all measured temperatures within the system, including the chamber air, specimen temperatures, PID controller measured temperature, and target temperature. Based on the specimen temperature, the datalogger communicates the target chamber temperature to the PID controller using the $\mathrm{RS}_{48} 5$ serial protocol. The datalogger also polls the PID controller for the temperature measured by its independent sensor.

\subsection{Temperature sensing}

The most important factor for the adiabatic control system is the accurate control of air temperature based on the measured specimen temperature. In the system shown in Figure 20, this involved measuring the specimen temperature, and then commanding the PID controller to set the chamber air to a given temperature. The type of temperature sensing element used in this control loop plays a critical role in the accuracy of the system. A primary concern for adiabatic testing is preventing the test chamber from adding heat to the hydrating specimen, or preventing the temperature of the air in the chamber from exceeding the temperature of the specimen. With perfectly accurate and precise temperature sensors, this would be as simple as setting the temperature of the chamber equal to that of the specimen; however, all temperature sensors have limitations on both accuracy and precision. In practice, to prevent the chamber temperature from exceeding the specimen temperature with certainty, the target air temperature must be slightly lower than that of the specimen temperature. The degree of offset necessary depends entirely on the precision of the sensor.

Initial test runs of the chamber were implemented using basic, twisted wire thermocouples made from Type $\mathrm{T}$ extension wire. These sensors are generally stated to have an accuracy of $1.0^{\circ} \mathrm{C}$, and are inexpensive and easy to manufacture. These were initially considered to be unsuitable for the control algorithm, however, due to this relatively low accuracy. Several 
test runs were executed using thermistors that were calibrated in-house; however, the response of these thermistors was nonlinear with temperature; specifically, as the temperature of the specimen increased, the relative accuracy of the sensor dropped. Platinum resistance temperature detectors (RTDs) were also employed, due to the highly linear response of those sensors; however, the sensors still needed to be calibrated individually in-house. Sensors that are embedded in concrete cannot be reused, and the expense of RTD elements combined with the labor required for calibration made this option not economical.

A further review of literature related to thermocouples revealed several facts that caused their suitability for this application to be reevaluated. The primary source of variation in the measurements of thermocouples is the variation in the purity of the two different metals used to create a junction. The accuracy statement on typical thermocouple wire is intended to encompass a large range of variation, so that any given spool of the same product will fall within the stated accuracy limits (Park et al. 1993). These variations occur as the wire is produced, and it has been determined experimentally that the variation of measurements taken from thermocouples manufactured from the same spool of wire can be half that of the variation in thermocouples manufactured from different spools. Additionally, the variation in thermocouples manufactured from the same few inches of wire may be as low as $0.05^{\circ} \mathrm{F}$ (Burns et al. 1993). Without calibration, the absolute accuracy of two thermocouples manufactured from the same few inches of wire may not be known; however, for the application of a differential control loop, this is not a concern.

Another convenient property of thermocouples is the simplicity with which an averaging sensor can be created. By connecting several thermocouples in parallel, a sensor is created that responds based on the average of the three sensing elements. This also enhances precision, reducing the limits of error by the square root of the number of sensors in the averaging element.

These factors resulted in the selection of an array of thermocouples for the control loop algorithm of the adiabatic testing chamber. For each test, six individual thermocouple junctions are created: three are wired in parallel and connected to the PID controller to control the chamber temperature, and three are wired in parallel and embedded in three individual fresh concrete specimens. This arrangement allows for very consistent control of 
the chamber air temperature, and minimizes the required negative offset. Measurement of the actual temperature of the test is accomplished through a calibrated RTD, which measures the temperature of the air.

\subsection{Size effect modeling}

The ATR curves collected from the chamber provide fundamental inputs for simulation of temperature rise in concrete structures of any geometry (Jeong and Zollinger 2006 ). This approach is well established for simulation of temperature rise in mass concrete structures, where excessive temperatures can result in thermal cracking (ACI 2007; ACI 2005). Models used are typically heat flow models with a custom source term to provide for a reaction corrected rate of heat generation based on the amount of heat that would be produced in adiabatic conditions at the equivalent temperature and amount of total heat (Martinelli et al. 2013). The approach used for this research is based on the method described in Martinelli et al. (2013), implemented in MATLAB using a finite element approach.

\subsection{Dosage tool development}

Figure 21 summarizes the workflow for development of the dosage tool, which generally relies on three distinct tasks: experimental data collection, enumeration and modeling of dosage and size cases, and model validation. Experimental data collection consists of simultaneous measurement of ATR as well as the temperature profiles of curing cylinders in both insulated and bare conditions, for a range of admixture dosages and fresh concrete temperatures. Model enumeration involves the building of a range of virtual placement geometries, and simulating their temperature rise across an array of admixture dosage ATR curves. Model validation will compare the results of simulated temperature rise with the experimental results obtained from insulated and bare cylinders. The data obtained from the modeling of a range of placement geometries, temperatures, and admix dosages will be used to build a tool that can interpolate to find the best dosage for a given fresh concrete and ambient temperature. 
Figure 21. Dosage tool development workflow.

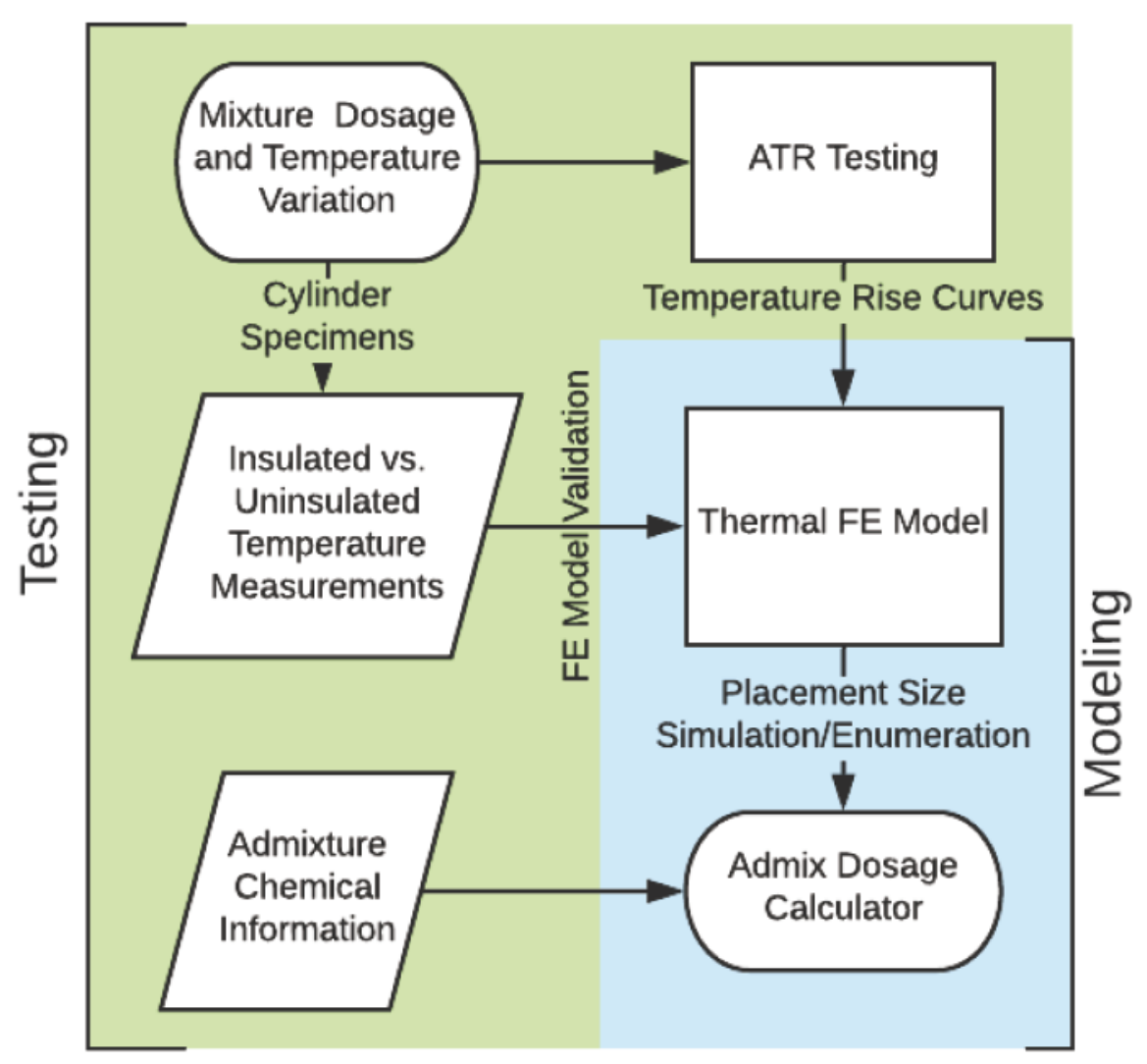

\subsection{Model input data}

For the first round of ATR testing, the cold weather admixture from manufacturer A, "P" was selected, due to its generally good performance and the simplicity of using one admixture versus a combination of two. The admixture was tested with the same mixture design used for all other experiments in this report, at three different dosages, and with two fresh mixture temperatures. The dosages were 30,60 , and $100 \mathrm{oz} / \mathrm{cwt}$ of admixture, and the target fresh temperatures were $55^{\circ} \mathrm{F}$ and $35^{\circ} \mathrm{F}$. Figures 22 to 28 show the resulting curves. In Figure 25, the $100 \mathrm{oz} / \mathrm{cwt}$ dosage is missing due to a flaw in that particular run of the test. This dosage will be retested. Generally speaking, as the dosage of admixture increases, the maximum temperature rises, and temperature increases at early ages. Validation data were also collected during the individual adiabatic tests, from insulated and bare cylinder specimens cured at a $23{ }^{\circ} \mathrm{F}$ ambient temperature. 
Figure 22. Adiabatic temperature rise (ATR) curves for three mixtures with a target fresh temperature of $55^{\circ} \mathrm{F}$. Mixtures tested were AP30, AP60, and AP100.

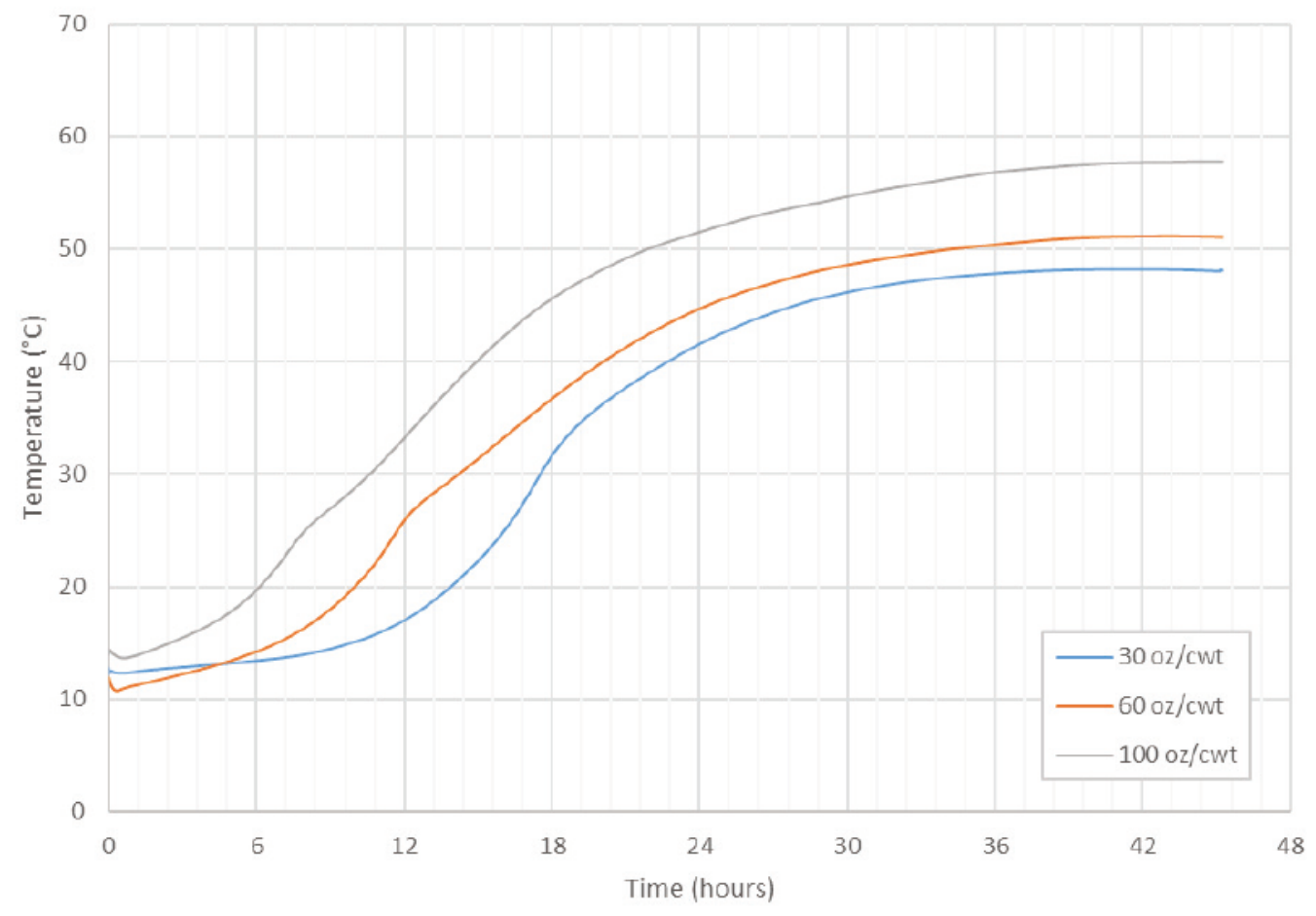

Figure 23. ATR curves for two mixtures with a target fresh temperature of $35^{\circ} \mathrm{F}$. Mixtures tested were AP30, AP60.

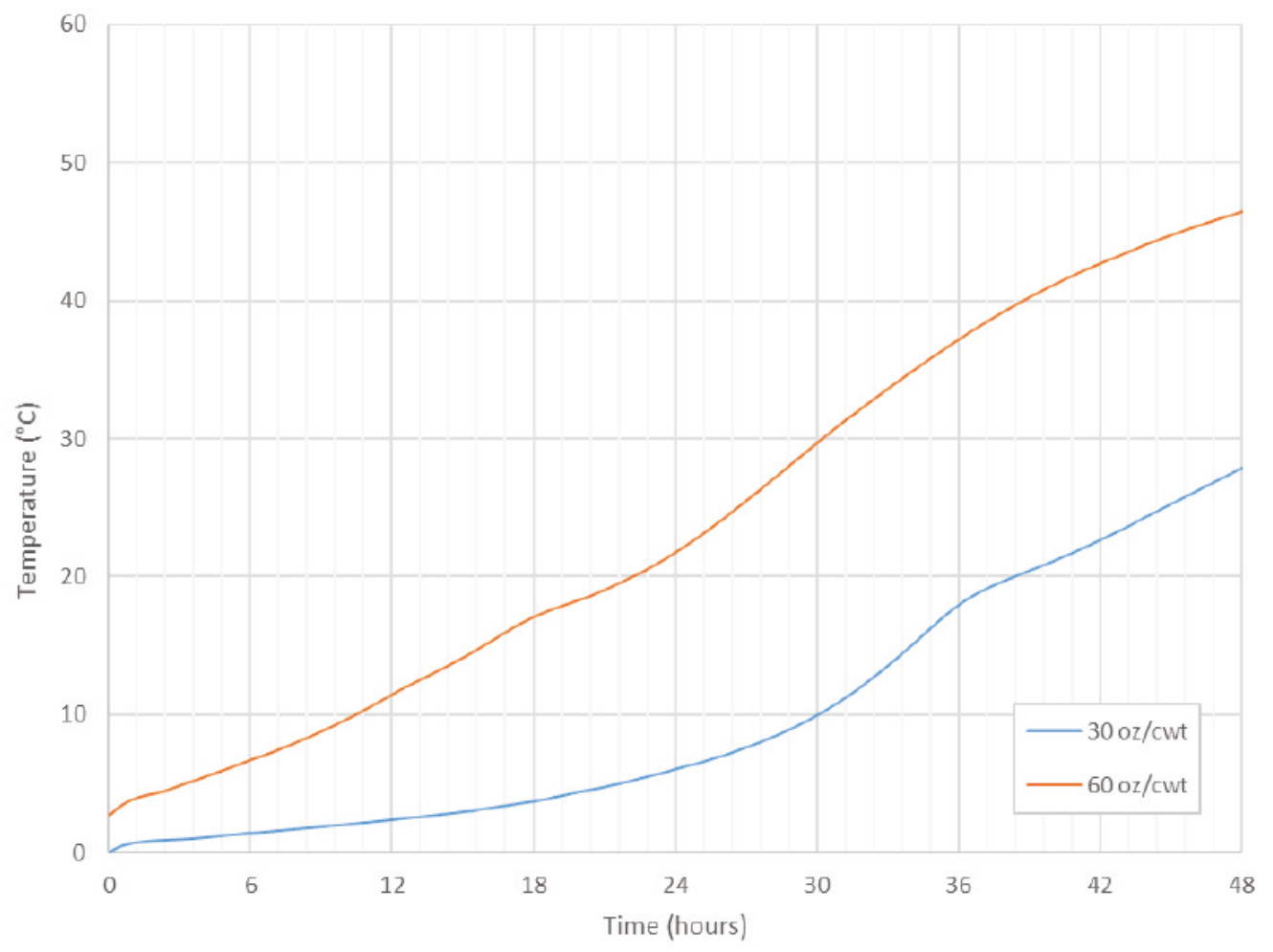


Figure 24. ATR curve for AP30 at $55^{\circ} \mathrm{F}$, with insulated and bare cylinder data for two replicates each (A and $B$ ).

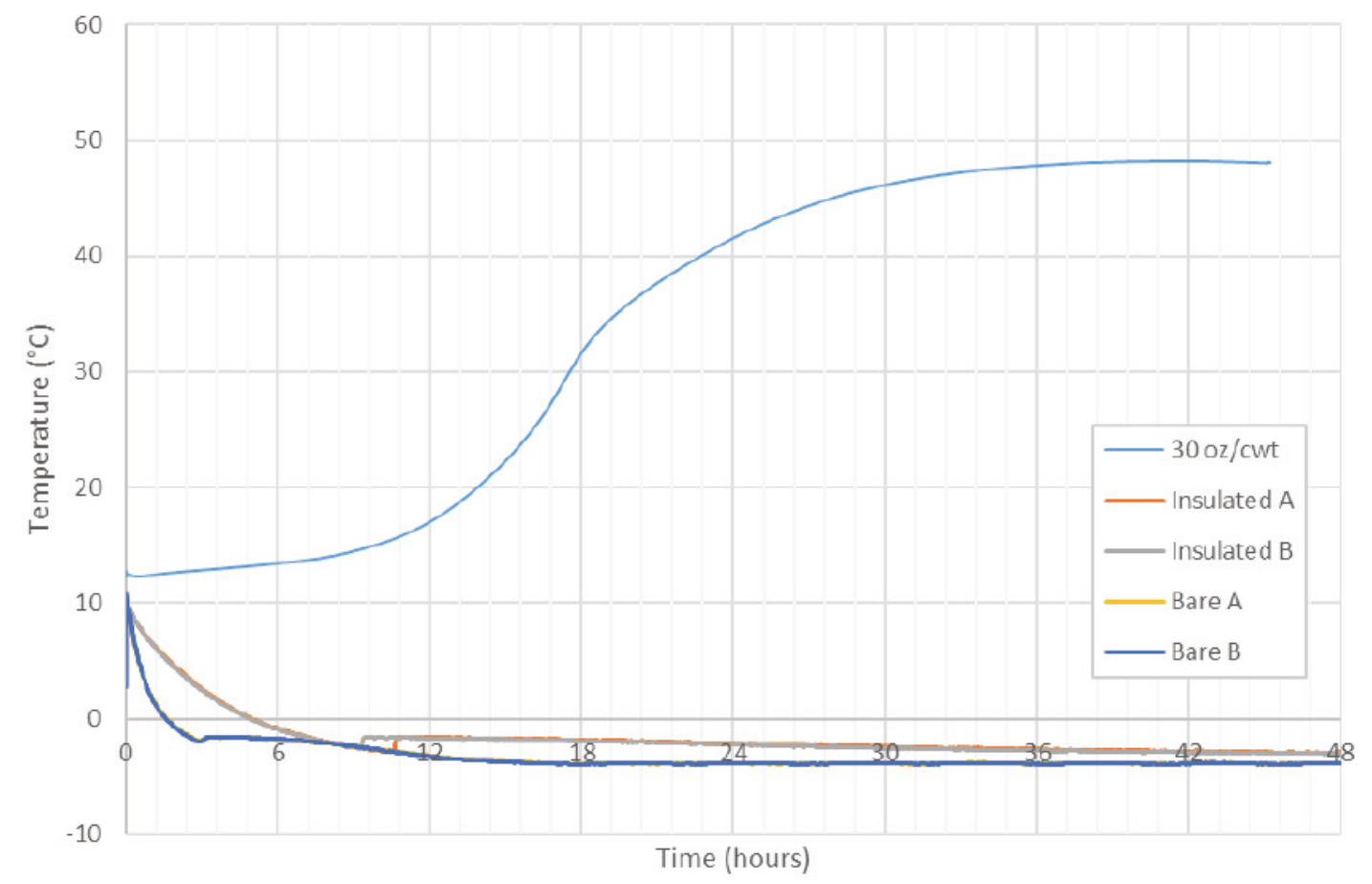

Figure 25. ATR curve for AP60 at $55^{\circ} \mathrm{F}$, with insulated and bare cylinder data two replicates each ( $A$ and $B)$.

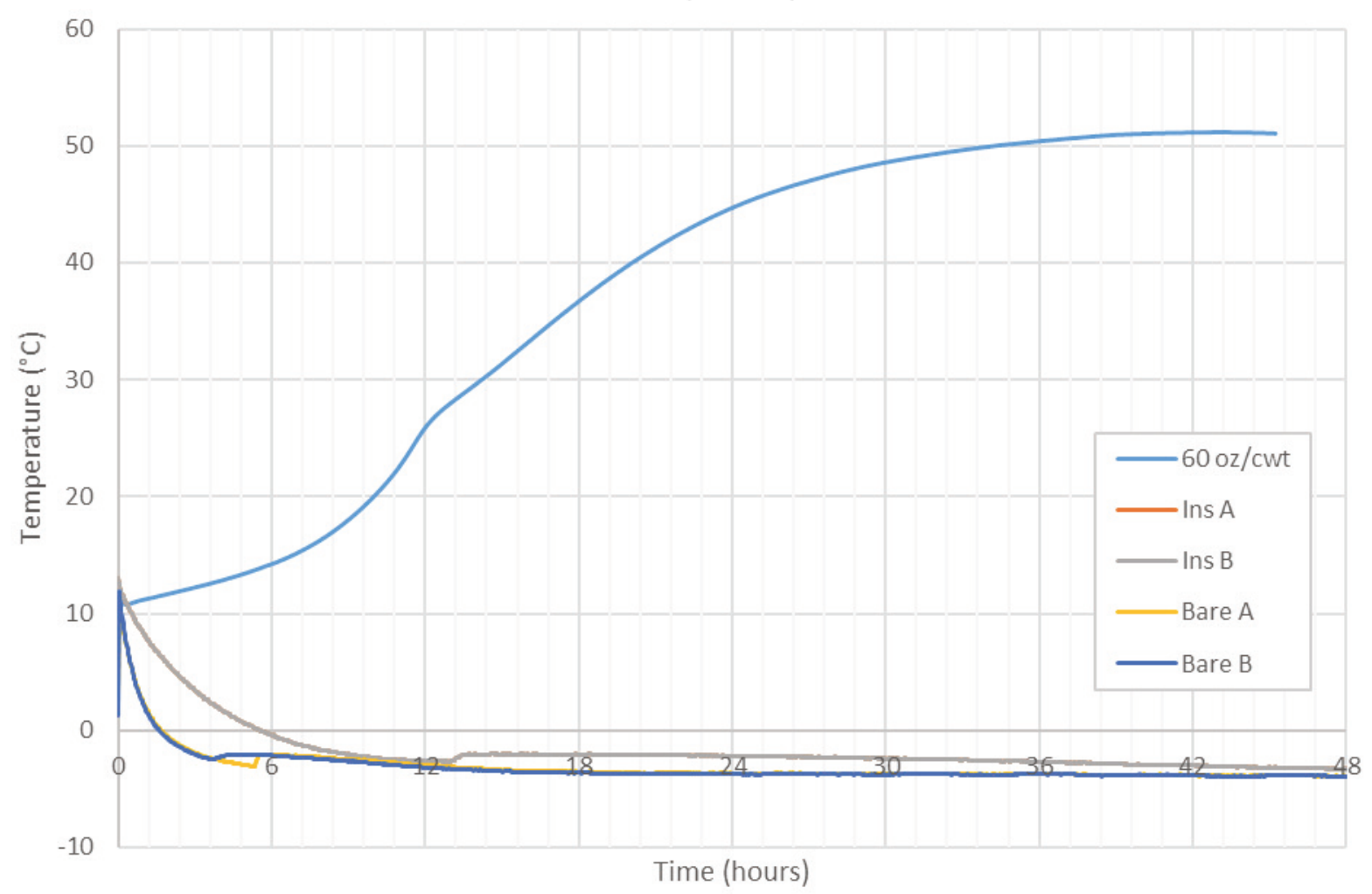


Figure 26. ATR curve for AP 100 at $55^{\circ} \mathrm{F}$, with insulated and bare cylinder data two replicates each (A and $B$ ).

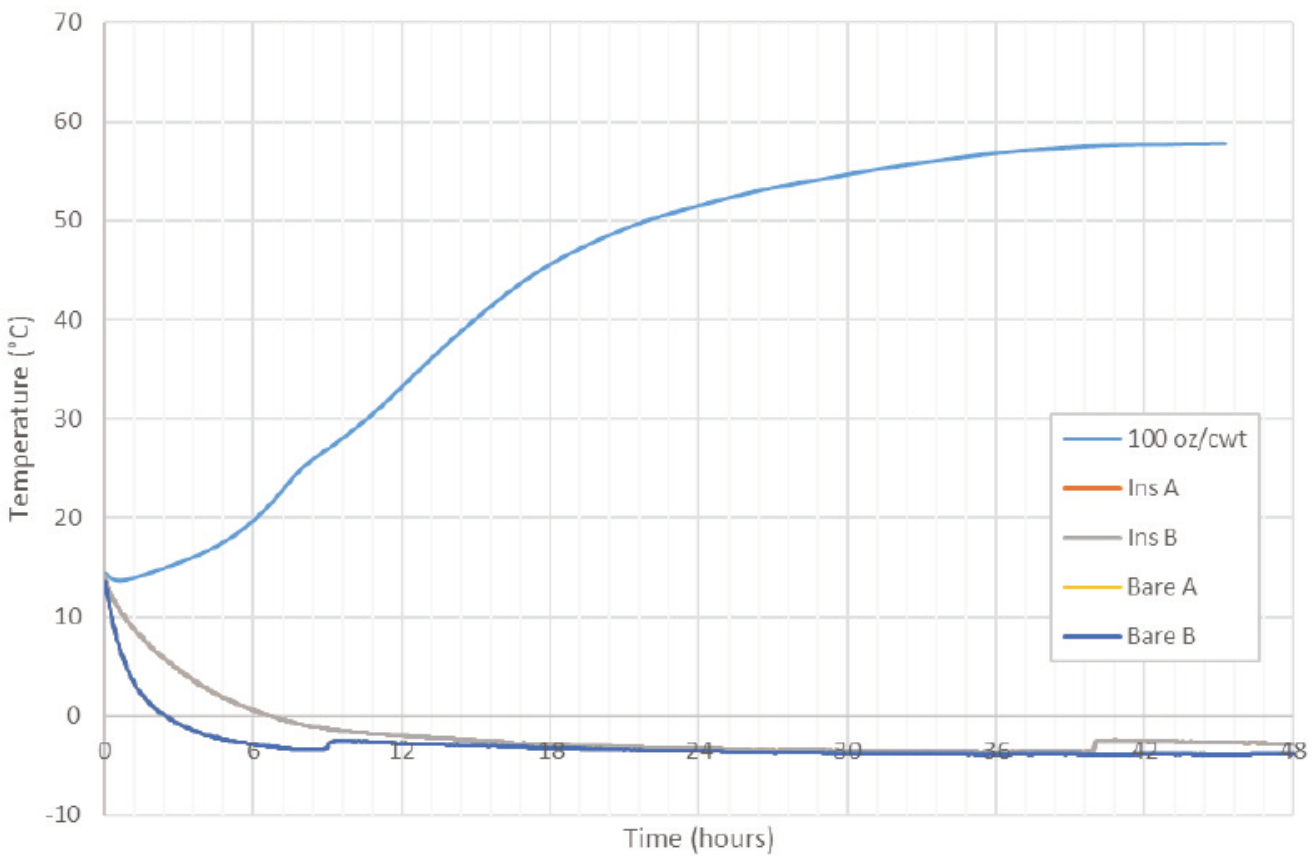

Figure 27. ATR curve for AP30 at $35^{\circ} \mathrm{F}$, with insulated and bare cylinder data two replicates each ( $A$ and $B)$.

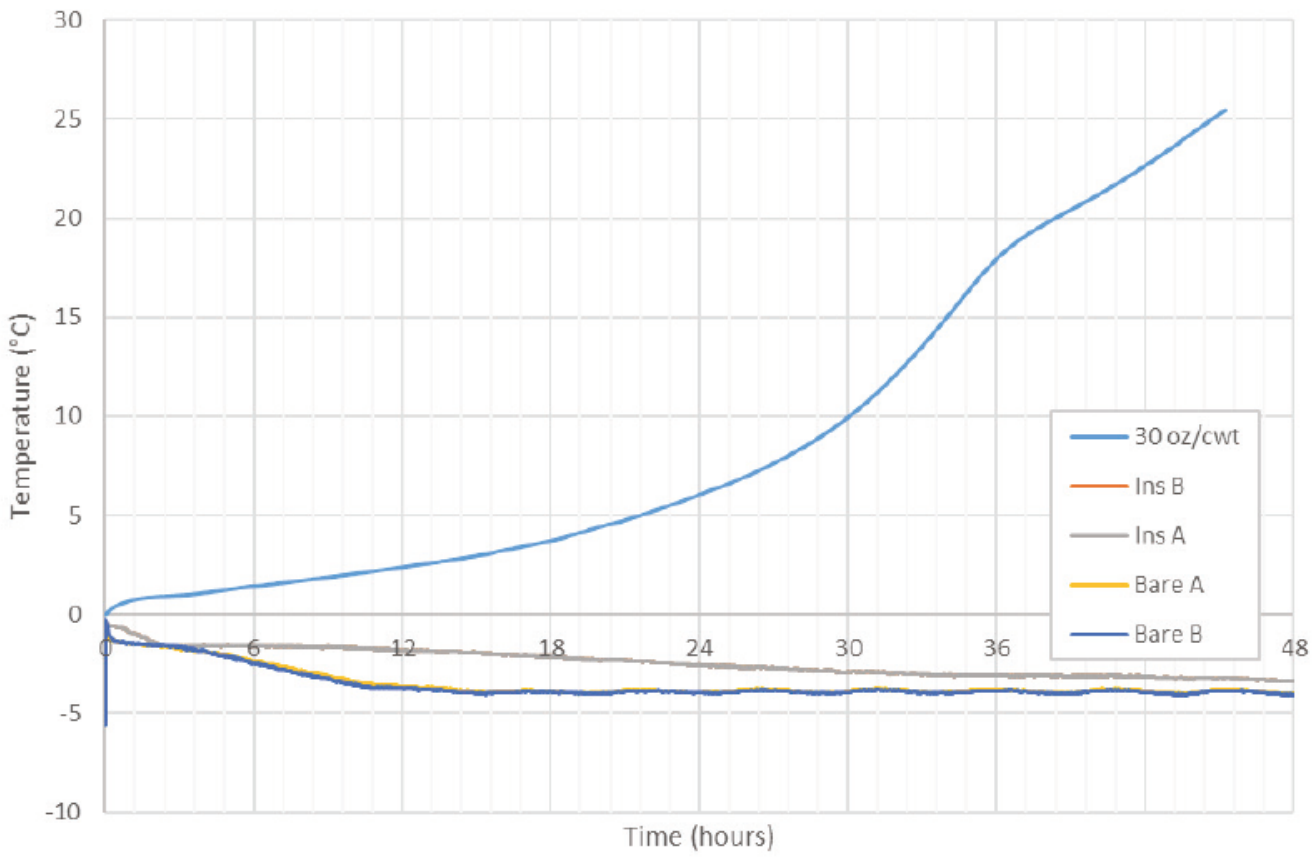


Figure 28. ATR curve for AP60 at $35^{\circ} \mathrm{F}$, with insulated and bare cylinder data two replicates each (A and B).

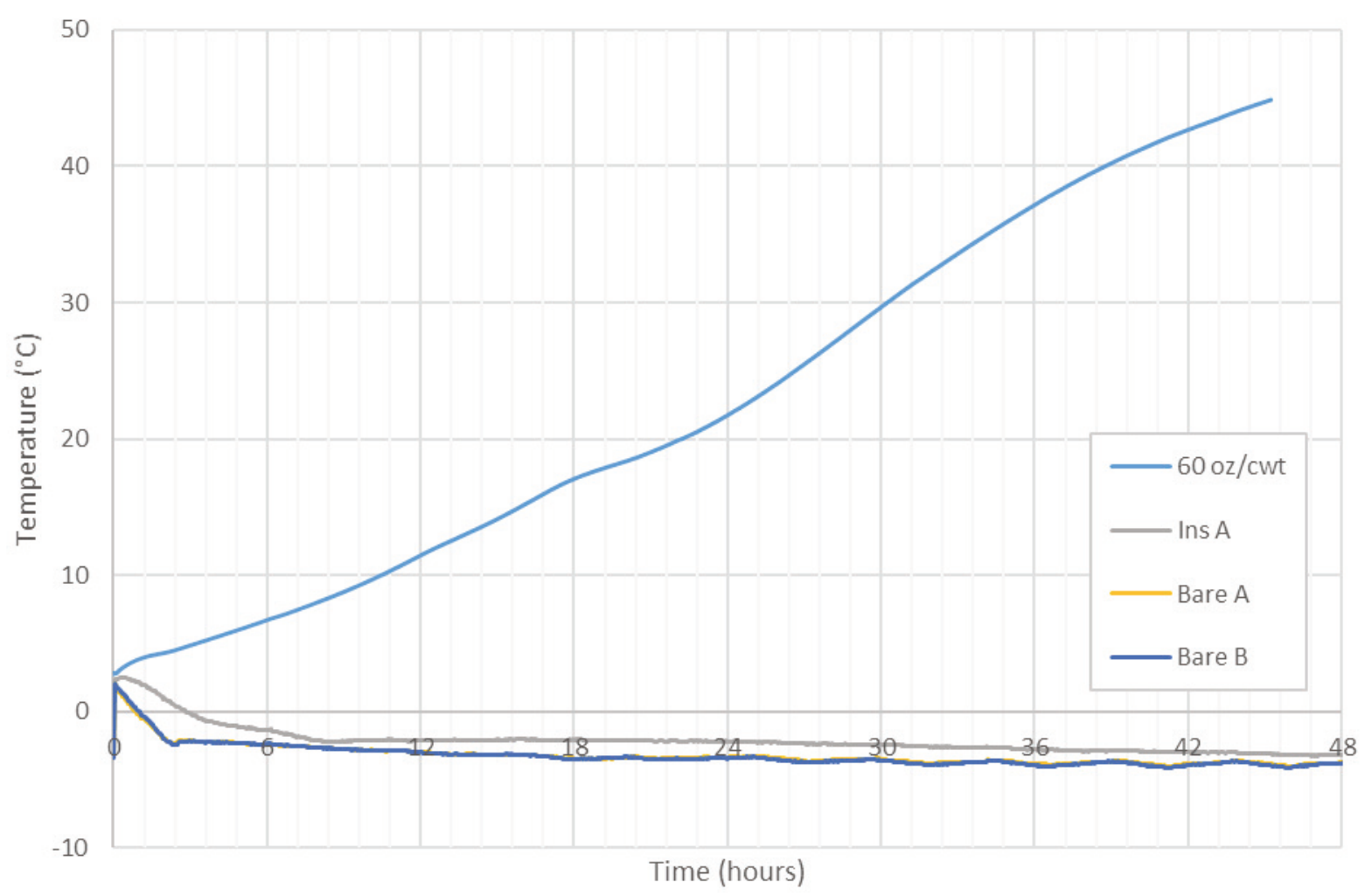




\section{Field Specimen Analysis Results and Discussion}

\subsection{Introduction}

A key aspect in understanding the durability of CWAS concrete that has been in field service for many years is isolating the potential contributions of the admixtures from more conventional methods such as air entrainment. To accomplish this, two types of forensic testing were performed on core samples obtained from historical placements. These core specimens from field investigations completed during Phase I of this work were sent to the Concrete Materials Branch of the Engineer Research and Development Center, Geotechnical and Structures Laboratory (ERDC-GSL), where researchers completed hardened air-void analysis and attempted to extract pore solution for chemical analysis (Hooton and Thomas 2009). Pore solution expression was attempted to assess the residual quantities of the CWAS admixture present in concrete that had been in field exposure conditions for extended periods of time. It may be possible that residual quantities of admixture were present in concrete to a degree that provide some residual freezing point depression effect.

\subsection{Procedures}

\subsubsection{Hardened air-void analysis}

The role of air content plays a large part in long-term durability of concrete in environments that undergo freezing and thawing events. As such, the hardened air-void content was measured in concrete core specimens obtained from the field investigation described in Phase I of this work. Hardened air content of the samples was measured using a modified method based on ASTM C457 (2016c); details of the modifications are described in Peterson et al. (2001). The specimen size recommended in the test method was reduced due to the size of the cores obtained.

Core specimens from three locations with diameters measuring 3 in. were selected for the analysis: Sault Ste. Marie, Michigan, Fort Wainwright, Alaska, and Fairbanks, Alaska. These sites were selected due to their availability and time in service exceeding 10 years. Phase I of this work shows initial durability verification through a visual inspection and non- 
destructive testing. To further validate and determine the durability of the in-service concrete, hardened air-void analysis was completed. During placement, fresh air content measurements were taken and recorded; however, the specific test method used to measure air content was not recorded, with the exception of Fort Wainwright, where the pressure method (ASTM C231 [2017]) was used.

\subsubsection{Pore solution expression}

Pore solution expression was performed by first crushing core specimens to remove the coarse aggregate, then by pressing the remaining mortar under extremely high pressure using an apparatus that allows any resulting fluid to be collected (Barneyback and Diamond 1981). Depending on the age and moisture condition of the concrete, the amount of pore solution collected may be very small. Fluid was then diluted and analyzed using ion chromatography (IC) to determine the anions present in the pore solution. For this study, the anions measured were selected based on the known chemical ingredients of admixtures used for cold weather concrete, as described in Appendix A.

\subsection{Results}

\subsubsection{Hardened air-void analysis}

Appendix B includes scanned images of each specimen. These scans show the initial image of the specimen, and the specimens after preparation. The specimens were prepared with a process that uses a permanent marker and silica powder to highlight the void structure. This method, a modified version of ASTM C457 (2016c), is employed by petrographers to estimate airvoid structure in hardened concrete in a more automated way. Figure 29 shows the scans of the Sault Ste. Marie, Michigan control section. As shown, the sample is prepared to accentuate the void structure and allow researchers to estimate the air content of the specimen more accurately. 
Figure 29. Hardened air-void analysis scans, Sample 2.
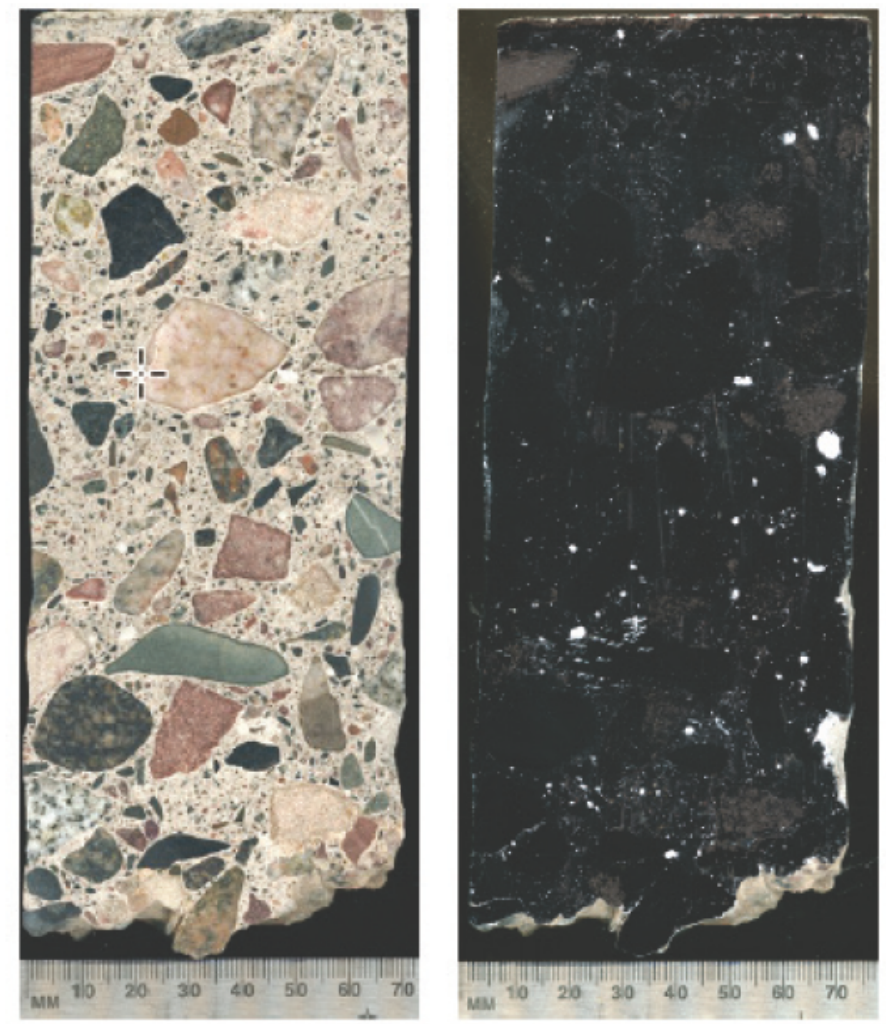

Of the 12 specimens analyzed, all had an estimated hardened air-void content higher than that of the fresh air content recorded at the time of placement, as listed in Table 8 . The placements in question have shown qualitative signs of durability after more than a decade in service. Completing hardened air-void analysis allows the researchers to postulate that a factor of this improved durability of a concrete placement in freezing temperatures is due to a proper air-void structure within the mixture. Additional information about mix designs and placement of each site can be found in the Phase I report of this work (Kennedy et al. 2019).

The Sault Ste. Marie, Michigan site was placed more than 25 years ago in March 1994 and is still in service today. The site included five admixtureamended slabs and one control slab, each 18 -ft x 20 -ft and 6-in. thick, and each incorporating a reinforcement grid. The control slab was kept heated and under a tent for the first several days to ensure proper curing. Sample 1 was cored from a slab that incorporated a prototype admixture and had a tent erected during early age curing, but was not heated. The remaining four slabs incorporated CWAS technology, but were not tented or externally heated. 
The Fort Wainwright site located in Fairbanks, Alaska was placed over a decade ago in March 2008 to be used as a military hardstand, and is still in use today. The site consists of five, 15 - $\mathrm{ft}$ x 25 - $\mathrm{ft}$, 6 -in. thick reinforced slabs on grade. The goal of this placement was to vary the admixture dosage and compare performance of each. A trial mixture was tested onsite and the five placements were completed over the following 2 days. None of the five slabs were tented or heated during the placement or curing process. Sample 7 was cored from a slab with the highest admixture dosage of the whole placement, which also resulted in the highest fresh and hardened air-void content. During the visual inspection of this location, this slab portrayed surface cracking throughout. The high air content may have resulted in a strength loss of this concrete, causing cracking, although there is not enough evidence to confirm this assumption. Samples 8 and 10 were cored from slabs with nearly equivalent CWAS contents, although a different type of water-reducing admixture was used. Different water reducers may have different effects on the initial slump of the mixture, which can require different amounts of water to be added onsite to achieve the desired workability. Samples 7, 8, 9, and 11 contained w/c of $0.38-0.39$ while sample 10, which incorporated a different water reducer than the previous four was placed with a w/c of 0.47 .

The Cold Climate Housing Research Center (CCHRC) site located in Fairbanks, Alaska was placed in March 2007 to be used as a sidewalk and bike path for the facility. This 8 - $\mathrm{ft}$ x 8 - $\mathrm{ft}$ and 4 -in. thick slab is still in use today and visual inspection shows no obvious deterioration after over a decade of use. Hardened air-void analysis of the sample cored from this site shows an extremely high air content of $23.05 \%$. Unfortunately, no information was officially published on the placement, making it difficult for researchers to diagnose the cause of such a high value. This air content value would typically cause a reduction in strength, although signs of weakened concrete were not discovered during the inspection documented in Phase I of this work. 
Table 8. Air content values.

\begin{tabular}{|c|c|c|c|c|c|}
\hline Sample \# & Location & Cast Date & Admixture Type & Plastic Air (\%) & Hardened Air (\%) \\
\hline 1 & Sault Ste. Marie, Ml & March 1994 & $\mathrm{BP}{ }_{1} 90$ & 3.2 & 4.59 \\
\hline 2 & Sault Ste. Marie, MI & March 1994 & Control & 3.2 & 3.87 \\
\hline 3 & Sault Ste. Marie, MI & March 1994 & $\mathrm{BP}{ }_{1} 150$ & 4.7 & 9.47 \\
\hline 4 & Sault Ste. Marie, MI & March 1994 & BN90 & 3.4 & 7.27 \\
\hline 5 & Sault Ste. Marie, MI & March 1994 & AP160 & 5.3 & 9.11 \\
\hline 6 & Sault Ste. Marie, MI & March 1994 & $\mathrm{AP}^{*} 5.2 \%$ ** & 8 & 10.6 \\
\hline 7 & Fort Wainwright, AK & March 2008 & BN68C4 & 5.8 & 10.84 \\
\hline 8 & Fort Wainwright, AK & March 2008 & BN34C23 & 5.2 & 6.61 \\
\hline 9 & Fort Wainwright, AK & March 2008 & BN45C3 & 5.4 & 8.64 \\
\hline 10 & Fort Wainwright, AK & March 2008 & BN34C23 & 5.5 & 9.24 \\
\hline 11 & Fort Wainwright, AK & March 2008 & BN22C15 & 5.7 & 9.57 \\
\hline 12 & CCHRC & March 2007 & BN90C5 & 8 & 23.05 \\
\hline
\end{tabular}

Through the visual inspection of these sites and the non-destructive testing completed in Phase I, it is apparent that each slab has shown signs of proven durability. Air-void structure plays a large role in durability in environments subjected to freezing and thawing. The results of higher than estimated air contents in each of the slabs could be a factor of the improved durability of these mixtures over time.

\subsubsection{Pore solution expression}

Pore solution expression was performed on different cores from the same concrete slabs as hardened air-void analysis; however, it was not possible to obtain pore solution from a significant portion of the specimens analyzed. Appendix $\mathrm{C}$ includes the results that could be obtained. For the concretes in place at the Sault Ste. Marie, MI site, pore solution was successfully obtained and analyzed from all slabs with the exception of the control. This is unfortunate, as it makes robust comparisons of the concentrations of different anions difficult due to the lack of a baseline from a mixture with no CWAS. Some basic observations can be made however, namely that nitrate and nitrite are both present in amounts ranging from $0.1 \%$ to $1.6 \%$ in concrete made with admixtures that contain calcium nitrate and calcium nitrite, as described in Appendix C. This indicates that some amount of these chemicals remains present in the pore solution of the concrete even after almost 30 years of exposure. 
To evaluate the potential for freeze-point reduction of the amounts of admixture present in the pore solution, the current chemical makeup of the pore solution can be compared to an estimate of the initial chemical concentration of the same species at the time of mixing. As an example, specimen \#4 was obtained from a slab that contained an initial dose of $90 \mathrm{oz} / \mathrm{cwt}$ of $\mathrm{BN}$ admixture (manufacturer $\mathrm{B}$, non-chloride accelerator), had a water-tocement ratio of 0.39 , and a cementitious content of $707 \mathrm{lb} / \mathrm{yd} 3$. Assuming the chemical makeup of the admixture $\mathrm{BN}$ is similar today to the mixture as it was in 1994 , the \% by mass of nitrate in the admixture is $29.5 \%$. The total volume of admixture $\mathrm{BN}$ per $\mathrm{yd} 3$ is $636 \mathrm{oz}$ or 4.97 gallons. With a density of $11 \mathrm{lb} / \mathrm{gal}$, the total mass of admixture in this mix would be $54.68 \mathrm{lb}, 29.5 \%$ of which is nitrate. This gives a total nitrate per cubic yard of $16.1 \mathrm{lb}$, which can be divided by the total water content of $275 \mathrm{lb}$, to give an initial nitrate concentration of $5.8 \%$ in the fluid component of the concrete mixture. This is an approximate estimate that can be compared to the measured nitrate concentration of the pore solution (from Table C-1) of $10126 \mathrm{ppm}$ or $1.01 \%$. The reduction, while significant, occurred over a span of 24 years, and indicates that freezing point depression of the pore solution provided by the admixture may have persisted for some time.

The results of this initial assessment indicate a significant possibility of lingering freezing point depression in hardened concrete containing CWAS; however, this observation currently requires additional verification and quantification. The implications of this observation are a potential reduction in the number of in-situ freeze-thaw cycles experienced by in-place structures. Further research would likely be necessary to measure the freezing point in conjunction with ambient conditions over an extended period of time to confirm and characterize this effect in more detail. 


\section{Conclusions and Recommendations}

\subsection{Conclusions}

The Phase II project has led to several significant conclusions regarding the use of freeze protection additives in cold weather concreting:

1. Mixtures cast and cured in a $23^{\circ} \mathrm{F}$ environment can achieve compressive strengths exceeding room-temperature control mixtures at 7, 28, and 90 days of age, with as little at $60 \mathrm{oz} / \mathrm{cwt}$ of freeze protection additive. These mixtures are durable to rapid freezing and thawing cycles when air entrained. This amount of freeze protection additive represents a $>50 \%$ reduction in quantity when compared to that recommended by previous research.

2. It is not necessary for the freezing point of a concrete mixture to be less than the lowest temperature experienced by the concrete. In the presence of freeze protection additives, it is possible for ice to form at early ages without preventing concrete from achieving useful compressive strengths.

3. The AP freeze protection additive is capable of producing higher strengths with less admixture than the ANC admixture combination.

4. The reduction in admixture dosage allows for an increase in handling time, with initial setting times as long at 3.5 hours. The reduction in admixture also directly reduces the cost of the mixture.

5. Manufacturer recommended maximum dosages of CWAS used in the past result in mixtures with working times of less than 30 minutes at typical winter temperatures for fresh concrete $\left(60^{\circ} \mathrm{F}\right)$.

6. All mixtures increased in strength with each successive testing age. 90-day compressive strengths for the $\mathrm{AN}_{45} \mathrm{C} 45$ mixture exceeded 8,000 psi. The continued gain in compressive strength from 28 to 90 days of age occurred despite a lack of additional curing moisture.

7. For both $\mathrm{AN}_{3} \mathrm{OC} 3$ and $\mathrm{AN}_{45} \mathrm{C}_{45}$ mixtures, air entrainment is required for mixtures to be durable to ASTM C666 (2015) freeze-thaw testing. The two mixtures without air entrainment experienced damage, with the AN3oC3.Ao failing first.

The conclusions listed above represent a significant step forward in the state of knowledge for use of freeze protection additives. The combination of reduced cost, increased handling time, and excellent mechanical performance that is achieved with lower doses of freeze protection additive may 
enable broader adoption due to an increase in user friendliness. The previously established temperature limit of $23^{\circ} \mathrm{F}$ is likely conservative; it may be possible to cure concrete with useful strength in a timely manner at temperatures significantly lower than $23{ }^{\circ} \mathrm{F}$. The role of freeze protection additives in the curing of concrete at below freezing temperatures is also not as simple as previously characterized. Based on temperature data from the first 72 hours of curing, ice clearly forms in mixtures such as $\mathrm{AN}_{3} \mathrm{OC} 3$ and AP6o; however, these mixtures achieve strengths exceeding roomtemperature control mixtures at all ages.

\subsection{Recommendations}

The advancements reported in this document are substantial; however, significant work remains to integrate other existing concrete technologies with freeze protection additives.

- An urgent need is to test the compatibility of freeze protection additives with supplementary cementitious materials including fly ash, blast furnace slag, and silica fume. These materials are common and sometimes mandatory components of modern concrete, and can significantly enhance the durability of the material in the cases of reactive aggregate.

- The effect of freeze protection additives on durability to rapid freezethaw cycling is well understood; however, many test methods which quantify durability operate by quantifying the permeability of the concrete. No research has been performed at CRREL to examine the effects of freeze protection additives on the permeability of concretes cured at below freezing temperatures.

- The current curing regime used to test freeze protection additives is unrealistic. A constant temperature below freezing which does not vary daily does not match any known location. The most realistic curing schedule would involve daily cycling of concrete temperature, with the highs and lows set based on climate data from different locations.

- The lower temperature limits associated with specific quantities of freeze protection additive should be determined.

\subsection{Future work}

The next phase of research involving freeze protection additives will focus on addressing the needs described above. This phase will also work to 
continue development of the dosage guidance tool, through adiabatic testing of more combinations and types of freeze protection additive. Larger scale mixtures need to be placed to validate the performance of the lower dosages of freeze protection additive, and to provide field validation data. Finally, the results of this report, as well as the next phase, are being incorporated into a new, comprehensive suite of tools and guidance for use of additives in cold weather concreting known as ARCTEC (Additive Regulated Concrete for Thermally Extreme Conditions).

\subsection{Additive regulated concrete for thermally extreme conditions}

ARCTEC incorporates freeze protection additives into a new system providing tools and methodology to recommend admixture dosage tailored to the conditions, materials, and geometry of each concrete placement. Figure 30 shows a functional diagram of ARCTEC, which illustrates the details of the input parameters required as well as the output information provided. ARCTEC will consist of three main components: an additive dosage calculator, a list of qualified additive products, and a performance prediction model, which will provide an indication of short and long-term concrete performance before placement. Ongoing laboratory research is supporting the development of the dosage guidance tool as well as the list of qualified additives; the performance prediction model will be the subject of future research efforts.

Figure 30. Functional diagram of ARCTEC detailing the role of the tool in design of a winter concrete mixture.

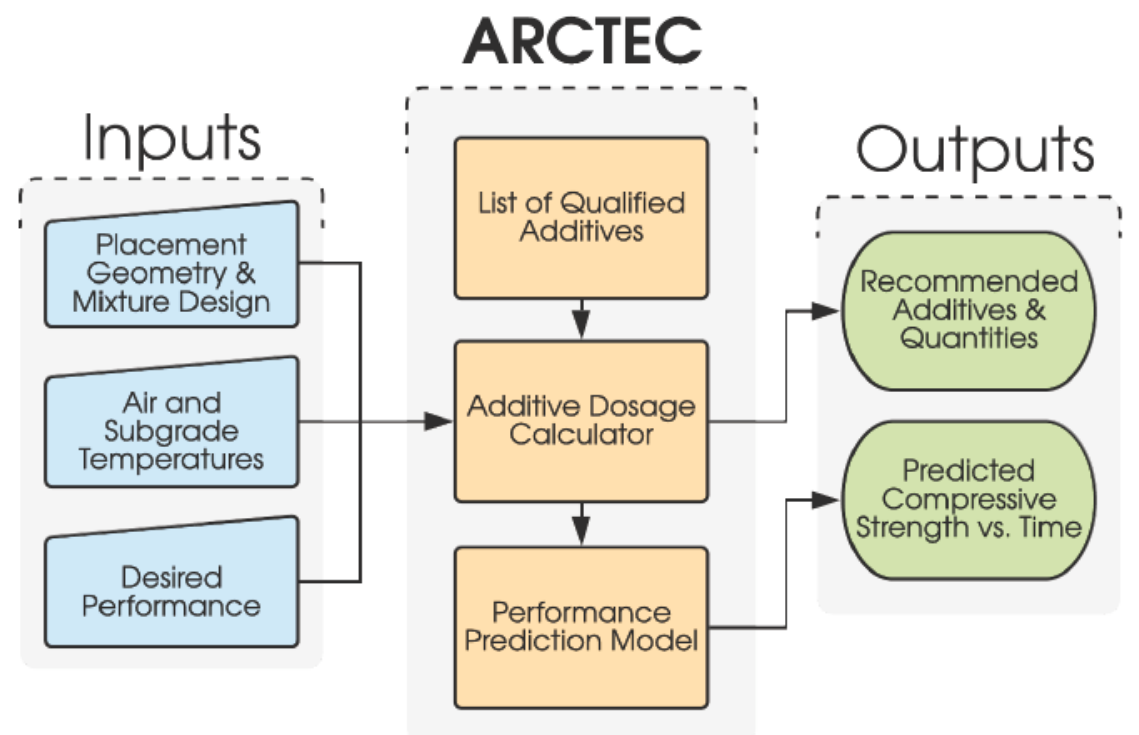




\section{References}

AASHTO (American Association of State and Highway Transportation Officials). 2017. Standard Method of Test for Surface Resistivity Indication of Concrete's Ability to Resist Chloride Ion Penetration. TP 358. Washington, DC: AASHTO.

AASHTO (American Association of State and Highway Transportation Officials). 2018. Standard Method of Test for Characterization of the Air-Void System of Freshly Mixed Concrete by the Sequential Pressure Method. TP 118. Washington, DC: AASHTO.

ACI (American Concrete Institute). 1990. Standard Specification for Cold Weather Concreting. ACI 306.1. Farmington Hills, MI: ACI.

ACI (American Concrete Institute). 1996. "Standard Practice for Selecting Proportions for Normal, Heavyweight, and Mass Concrete." ACI Manual of Concrete Practice, Part 1. ACI 211.1-91. Farmington Hills, MI: ACI Committee 211.

ACI (American Concrete Institute). 2005. Guide to Mass Concrete. ACI 207.1 R-05. Farmington Hills, MI: ACI.

ACI (American Concrete Institute) 2007. Report on Thermal and Volume Change Effects on Cracking of Mass Concrete. Farmington Hills, MI: ACI Committee 207.

ACI (American Concrete Institute). 2016. Guide to Cold Weather Concreting. ACI 306R16. Farmington Hills, MI: ACI.

ASTM (American Society for Testing and Materials). 2008a. Standard Test Method for Length Change of Hardened Hydraulic-Cement Mortar and Concrete. C157/157M. ASTM West Conshohocken, PA: ASTM International. http://www.astm.org/Standards/C157.htm, p 7.

ASTM (American Society for Testing and Materials). 2008b. Standard Test Method for Time of Setting of Concrete Mixtures by Penetration Resistance. ASTM C403. West Conshohocken, PA: ASTM International. http://www.astm.org/Standards/C403.htm.

ASTM (American Society for Testing and Materials). 2012a. Standard Test Method for Slump of Hydraulic-Cement Concrete. C143/143M. ASTM West Conshohocken, PA: ASTM International. http://www.astm.org/Standards/C143.htm.

ASTM (American Society for Testing and Materials). 2012b. Standard Test Method for Scaling Resistance of Concrete Surfaces Exposed to Deicing Chemicals. C672/C672M-12. ASTM West Conshohocken, PA: ASTM International.

ASTM (American Society for Testing and Materials). 2013. Standard Test Method for Density (Unit Weight), Yield, and Air Content (Gravimetric) of Concrete. ASTM $\mathrm{C}_{13} 8 / 138 \mathrm{M}$. ASTM West Conshohocken, PA: ASTM International. http://www.astm.org/Standards/C138.htm. 
ASTM (American Society for Testing and Materials). 2013b. Standard Test Method for Temperature of Freshly Mixed Hydraulic-Cement Concrete. C1064/1064M. ASTM West Conshohocken, PA: ASTM International. http://www.astm.org/Standards/C1064.htm.

ASTM (American Society for Testing and Materials). 2014a. Standard Test Method for Fundamental Transverse, Longitudinal, and Torsional Resonant Frequencies of Concrete Specimens. C215. ASTM West Conshohocken, PA: ASTM International.

ASTM (American Society for Testing and Materials). 2014b. Standard Test Method for Static Modulus of Elasticity and Poisson's Ratio of Concrete in Compression. C469. ASTM West Conshohocken, PA: ASTM International. http://www.astm.org/Standards/C469.htm.

ASTM (American Society for Testing and Materials). 2014c. Standard Test Method for Compressive Strength of Cylindrical Concrete Specimens. ASTM C39/39M. West Conshohocken, PA: ASTM International. http://www.astm.org/Standards/C39.htm.

ASTM (American Society for Testing and Materials). 2015. Standard Test Method for Resistance of Concrete to Rapid Freezing and Thawing. C666. ASTM West Conshohocken, PA: ASTM International.

ASTM (American Society for Testing and Materials). 2016a. Standard Specification for Cold-Weather Admixture Systems. C1622. Farmington Hills, MI: ACI.

ASTM (American Society for Testing and Materials). 2016b. Standard Test Method for Air Content of Freshly Mixed Concrete by the Volumetric Method. C173. ASTM West Conshohocken, PA: ASTM International.

ASTM (American Society for Testing and Materials). 2016c. Standard Test Method for Microscopical Determination of Parameters of the Air-Void System in Hardened Concrete. C457. ASTM West Conshohocken, PA: ASTM International.

ASTM (American Society for Testing and Materials). 2017. Standard Test Method for Air Content of Freshly Mixed Concrete by the Pressure Method. C231. ASTM West Conshohocken, PA: ASTM International.

Barna, L., and C. Korhonen. 2012. Guidance for Optimizing Admixture Dosage Rates for Cold Weather Admixture Systems. Hanover. NH: ERDC-CRREL. https://doi.org/10.1061/9780784412473.018, pp 175-185

Barna, L. A., P. M. Seman, and C. J. Korhonen. 2010. Cold Weather Admixture Systems Demonstration at Fort Wainwright, Alaska. Hanover. NH: Engineer Research and Development Center, Cold Regions Research and Engineering Laboratory (ERDC-CRREL).

Barneyback, R., and S. Diamond. 1981. "Expression and Analysis of Pore Fluids from Hardened Cement Pastes and Mortars." Cement and Concrete Research 11(2):279-285. 
Burns, G., M. Scroger, G. Strouse, M. Croarkin, and W. Guthrie. 1993. TemperatureElectromotive Force Reference Functions and Tables for the Letter-Designated Thermocouple Types Based on the IPTS-go. NIST Monograph 175. Washington, DC: U.S. Department of Commerce.

Cai, H., and X. Liu. 1998. "Freeze-Thaw Durability of Concrete: Ice Formation Process in Pores." Cement and Concrete Research. 28(9):1281-1287. https://doi.org/10.1016/S0008-8846(98)00103-3.

Fridh, K. 2005. Internal Frost Damage in Concrete-Experimental Studies of Destruction Mechanisms. Thesis. Lund, Skåne, Sweden: Lund Institute of Technology. http://lup.lub.lu.se/record/24581.

Hooton, R. D., and M. D. Thomas. 2009. Pore Solution Analysis as a Tool for Studying Early-Age Hydration \& Predicting Future Durability. Cement Hydration Summit.

HQUSACE (Headquarters, U.S. Army Corps of Engineers) 1973. Method of Test for Temperature Rise in Concrete. CRD-C $38-73$. Washington, DC: HQUSACE.

Jeong, J.-H., and D. G. Zollinger. 2006. "Finite-Element Modeling and Calibration of Temperature Prediction of Hydrating Portland Cement Concrete Pavements." Journal of Materials in Civil Engineering 18(3):317-324.

Kazmierczak, C. de S., J. K. B. Boaro, M. P. Lunardi, M. P. Kulakowski, and M. Mancio. 2019. "Influence of the Moisture Content on the Dynamic Modulus of Elasticity of Concrete Made with Recycled Aggregate." Ambiente Construído 19(2):79-89. https://doi.org/10.1590/s1678-86212019000200309.

Kennedy, D. E., B. E. Watts, C. E. Smith, and J. I. Oren. 2019. Long-Term Durability of Cold Weather Concrete Phase I Report. ERDC/CRREL TR-19-22. Hanover, NH: ERDC-CRELL. https://erdc-library.erdc.dren.mil/ispui/handle/11681/34464.

Korhonen, C. J. 1999. Expedient Low-Temperature Concrete Admixtures for the Army. CRREL Technical Report (TR) 99-17. Hanover, NH: ERDC-CRREL.

Korhonen, C. J., and J. W. Brook. 1996. Freezing Temperature Protection Admixture for Portland Cement Concrete. CRREL TR 96-28. Hanover, NH: ERDC-CRREL.

Korhonen, C., J. Hughes, F. Best, and G. Mass. 1998. "Low-Temperature Repair of the Ice Condenser Floor Slab at the Sequoyah Nuclear Power Plant." Cold Regions Impact on Civil Works, pp 258-270.

Kosmatka, S. H., and M. L. Wilson. 2015. Design and Control of Concrete Mixtures. Skokie, IL: Portland Cement Association, p 165.

Layssi, H., P. Ghods, A. R. Alizadeh, and M. Salehi. 2015. "Electrical Resistivity of Concrete." Concrete International 37(5):41-46. 
Ley, M. T., D. Welchel, J. Peery, S. Khatibmasjedi, and J. LeFlore. 2017. "Determining the Air-Void Distribution in Fresh Concrete with the Sequential Air Method." Construction and Building Materials 150:723-737. https://doi.org/10.1016/i.conbuildmat.2017.06.037.

Martinelli, E., E. A. B. Koenders, and A. Caggiano. 2013. "A Numerical Recipe for Modelling Hydration and Heat Flow in Hardening Concrete." Cement and Concrete Composites 40:48-58. https://doi.org/10.1016/i.cemconcomp.2013.04.004.

Mindess, S., F. Young, and D. Darwin. 2003. Concrete. Upper Saddle River, NJ: PrenticeHall, Inc.

Nokken, M. R., R. Hooton, and C. Rogers. 2004. "Measured Internal Temperatures in Concrete Exposed to Outdoor Cyclic Freezing." Cement, Concrete and Aggregates 26(1):1-7.

Nokken, M., A. Boddy, X. Wu, and R. D. Hooton. 2008. "Effects of Temperature, Chemical, and Mineral Admixtures on the Electrical Conductivity of Concrete." Journal of ASTM International 5(5):1-9. https://doi.org/10.1520/JAl101296.

Park, R., R. Carroll, P. Bliss, G. Burns, R. Desmaris, F. Hall, Hall, M. Herzkovitz, D. MacKenzie, E. McGuire, R. Reed, L. Sparks, and T. Wang. (eds.). 1993. "Manual on the Use of Thermocouples in Temperature Measurement." ASTM International. https://doi.org/10.1520/MNL12-4TH-EB.

Peterson, K. W., R. A. Swartz, L. L. Sutter, and T. J. Van Dam. 2001. "Hardened Concrete Air Void Analysis with a Flatbed Scanner." Transportation Research Record 1775(1):36-43· https://doi.org/10.3141/1775-06.

Powers, T. C. 1955. "Basic Considerations Pertaining to Freezing-and-Thawing Tests." ASTM Proceedings. 55:1132-1155.

Spragg, R., C. Villani, K. A. Snyder, D. P. Bentz, J. W. Bullard, and J. Weiss. 2013. "Electrical Resistivity Measurements in Cementitious Systems: Observations of Factors that Influence the Measurements." Journal of the Transportation Research Board Vol. 2342. https://www.nist.gov/publications/electrical-resistivitymeasurements-cementitious-systems-observations-factors-influence.

Taylor, H. 2004. Cement Chemistry. 2d ed. London, UK: Thomas Telford Publishing. 


\section{Acronyms and Abbreviations}

\begin{tabular}{|l|l|}
\hline Abbreviation & Term \\
\hline AC & Alternating Current \\
\hline ACI & American Concrete Institute \\
\hline ARCTEC & Additive Regulated Concrete for Thermally Extreme Conditions \\
\hline ASTM & American Society for Testing and Materials \\
\hline ATR & Adiabatic temperature rise \\
\hline BN & Manufacturer B, Non-Chloride Accelerator \\
\hline CCHRC & Cold Climate Housing Research Center \\
\hline CRREL & Cold Regions Research and Engineering Laboratory \\
\hline CWAS & Cold Weather Admixture Systems \\
\hline ERDC & Engineer Research and Development Center \\
\hline ERDC-GSL & Engineer Research and Development Center, Geotechnical and \\
\hline Structures Laboratory \\
\hline LiDAR & Ion Chromatography \\
\hline MTS & Light Detection and Ranging \\
\hline PID & Materials Test System \\
\hline RTD & Proportional Integral Derivative \\
\hline SAM & Resistance Temperature Detectors \\
\hline USACE & Sequential Air Method \\
\hline
\end{tabular}




\section{Appendix A: Admixture Chemical Analysis}

Table A-1. Admixture chemical analysis.

\begin{tabular}{|l|c|c|c|c|c|}
\hline \multicolumn{1}{|c|}{ Ion } & AP & AN & BN & BC & AC \\
\hline Chloride & 0.07 & 0.01 & 0.07 & 0.03 & 0.04 \\
\hline Nitrite & 12.16 & 2.63 & 0.03 & 21.78 & 22.86 \\
\hline Bromide & 1.39 & 0.00 & 0.00 & 0.00 & 0.00 \\
\hline Sulfate & 0.08 & 0.09 & 0.05 & 0.06 & 0.05 \\
\hline Nitrate & 13.59 & 29.27 & 29.54 & 1.05 & 1.61 \\
\hline Phosphate & 0 & 0 & 0 & 0 & 0 \\
\hline Lithium & 0.00 & 0.00 & 0.00 & 0.00 & 0.00 \\
\hline Sodium & 0.08 & 1.02 & 1.11 & 0.10 & 0.07 \\
\hline Ammonium & 0.00 & 0.01 & 0.00 & 0.00 & 0.01 \\
\hline Potassium & 0.00 & 0.00 & 0.00 & 0.00 & 0.00 \\
\hline Magnesium & 0.00 & 0.02 & 0.00 & 0.00 & 0.00 \\
\hline Calcium & 10.0 & 10.5 & 9.4 & 9.6 & 10.3 \\
\hline
\end{tabular}




\section{Appendix B: Durability Trials Temperature and Resistivity Curves}

Figure B-1. Temperature curve for insulated and bare specimens for AN30C3 with $7.1 \%$ air.

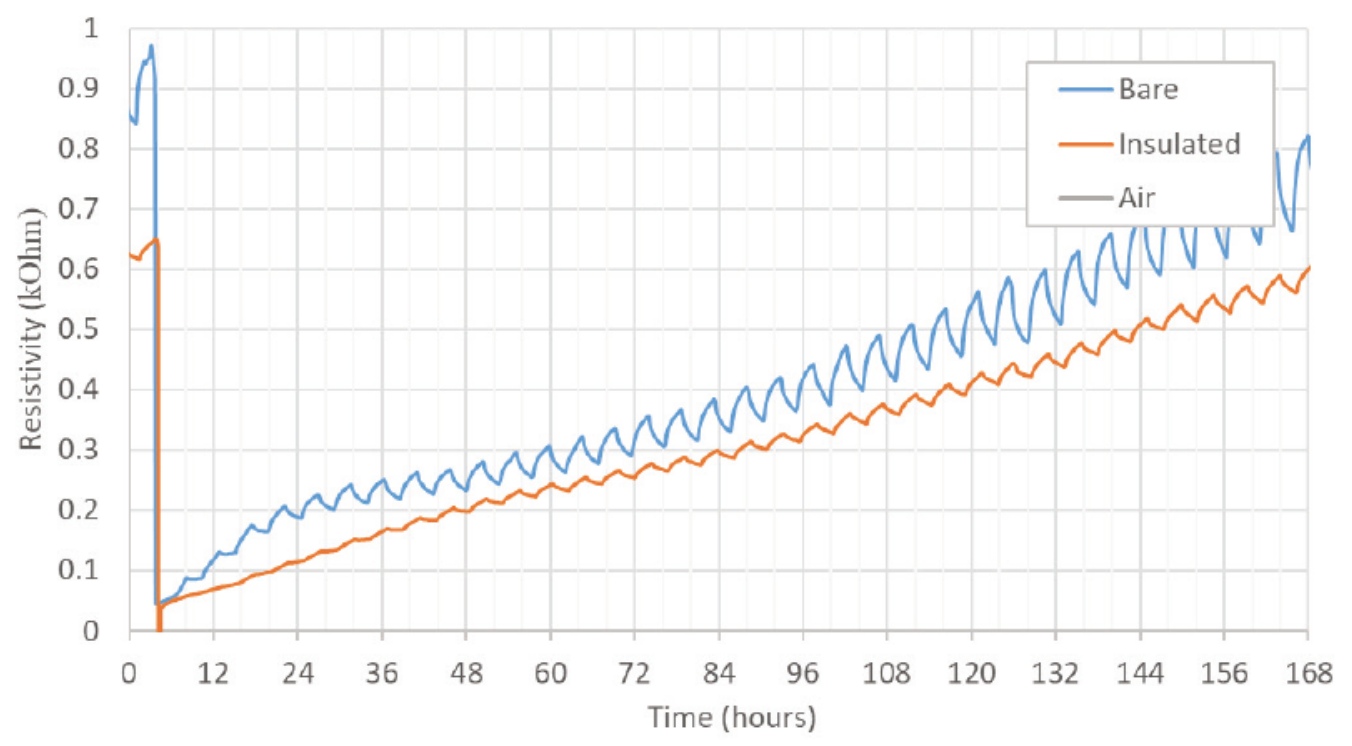

Figure B-2. Resistivity curve for insulated and bare specimens for AN30C3 with $7.1 \%$ air. Large values at t-zero are a result of the open circuit reading of the data logger before specimen connection.

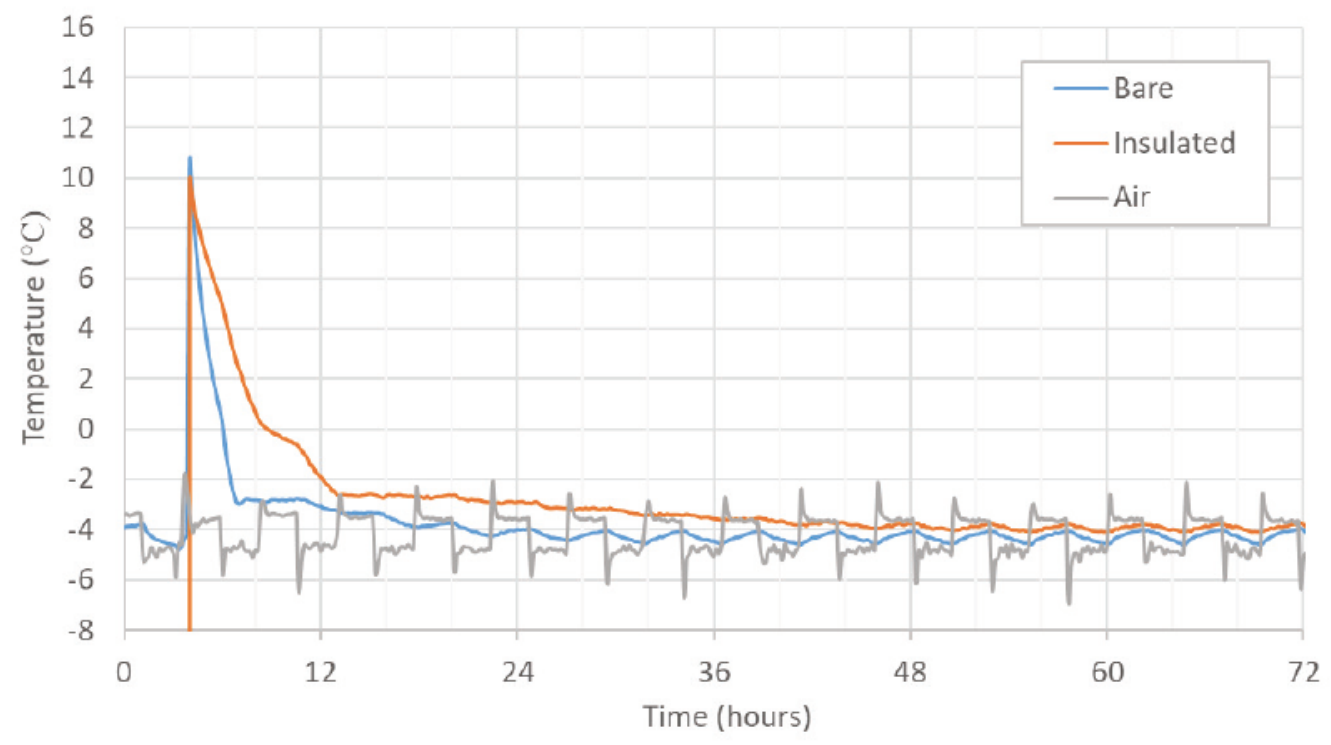


Figure B-3. Temperature curve for insulated and bare specimens for AN30C3 with $10.3 \%$ air.

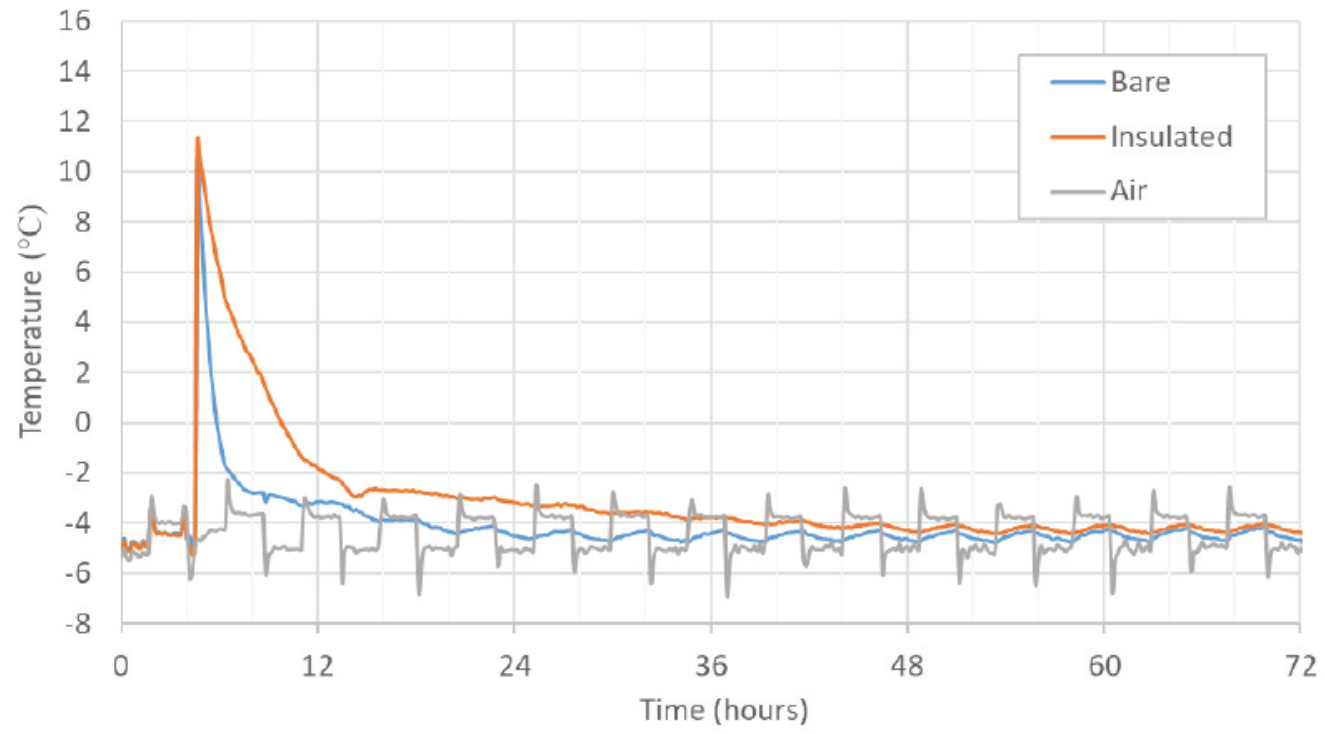

Figure B-4. Resistivity curve for insulated and bare specimens for AN30C3 with $10.3 \%$ air. Large values at t-zero are a result of the open circuit reading of the data logger before specimen connection.

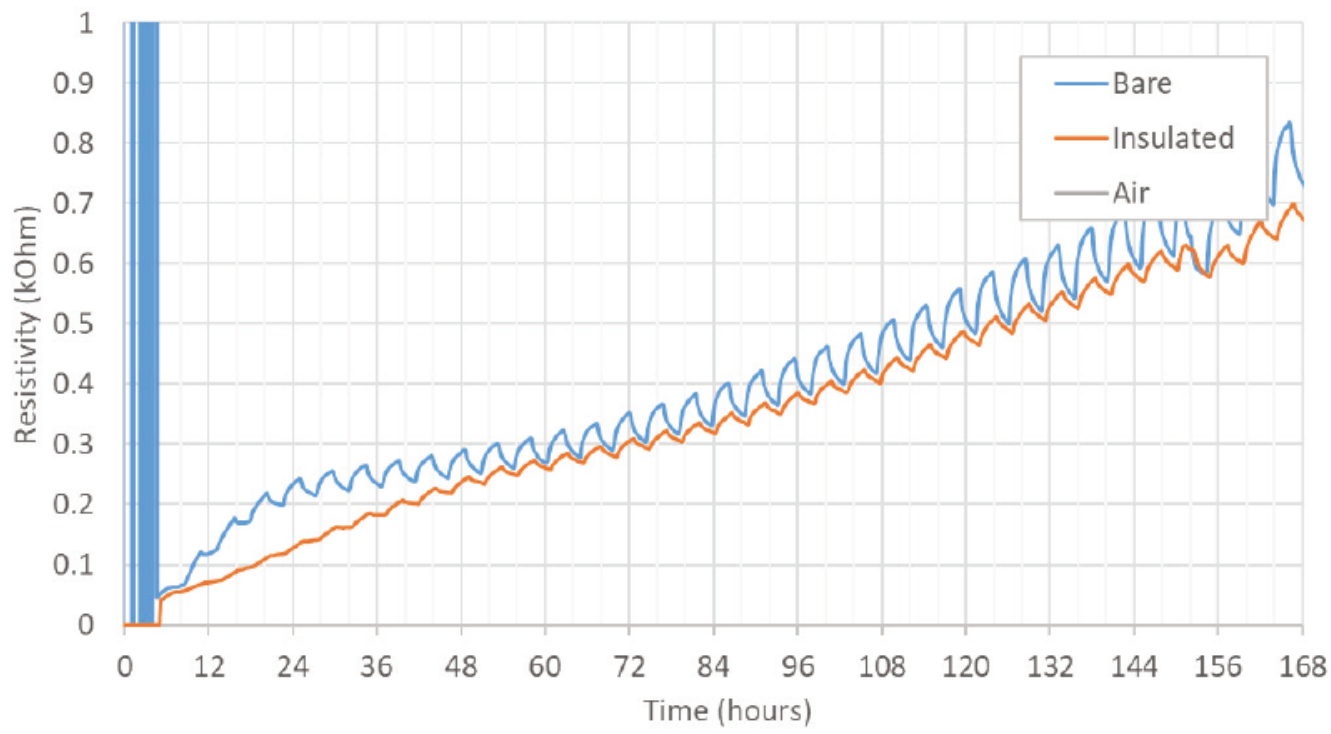


Figure B-5. Temperature curve for insulated and bare specimens for AN30C3.AO with 2.2\% air.

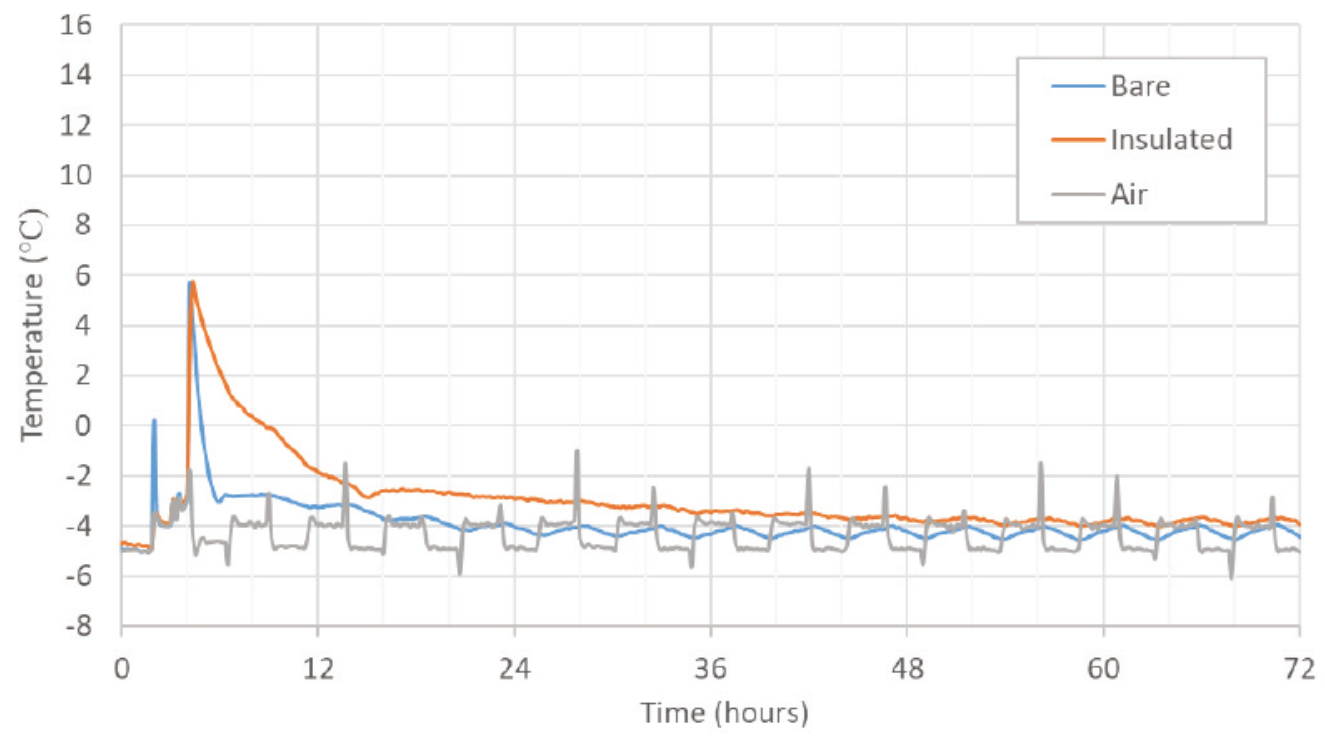

Figure B-6. Resistivity curve for insulated and bare specimens for AN30C3.AO with $2.2 \%$ air. Large values at t-zero are a result of the open circuit reading of the data logger before specimen connection.

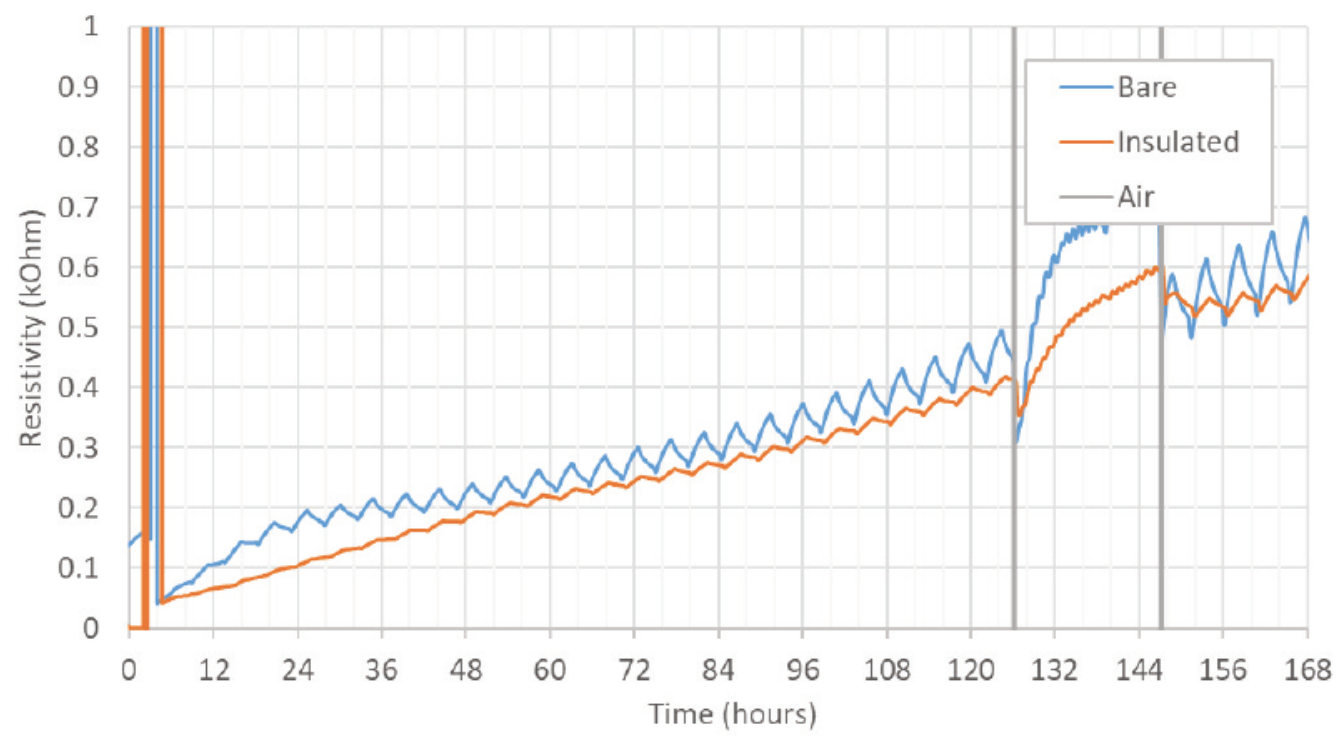


Figure B-7. Temperature curve for insulated and bare specimens for AN30C3.F45 with $9.2 \%$ air.

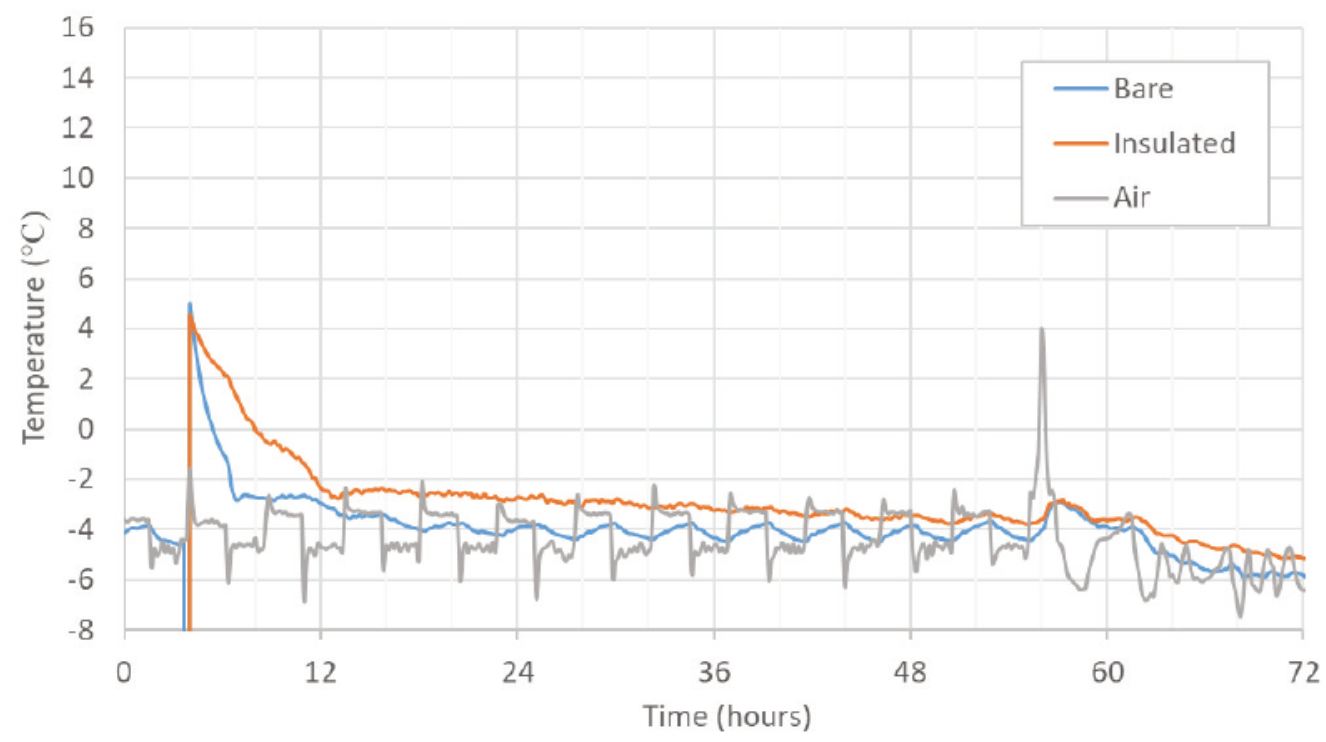

Figure B-8. Resistivity curve for insulated and bare specimens for AN30C3.F45 with $9.2 \%$ air. Large values at t-zero are a result of the open circuit reading of the data logger before specimen connection.

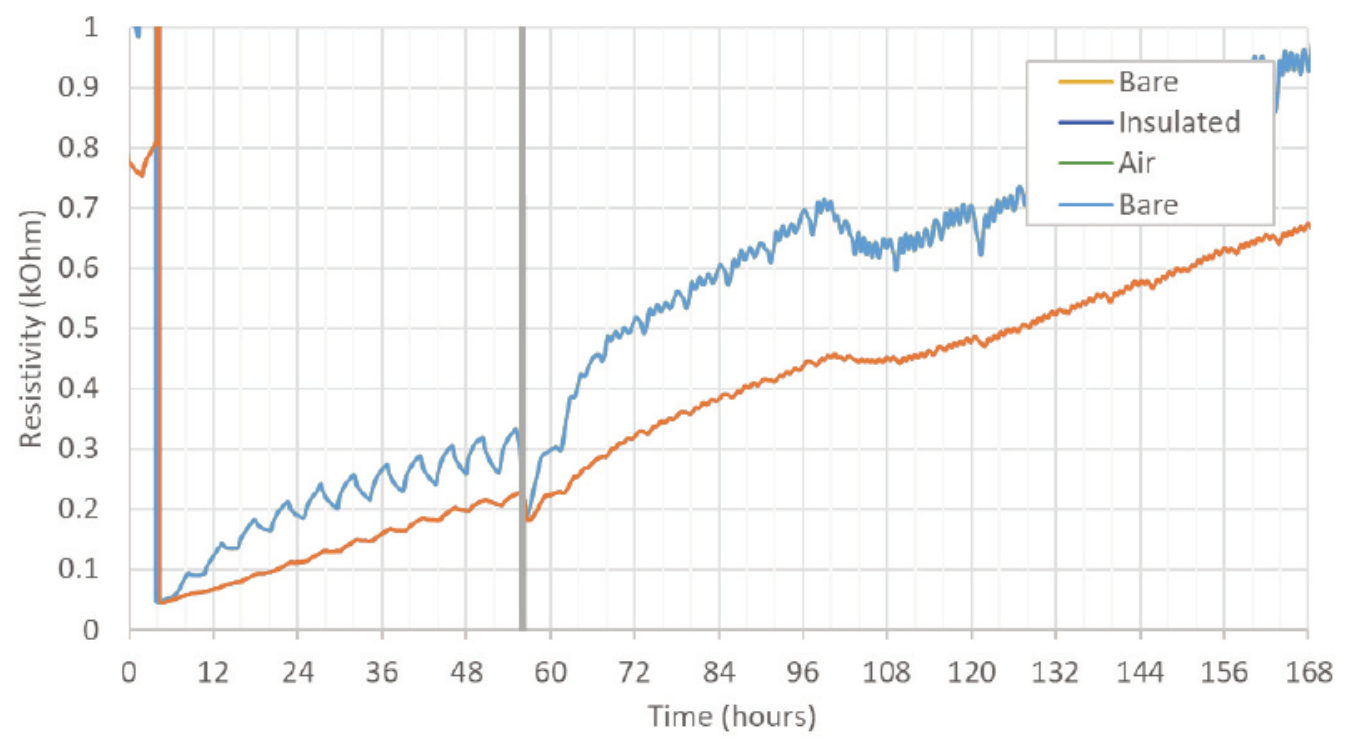


Figure B-9. Temperature curve for insulated and bare specimens for AN45C45.AO with $2.3 \%$ air.

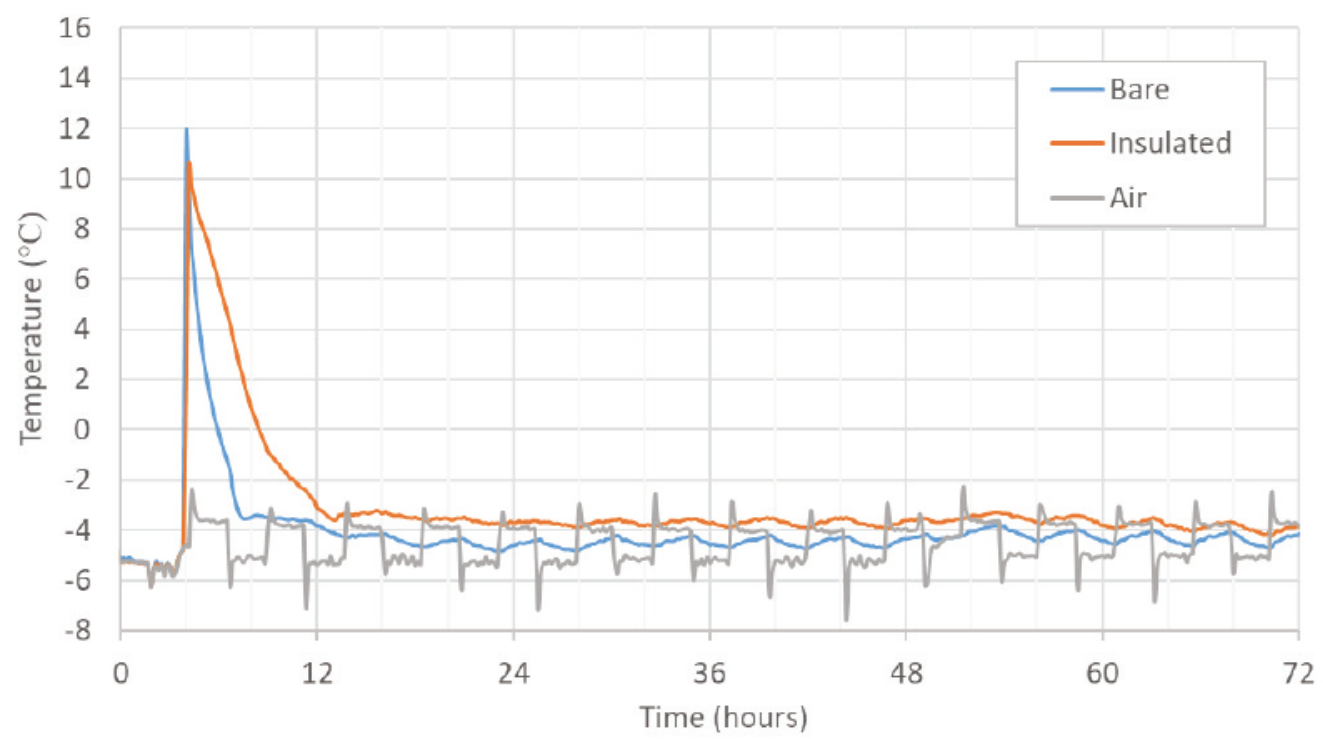

Figure B-10. Resistivity curve for insulated and bare specimens for AN45C45.A0 with 2.3\% air. Large values at t-zero are a result of the open circuit reading of the data logger before specimen connection.

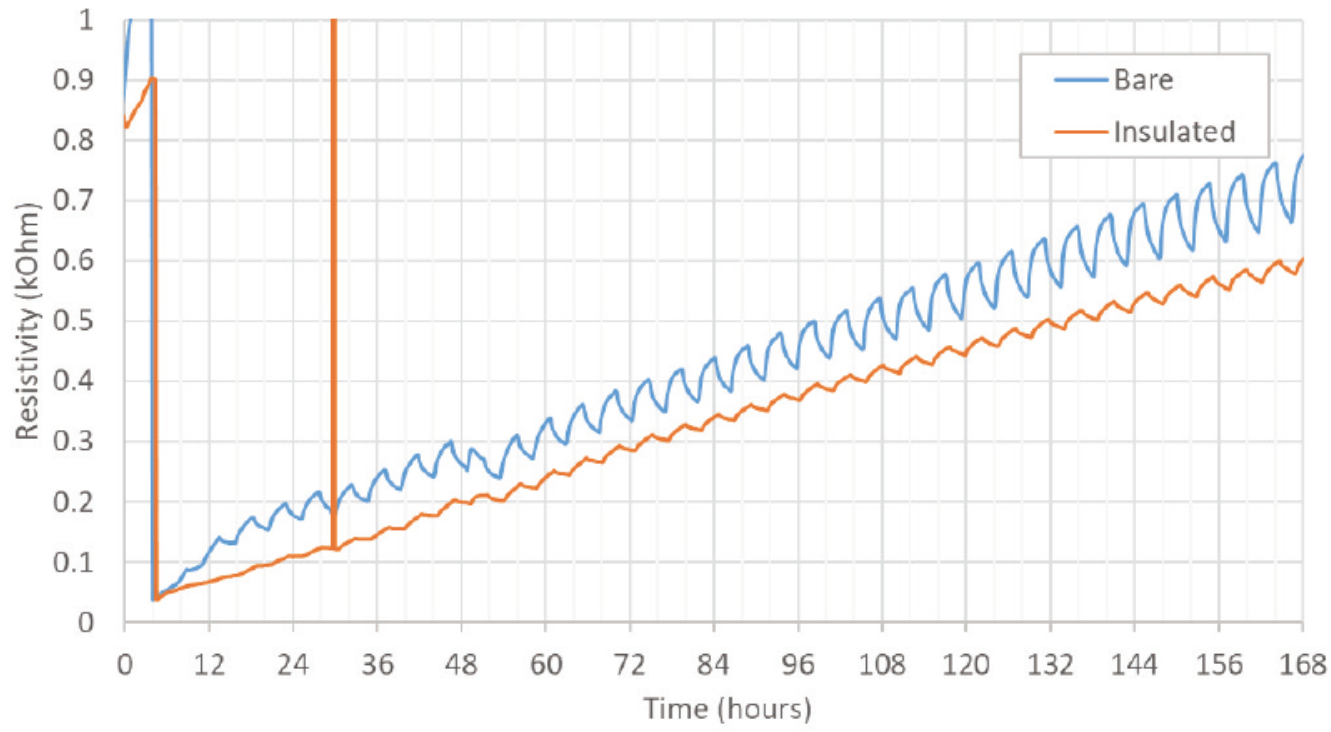


Figure B-11. Temperature curve for insulated and bare specimens for AN45C45 with $4.2 \%$ air.

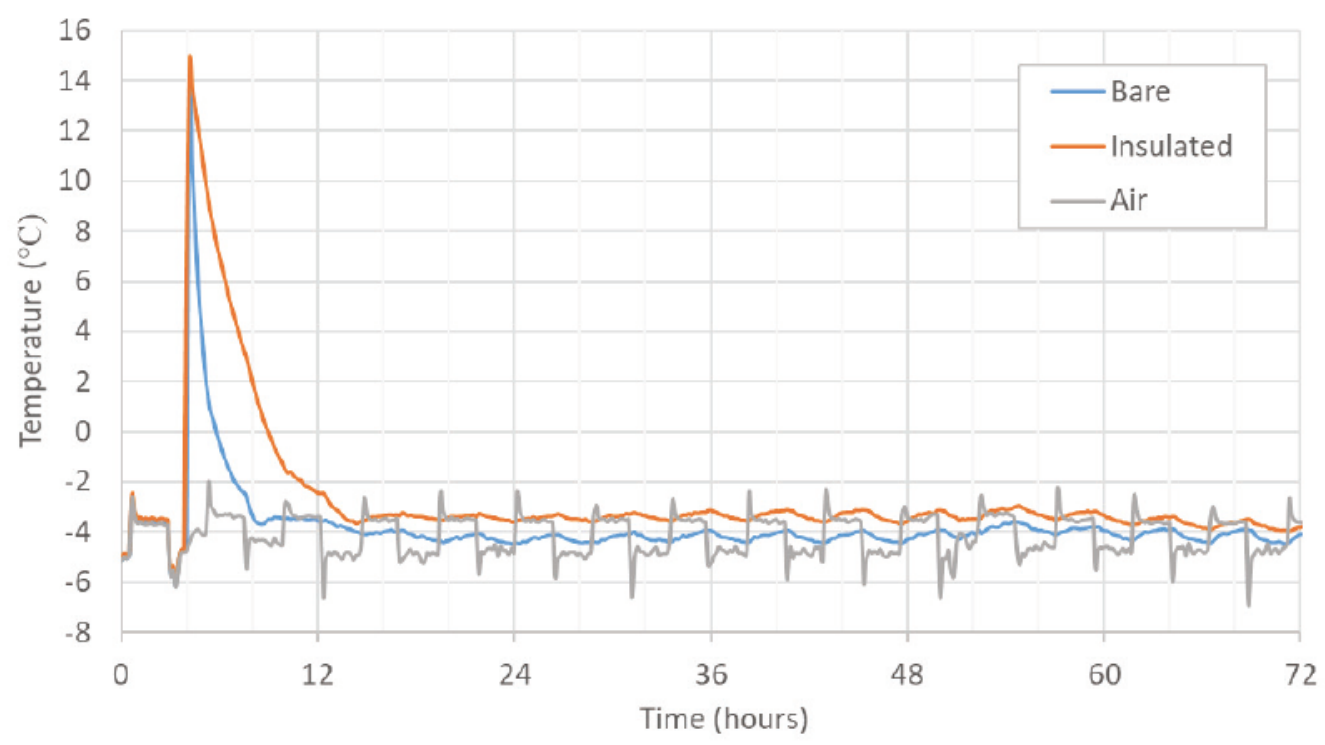

Figure B-12. Resistivity curve for insulated and bare specimens for AN45C45 with $4.2 \%$ air. Large values at t-zero are a result of the open circuit reading of the data logger before specimen connection.

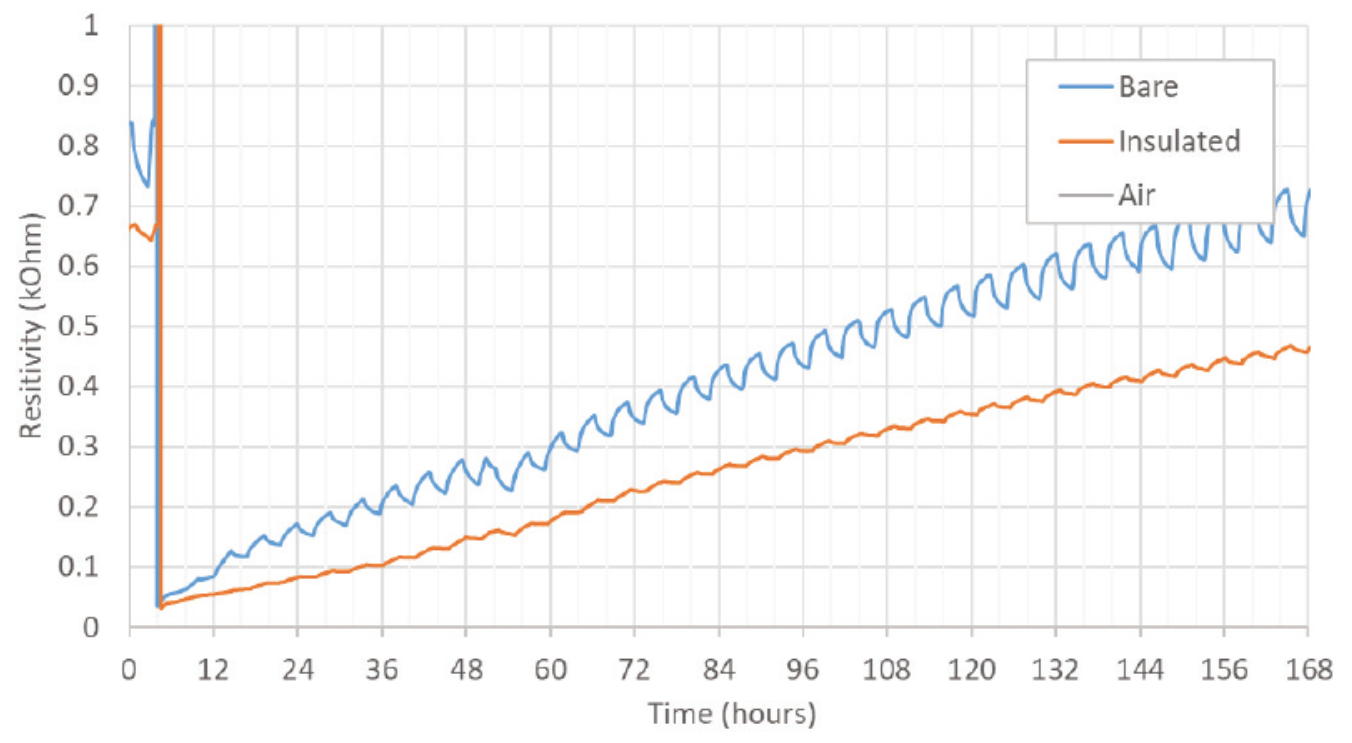


Figure B-13. Temperature curve for insulated and bare specimens for AP60 with $4.9 \%$ air.

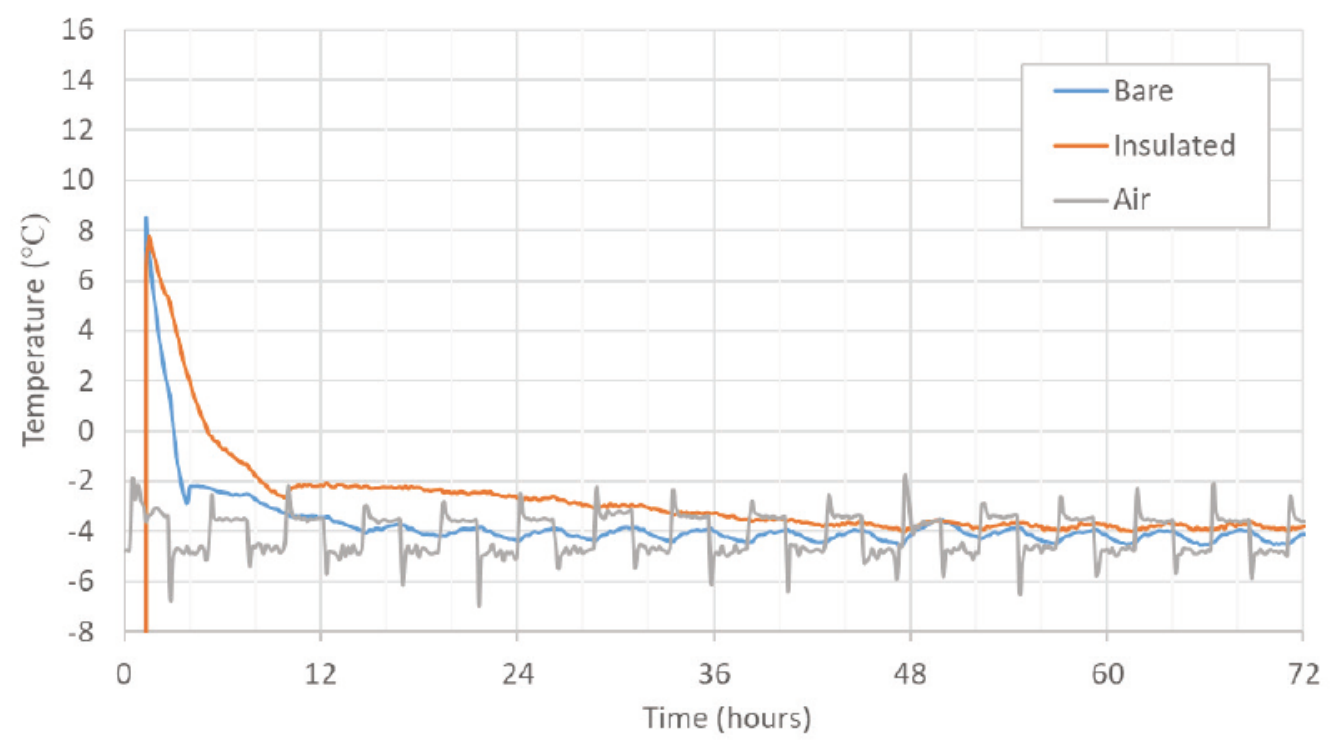

Figure B-14. Resistivity curve for insulated and bare specimens for AP60 with $4.9 \%$ air. Large values at t-zero are a result of the open circuit reading of the data logger before specimen connection.

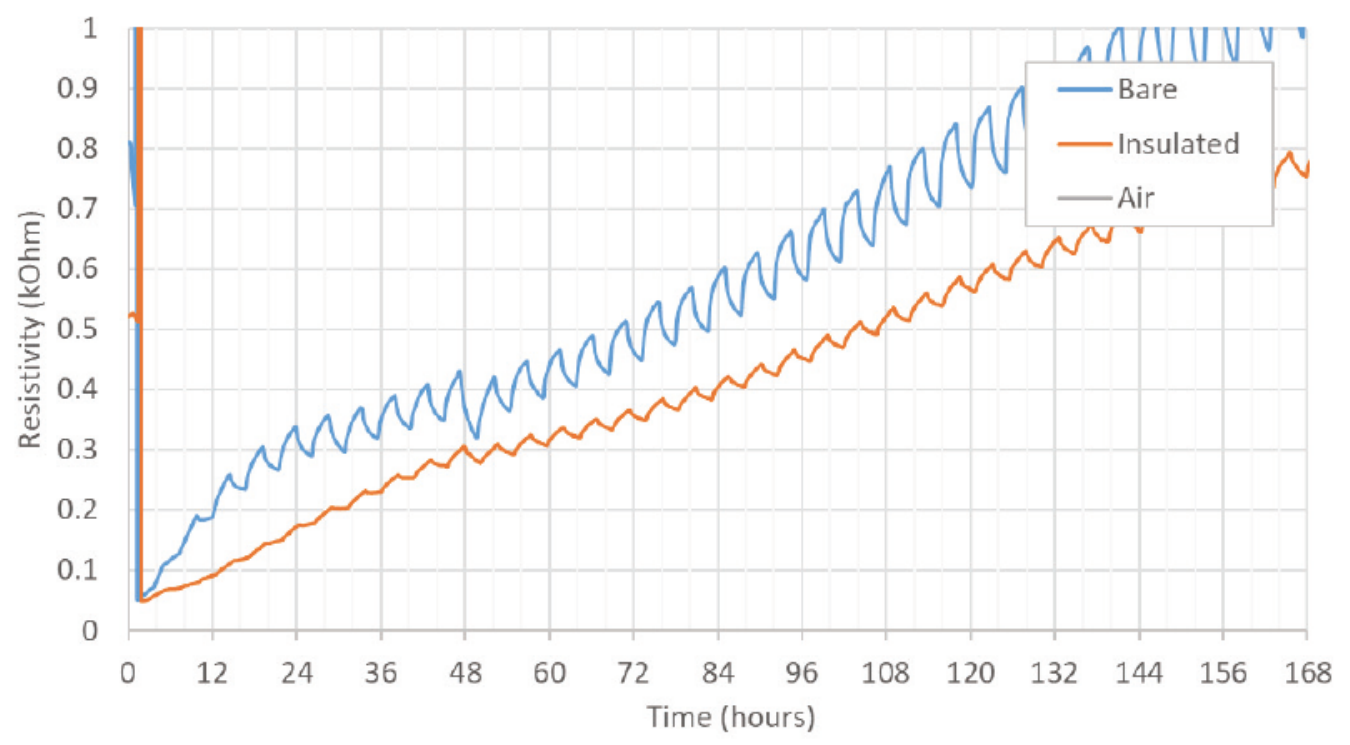


Figure B-15. Temperature curve for insulated and bare specimens for AP100 with $6.1 \%$ air.

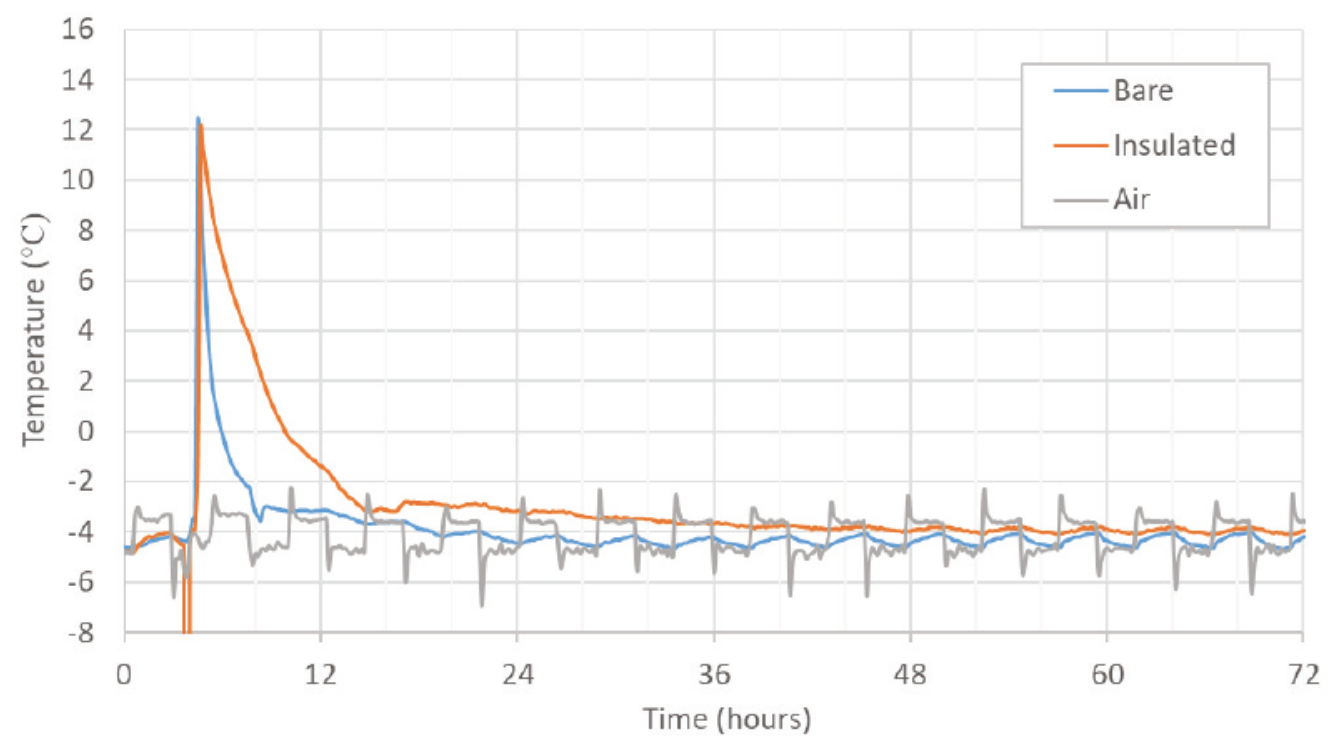

Figure B-16. Resistivity curve for insulated and bare specimens for AP100 with $6.1 \%$ air. Large values at t-zero are a result of the open circuit reading of the data logger before specimen connection.

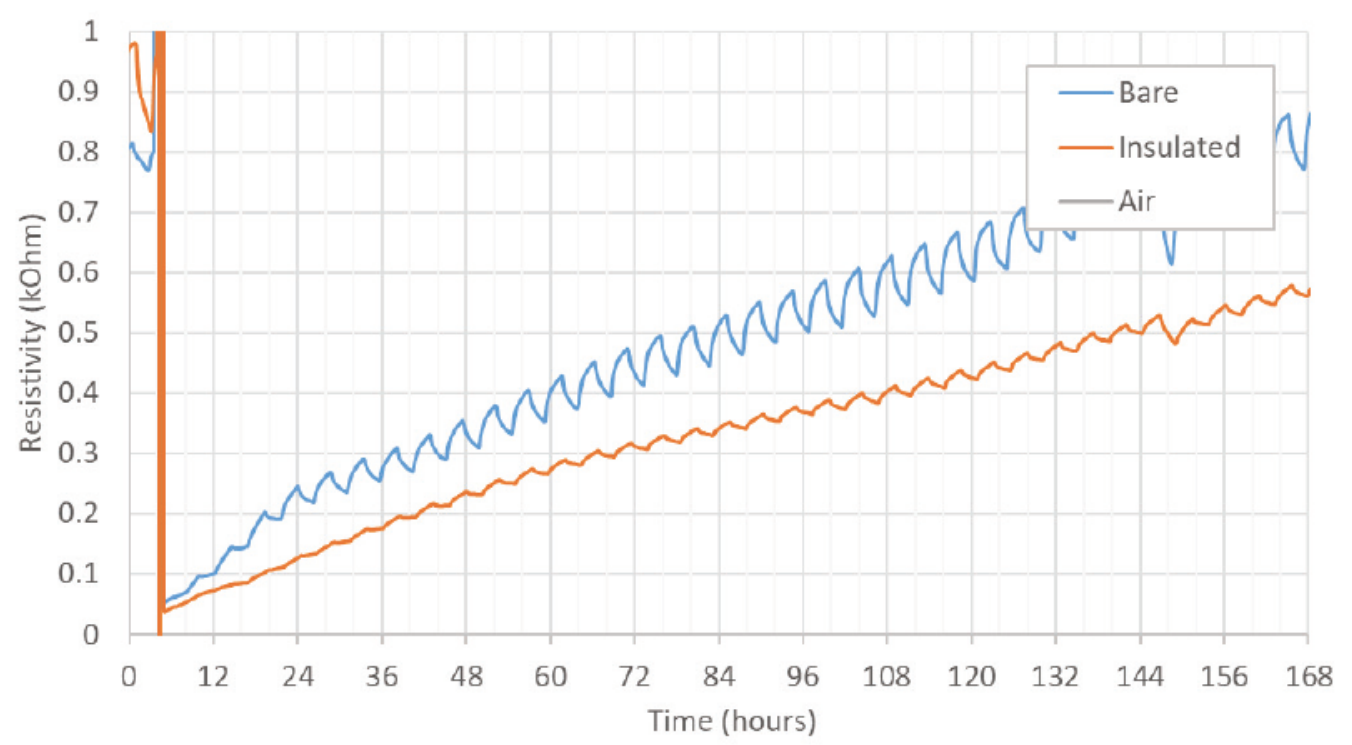


THIS PAGE INTENTIONALLY LEFT BLANK 


\section{Appendix C: Forensic Testing Results}




\section{C.1 Pore solution expression results}

\begin{tabular}{|c|c|c|c|c|c|c|c|c|c|c|c|c|}
\hline 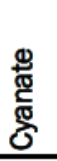 & 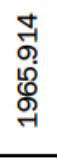 & 1 & 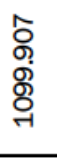 & ণ্ণু & $\begin{array}{l}\text { ్ֶర్ } \\
\text { तิ } \\
\text { ते }\end{array}$ & 1 & 1 & 1 & 1 & 1 & $\begin{array}{l}\text { స̃ } \\
\text { ָุ } \\
\text { }\end{array}$ & 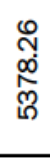 \\
\hline 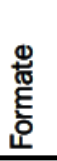 & 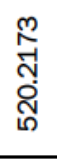 & 1 & 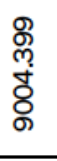 & 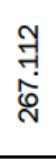 & 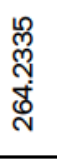 & 1 & 1 & 1 & 1 & 1 & 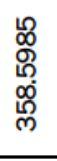 & 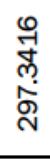 \\
\hline 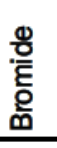 & $\begin{array}{l}\stackrel{\infty}{N} \\
\text { ஸे } \\
\stackrel{\$}{\sigma}\end{array}$ & 1 & 1 & 1 & 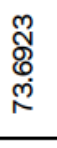 & 1 & 1 & 1 & 1 & 1 & 1 & 1 \\
\hline $\begin{array}{l}\Phi \\
\frac{\Phi}{6} \\
\frac{5}{5} \\
0 \\
\end{array}$ & 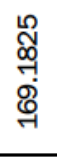 & 1 & 1 & $\begin{array}{l}\text { ते } \\
\text { ু } \\
\text { से }\end{array}$ & 1 & 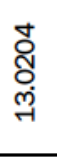 & 1 & 1 & 1 & 1 & 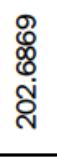 & 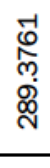 \\
\hline $\begin{array}{l}\text { 은 } \\
\text { 응 }\end{array}$ & $\begin{array}{l}\hat{n} \\
\text { f. } \\
\stackrel{g}{\mathrm{~g}}\end{array}$ & 1 & 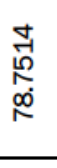 & 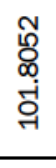 & 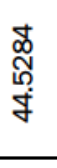 & 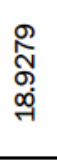 & 1 & 1 & 1 & 1 & $\begin{array}{l}\stackrel{8}{G} \\
\text { స } \\
\text { में }\end{array}$ & 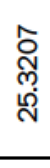 \\
\hline $\begin{array}{l}\stackrel{9}{\underline{T}} \\
\frac{1}{z}\end{array}$ & 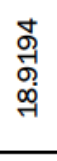 & 1 & 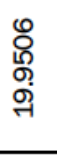 & 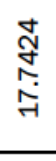 & 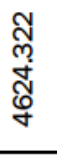 & 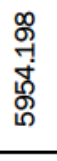 & 1 & 1 & 1 & 1 & 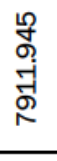 & 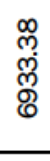 \\
\hline 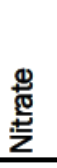 & 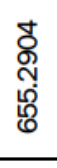 & 1 & 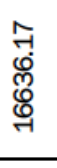 & 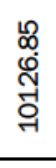 & 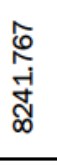 & $\begin{array}{l}\text { m } \\
\underset{\infty}{0} \\
\text { O্] }\end{array}$ & 1 & 1 & 1 & 1 & $\begin{array}{l}\infty \\
\stackrel{\infty}{0} \\
\stackrel{0}{0} \\
\infty \\
0 \\
0\end{array}$ & 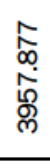 \\
\hline 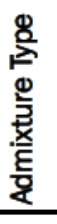 & $\begin{array}{l}8 \\
\frac{8}{*} \\
0 \\
0\end{array}$ & $\begin{array}{l}\overline{0} \\
\text { 을 }\end{array}$ & 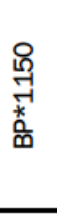 & 商 & 过 & 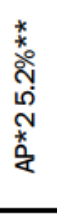 & $\begin{array}{l}\text { ठ্ } \\
\text { O } \\
\text { Ż }\end{array}$ & 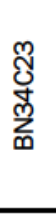 & $\begin{array}{l}\text { O్ర } \\
\text { Z్ } \\
\text { Ż }\end{array}$ & 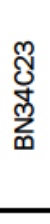 & 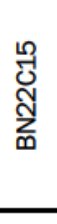 & $\begin{array}{l}\text { L } \\
\text { o. } \\
\text { 面 }\end{array}$ \\
\hline 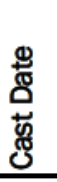 & 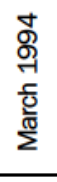 & 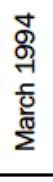 & 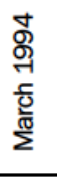 & $\begin{array}{l}\text { ু } \\
\text { స్ } \\
\frac{1}{0} \\
\sum^{\pi}\end{array}$ & 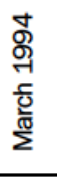 & 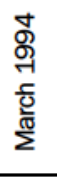 & 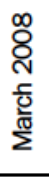 & 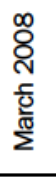 & $\begin{array}{l}\infty \\
\text { ర్ల } \\
\frac{0}{0} \\
\sum^{\frac{0}{2}}\end{array}$ & $\begin{array}{l}\infty \\
\stackrel{2}{0} \\
\frac{1}{0} \\
\sum^{\frac{\pi}{2}}\end{array}$ & $\begin{array}{l}\stackrel{D}{0}^{2} \\
\text { } \\
\frac{0}{0} \\
\sum^{\frac{\pi}{2}}\end{array}$ & $\begin{array}{l}\hat{\&} \\
\text { N } \\
\text { के } \\
\frac{0}{2}\end{array}$ \\
\hline 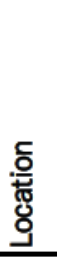 & 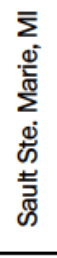 & 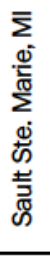 & 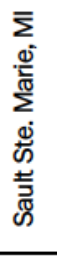 & 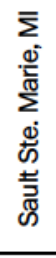 & 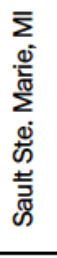 & 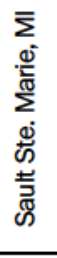 & 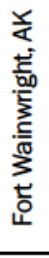 & 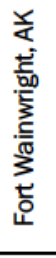 & 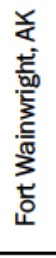 & 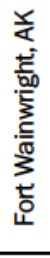 & 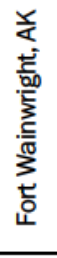 & 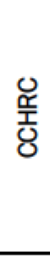 \\
\hline 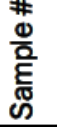 & -1 & $N$ & $m$ & $\nabla$ & م & 0 & N & $\infty$ & $\sigma$ & 의 & 7 & ㄱำ \\
\hline
\end{tabular}




\section{C.2 Samples, hardened air-void analysis}

Figure C-1. Sample 1, hardened air-void analysis (4.59\%).
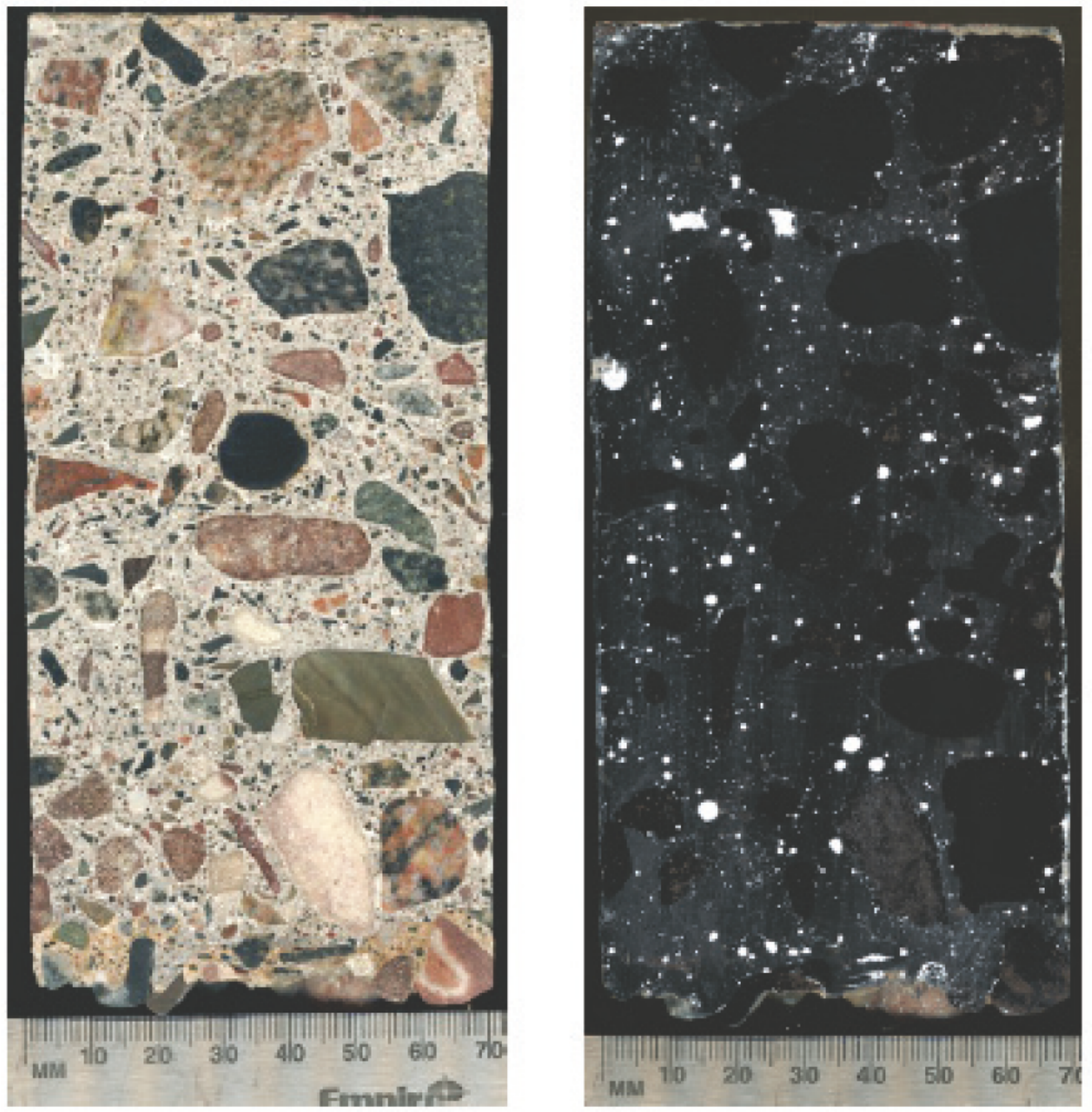
Figure C-2. Sample 2, hardened air-void analysis (3.87\%).
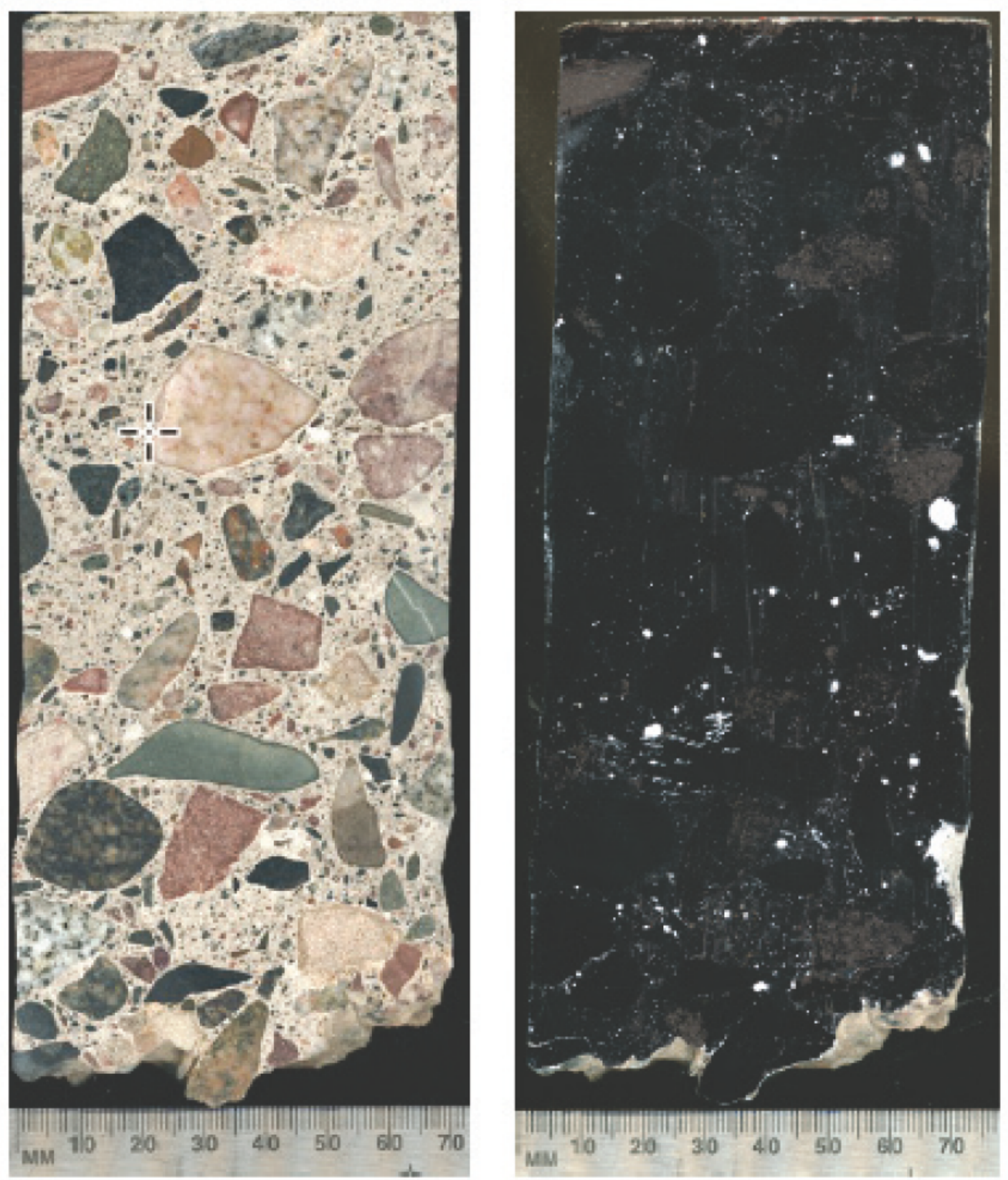
Figure C-3. Sample 3, hardened air-void analysis (9.47\%).
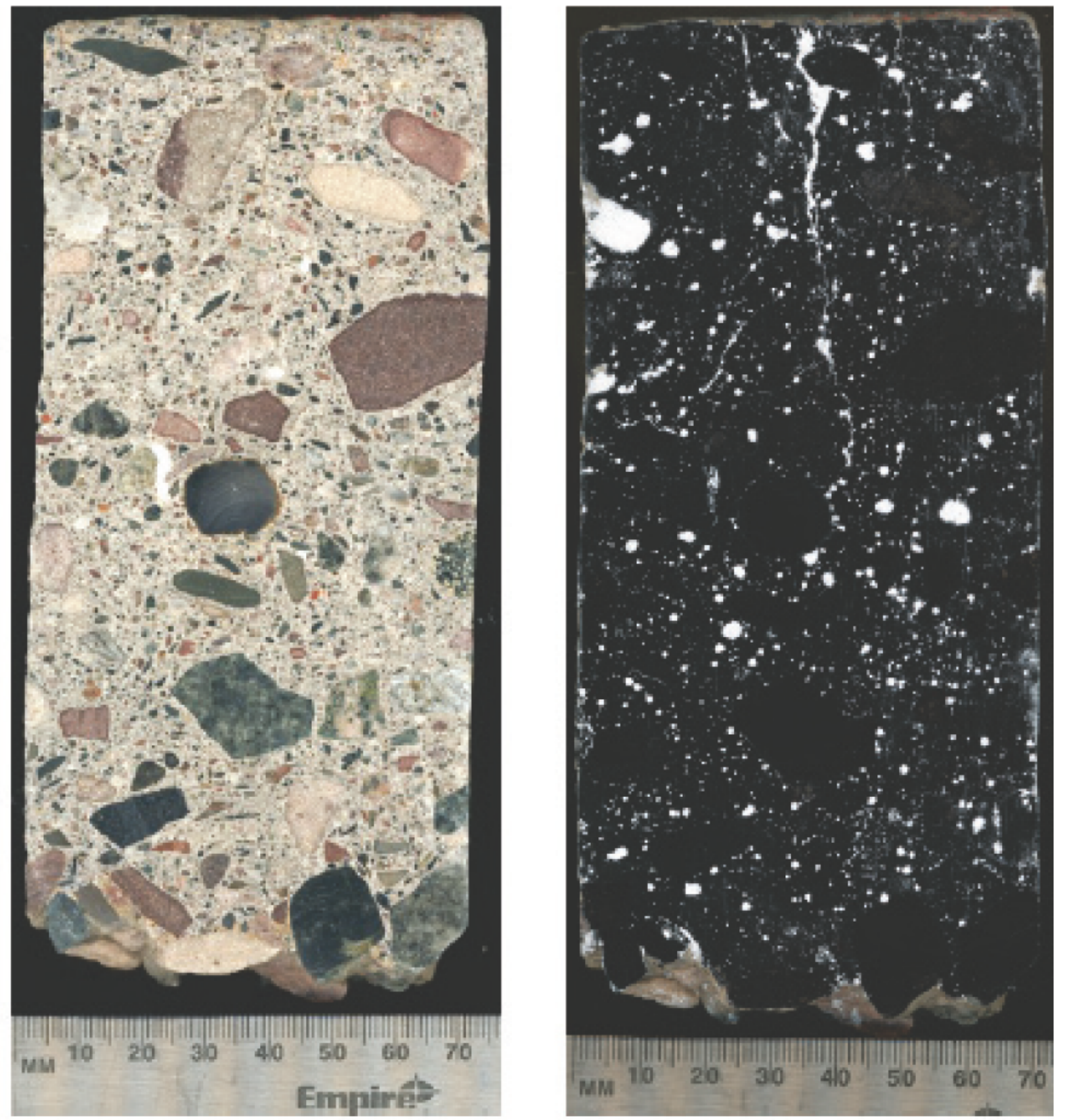
Figure C-4. Sample 4, hardened air-void analysis (7.27\%).
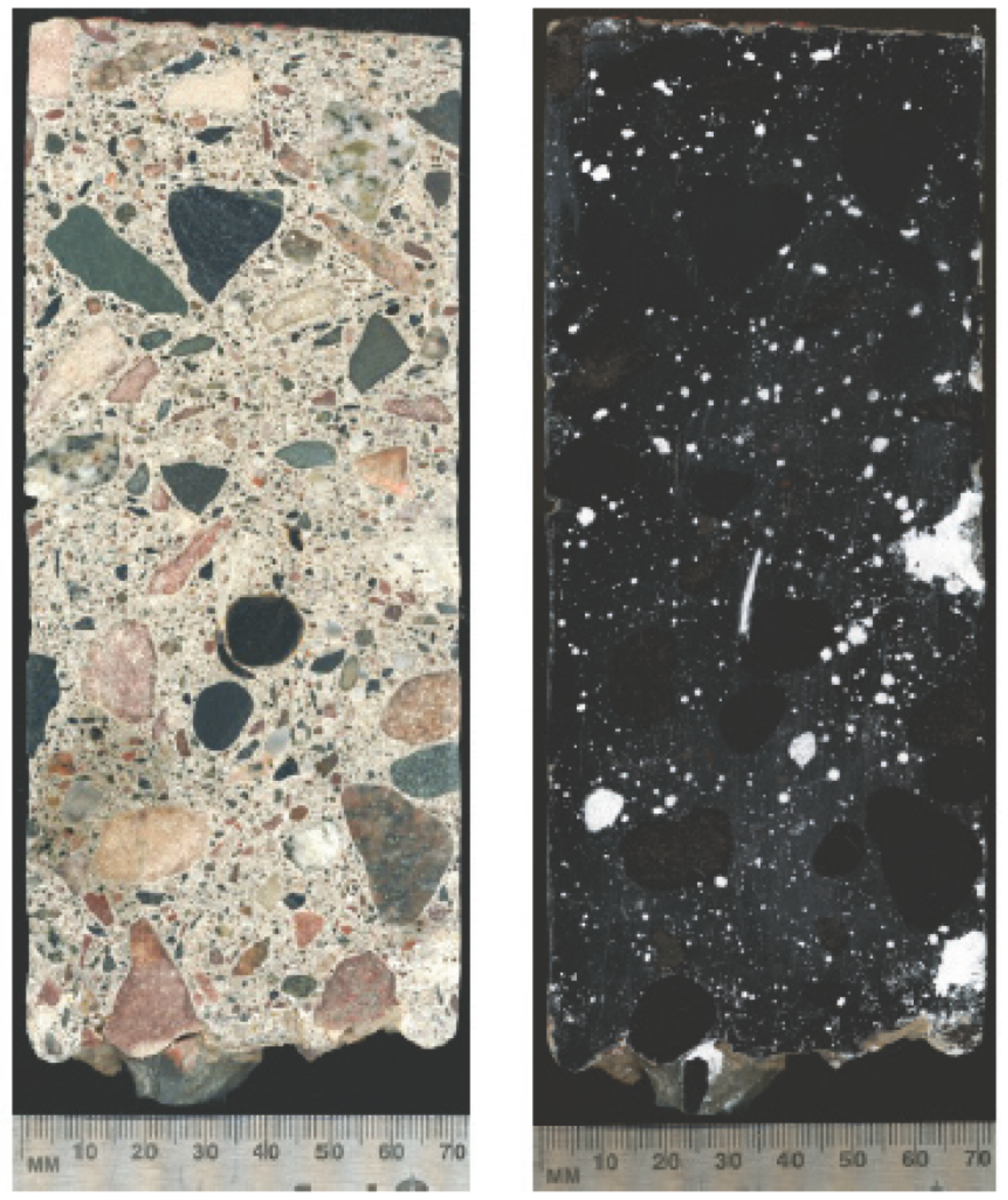
Figure C-5. Sample 5, hardened air-void analysis (9.11\%).
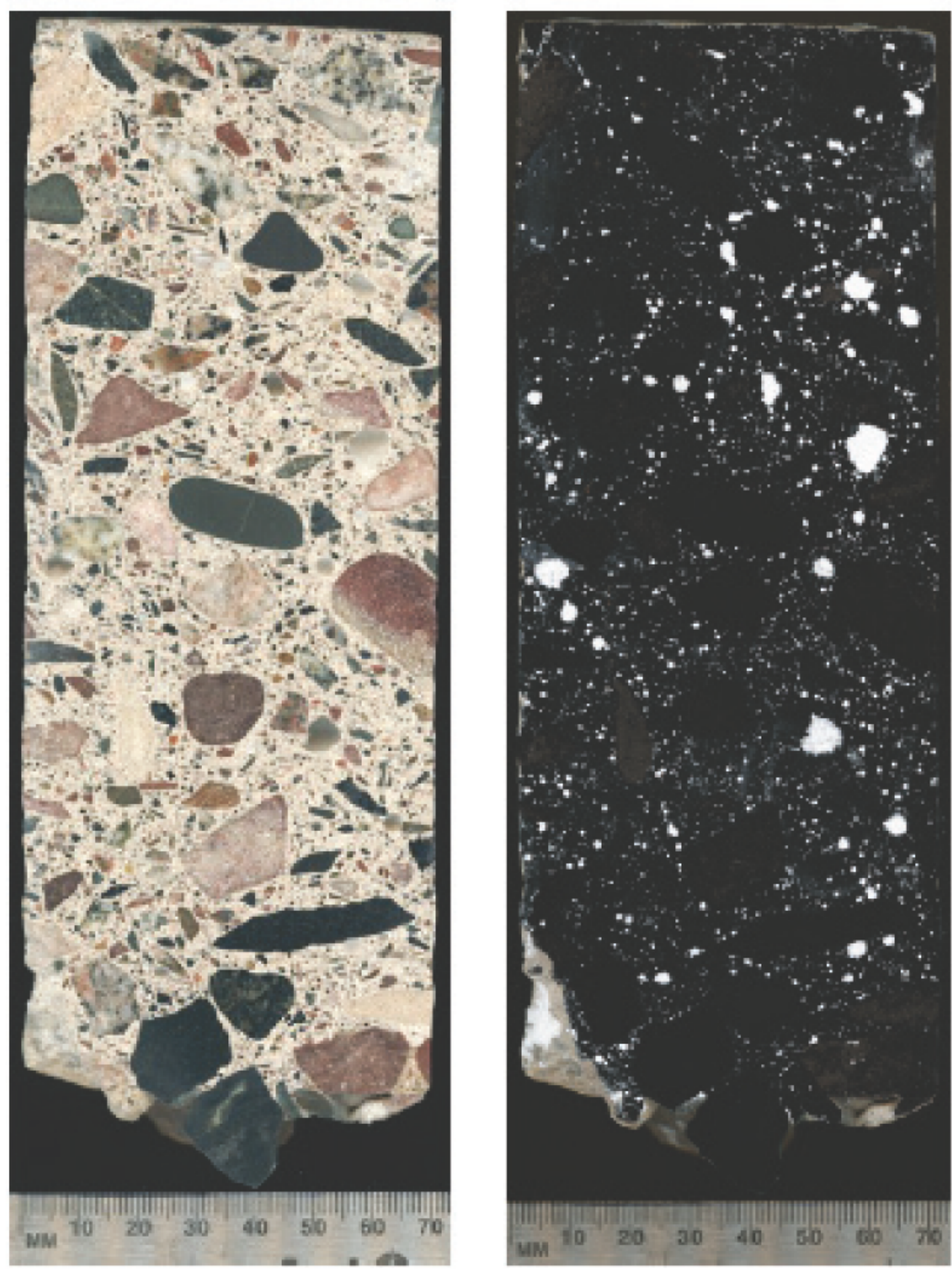
Figure C-6. Sample 6, hardened air-void analysis (10.6\%).
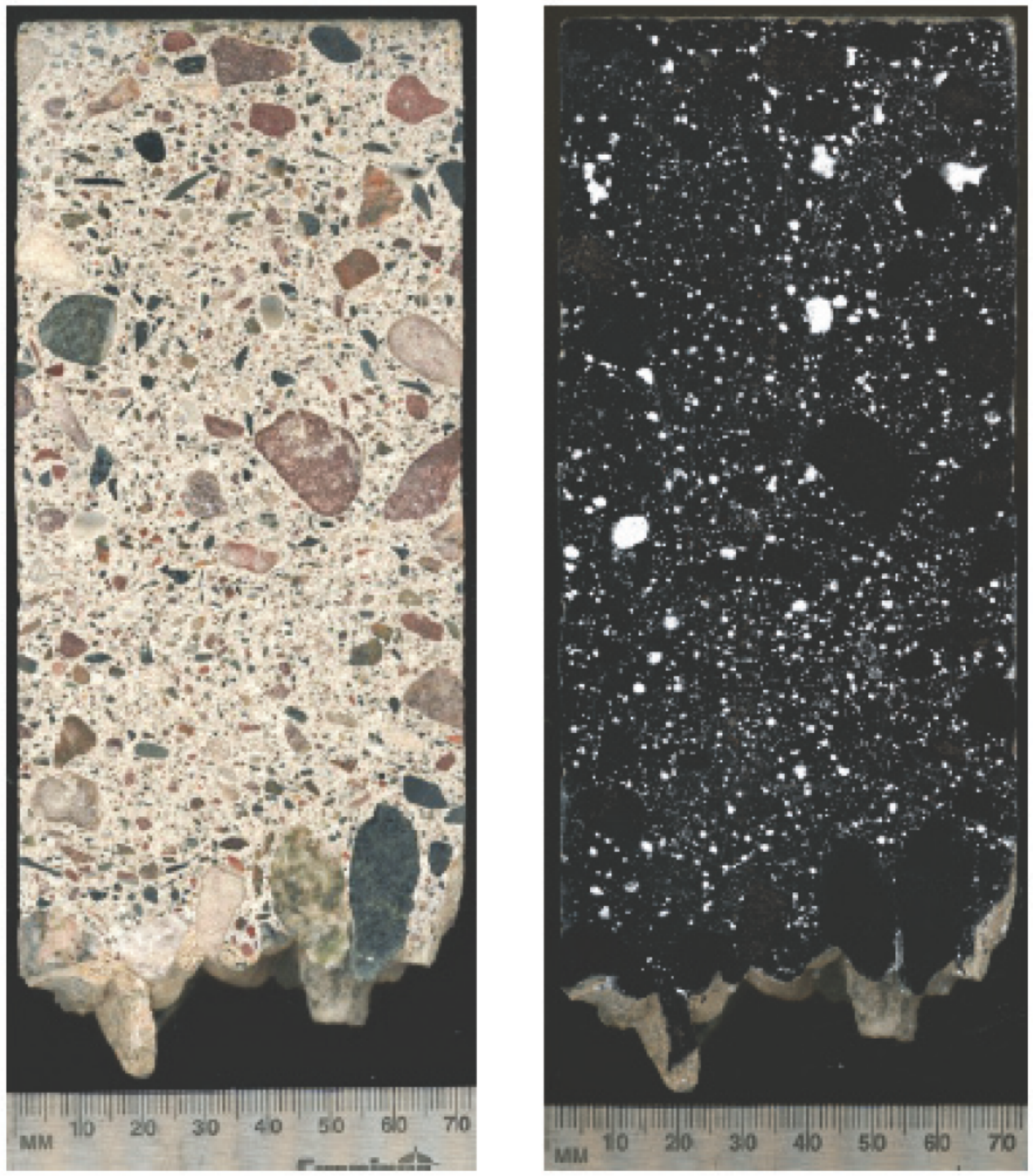
Figure C-7. Sample 7, hardened air-void analysis (10.84\%).
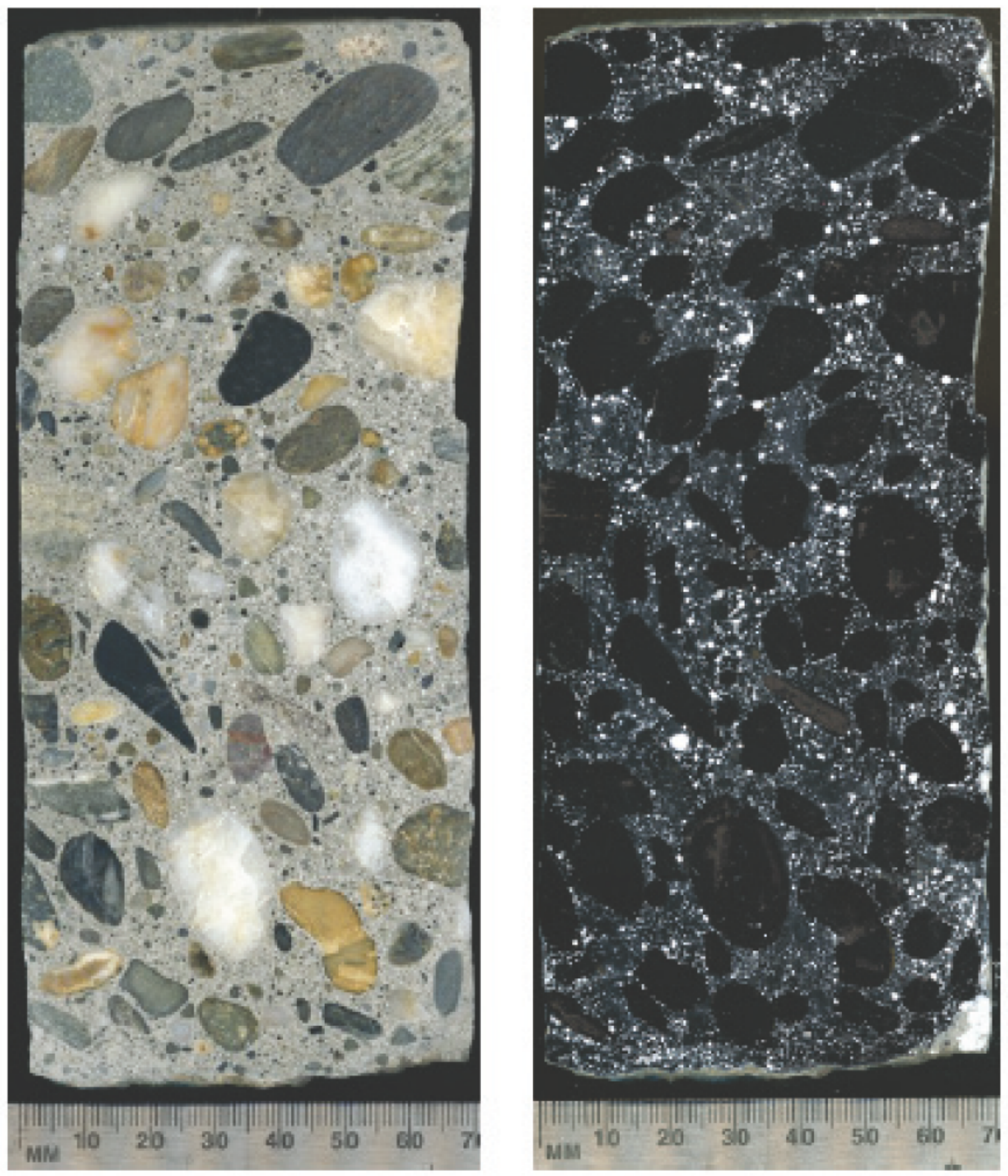
Figure C-8. Sample 8, hardened air-void analysis (6.61\%).
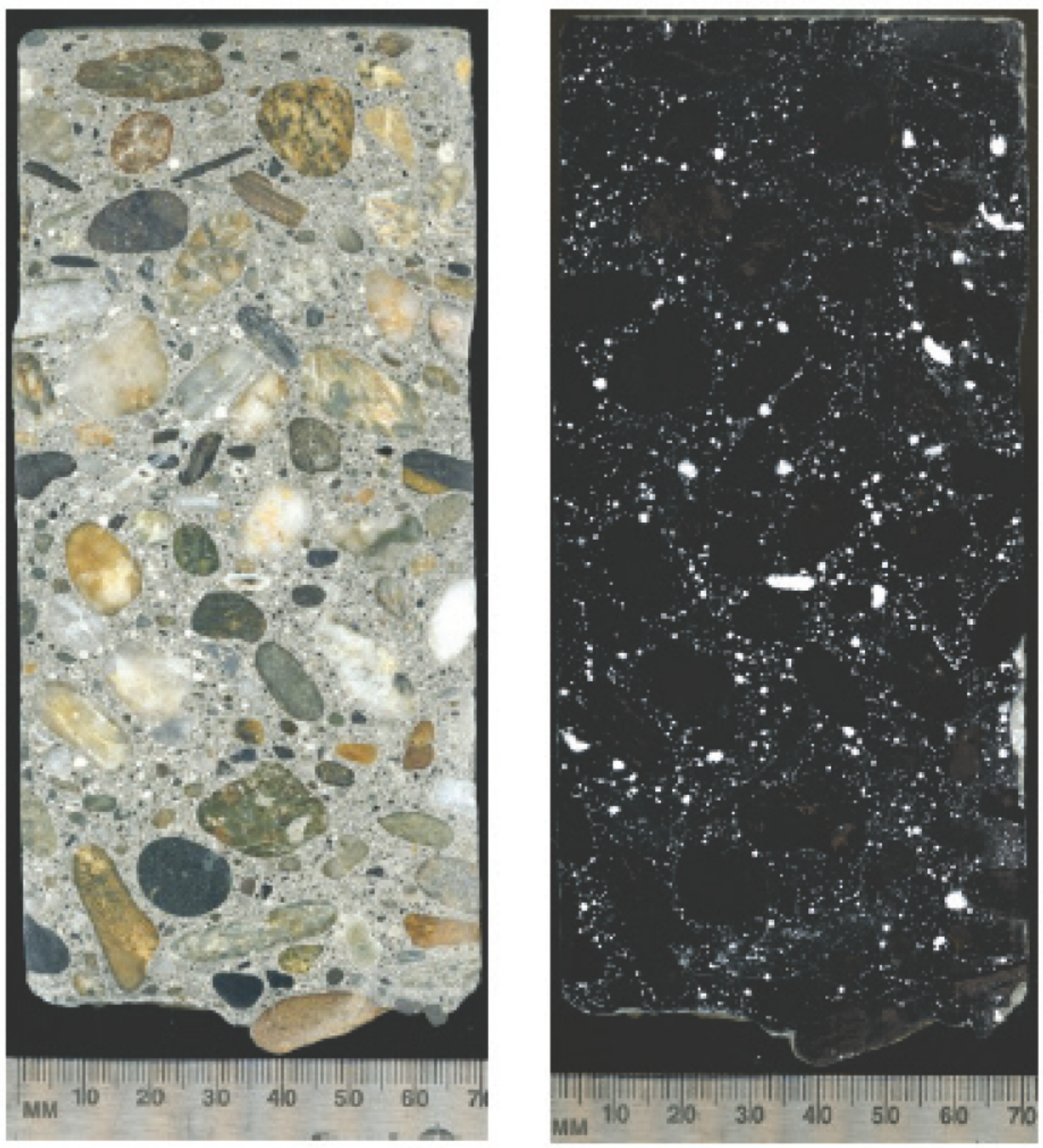
Figure C-9. Sample 9, hardened air-void analysis (8.64\%).
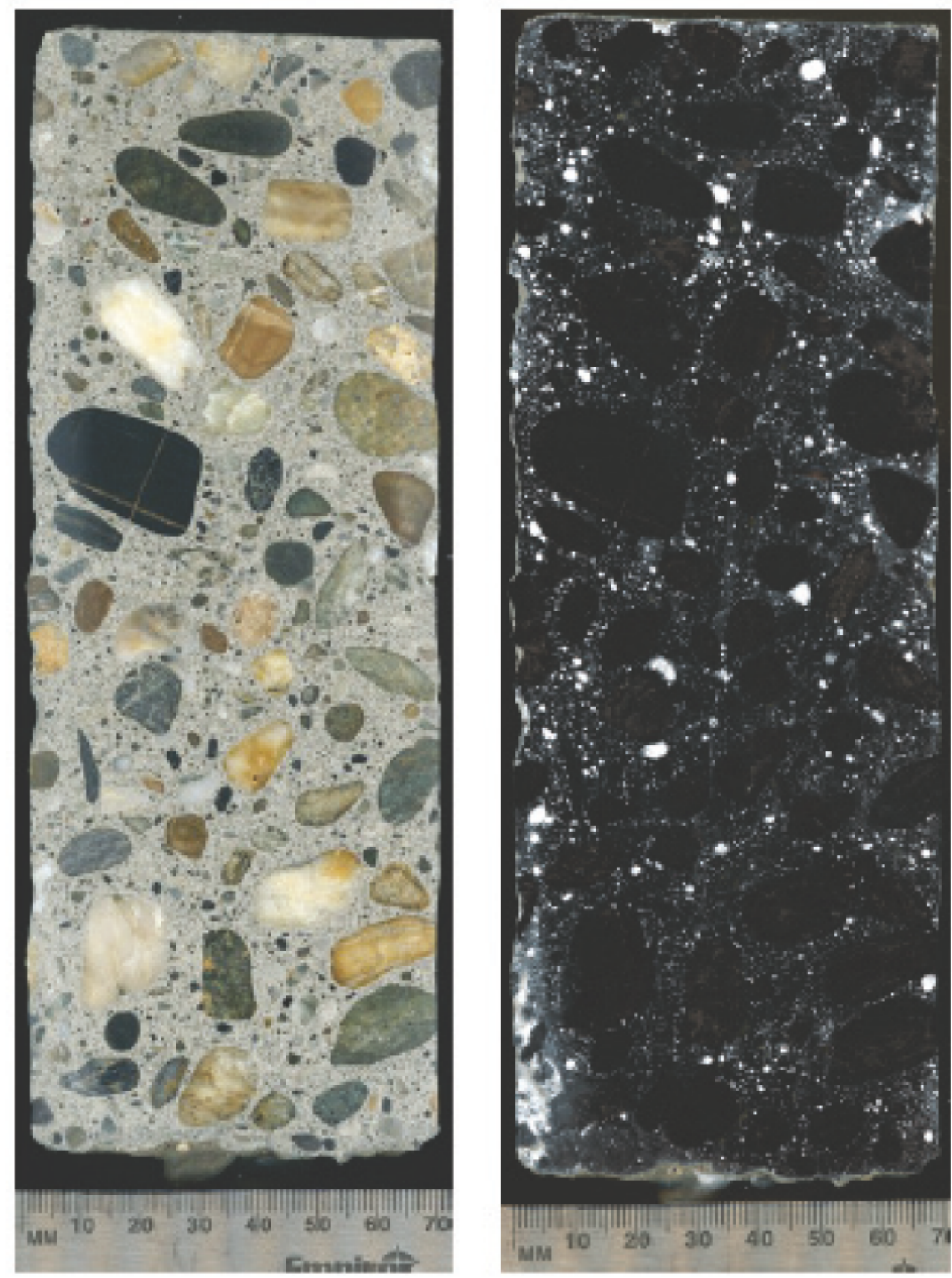
Figure C-10. Sample 10, Hardened air-void analysis (9.24\%).
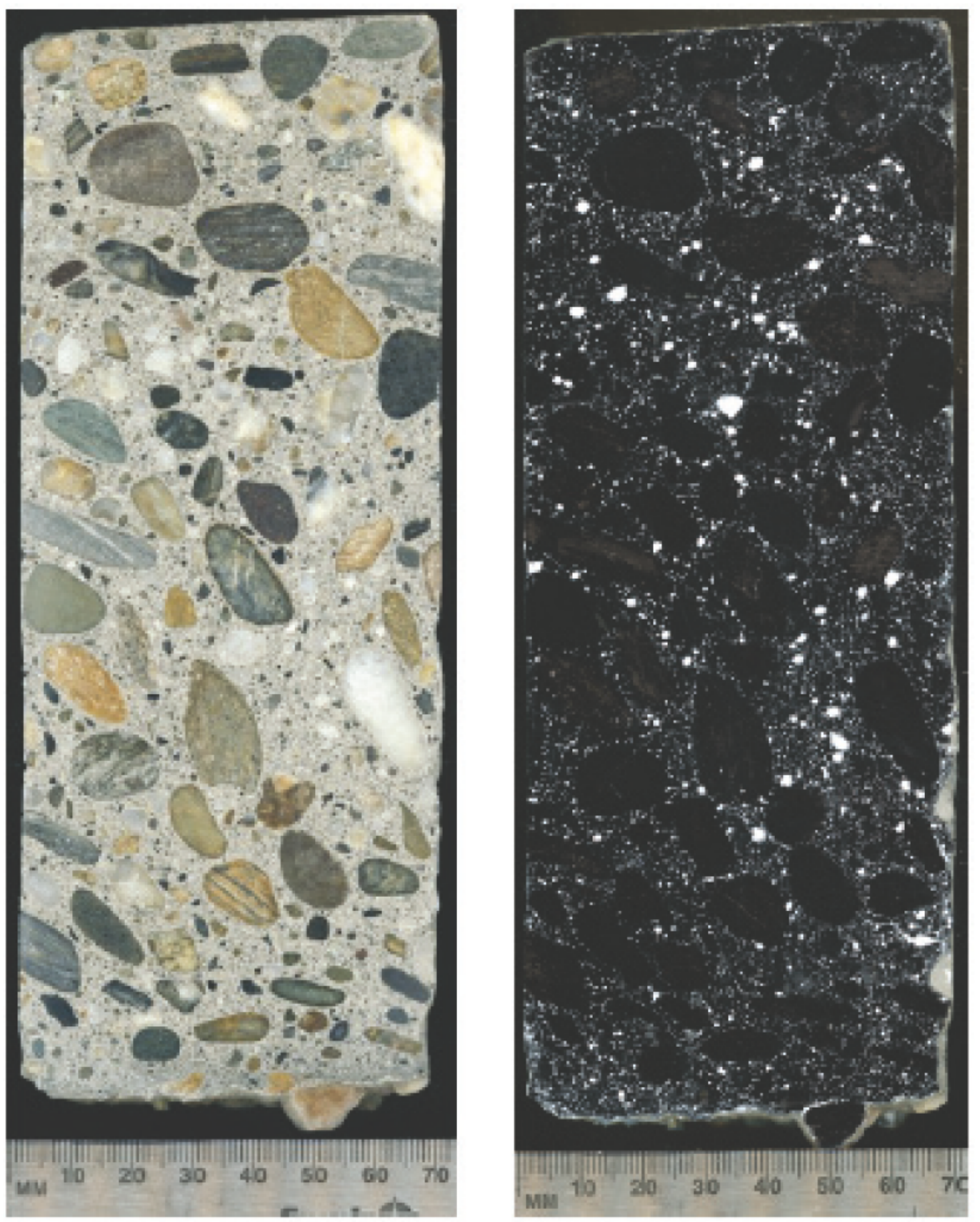
Figure C-11. Sample 11, hardened air-void analysis (9.57\%).
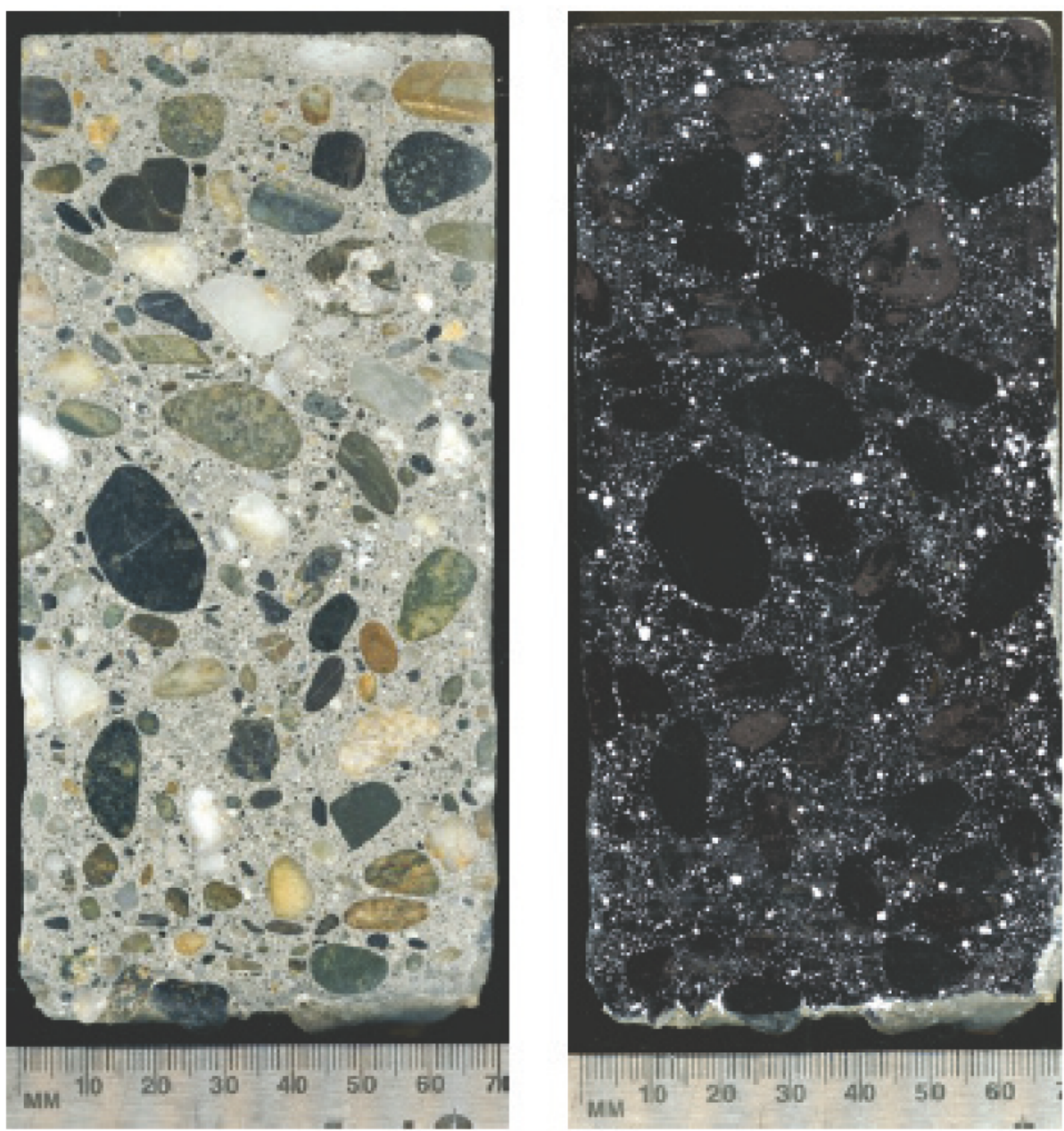

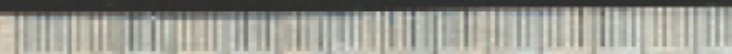
MM $10^{2} \quad 20 \quad 30 \quad 40 \quad 50 \quad 60$ 
Figure C-12. Sample 12, hardened air-void analysis (23.05\%).
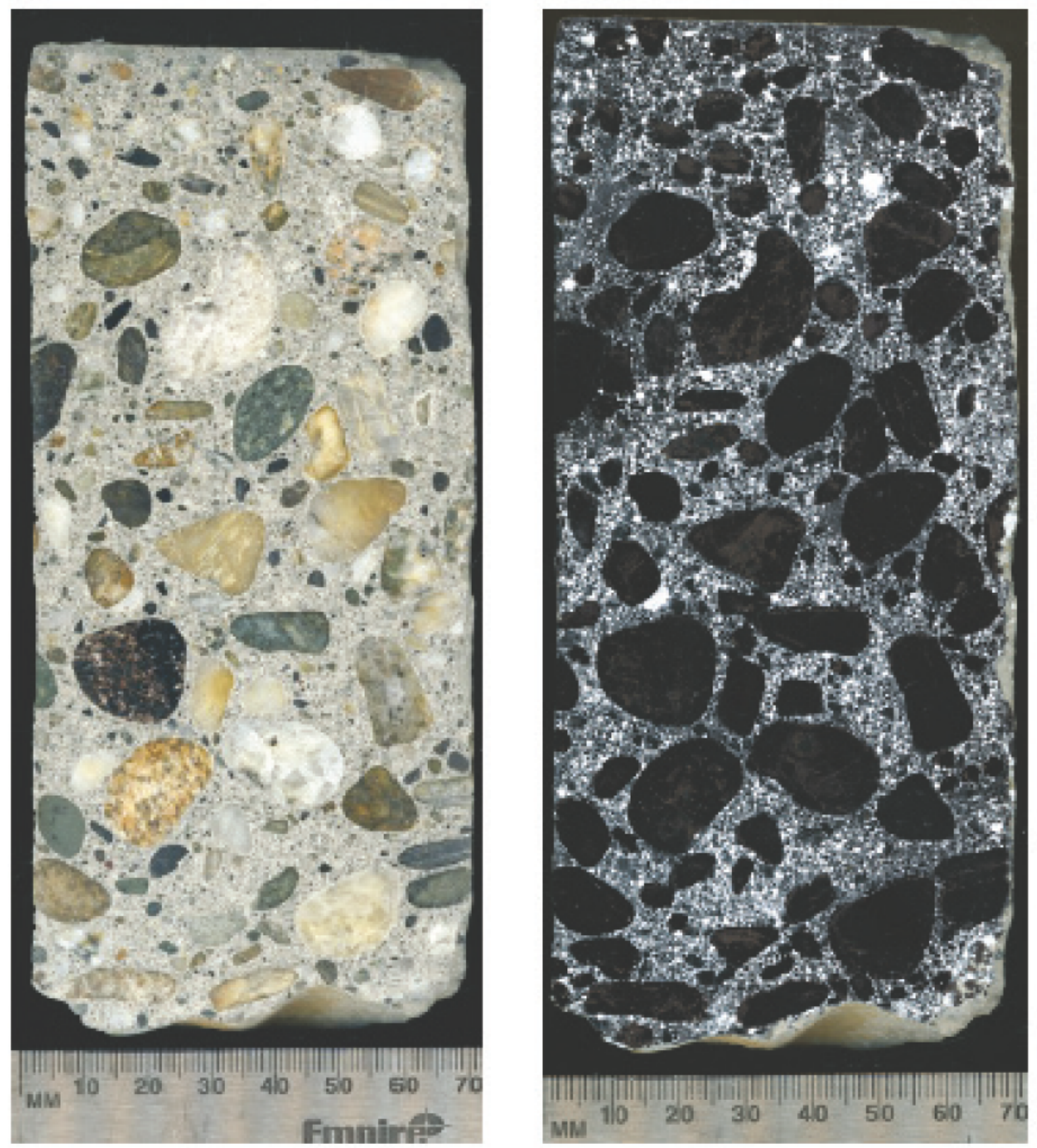


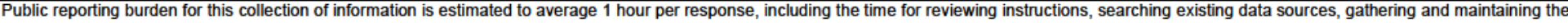

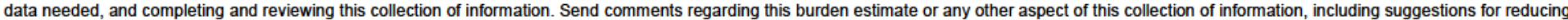

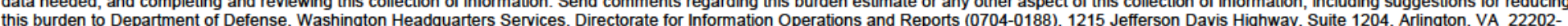

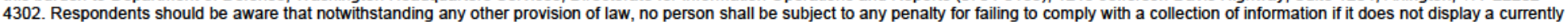
valid OMB control number. PLEASE DO NOT RETURN YOUR FORM TO THE ABOVE ADDRESS.
1. REPORT DATE (DD-MM-YYYY)
2. REPORT TYPE
$01 / 01 / 2021$
Final Technical Report (TR)

\section{TITLE AND SUBTITLE}

Long-Term Durability of Cold Weather Concrete: Phase II

5a. CONTRACT NUMBER

5b. GRANT NUMBER

5c. PROGRAM ELEMENT

$62784 / \mathrm{T}_{53}$

6. AUTHOR(S)

Benjamin E. Watts, Danielle E. Kennedy, Ethan W. Thomas, Andrew P. Bernier, and Jared I. Oren

5d. PROJECT NUMBER

5e. TASK NUMBER

5f. WORK UNIT NUMBER

7. PERFORMING ORGANIZATION NAME(S) AND ADDRESS(ES)

U.S. Army Engineer Research and Development Center (ERDC)

Cold Regions Research and Engineering Laboratory (CRREL)

8. PERFORMING ORGANIZATION REPORT NUMBER

72 Lyme Road

Hanover, NH o3755-1290

ERDC/CRREL TR-21-1

\section{SPONSORING / MONITORING AGENCY NAME(S) AND ADDRESS(ES)}

Headquarters, U.S. Army Corps of Engineers (USACE)

$441 \mathrm{G}$ Street, NW

Washington, DC 20314-1000

\section{DISTRIBUTION / AVAILABILITY STATEMENT}

Approved for public release; distribution is unlimited.
10. SPONSOR/MONITOR'S ACRONYM(S)

11. SPONSOR/MONITOR'S REPORT NUMBER(S)

\section{SUPPLEMENTARY NOTES}

\section{ABSTRACT}

Recent laboratory results confirm that it is possible to protect concrete from freezing solely using chemical admixtures and indicate that the amount of admixture required may be significantly less than previously recommended. Researchers have also verified that admixture-based freeze protection can produce concrete that is durable to winter exposure for a minimum of 20 years, through petrographic examination of core specimens obtained from past field demonstrations.

Freeze protection for concrete using chemical admixtures alone has been an area of active research for 3 decades; however, the most recent methodology recommends very high addition rates of accelerating and corrosion inhibiting admixtures, which result in significant challenges, including slump loss, rapid setting, and potentially excessive temperature rise. As part of a laboratory study, researchers systematically varied the dosage of freeze protection admixtures used in concrete cured in a $23{ }^{\circ} \mathrm{F}$ environment. Preliminary findings indicate that a $50 \%$ reduction in admixture dose maintained adequate freeze protection and resulted in compressive strengths exceeding those of roomtemperature controls at 7 and 28 days. The combination of improved handling, reduced cost, and verified durability associated with the use of admixtures for freeze protection makes a compelling case for broader adoption of this technique in winter operations.

\section{SUBJECT TERMS}

Concrete--Service life, Concrete construction--Cold weather conditions, Concrete--Effect of temperature on Concrete--Additives

\section{SECURITY CLASSIFICATION OF:}

\section{a. REPORT}

Unclassified

\section{b. ABSTRACT \\ Unclassified}

17. LIMITATION
OF ABSTRACT
SAR

c. THIS PAGE

Unclassified

\begin{tabular}{c|c}
$\begin{array}{l}\text { 18. NUMBER } \\
\text { OF PAGES }\end{array}$ & \\
\cline { 2 - 2 } 9 & \\
&
\end{tabular}

9a. NAME OF RESPONSIBLE PERSON

19b. TELEPHONE NUMBER (include area code) 